Portland State University

PDXScholar

$1-1-1978$

\title{
Aspects of the ecology of the common raven in Harney Basin, Oregon
}

Richard B. Stiehl

Portland State University

Follow this and additional works at: https://pdxscholar.library.pdx.edu/open_access_etds Let us know how access to this document benefits you.

\section{Recommended Citation}

Stiehl, Richard B., "Aspects of the ecology of the common raven in Harney Basin, Oregon" (1978). Dissertations and Theses. Paper 762.

https://doi.org/10.15760/etd.762

This Dissertation is brought to you for free and open access. It has been accepted for inclusion in Dissertations and Theses by an authorized administrator of PDXScholar. Please contact us if we can make this document more accessible: pdxscholar@pdx.edu. 


\section{ASPECTS OF THE ECOLOGY OF THE COMMON RAVEN \\ IN HARNEY BASIN, OREGON}

by

RICHARD B. STIEHL

A dissertation submitted in partial fulfillment of the requirements for the degree of

DOCTOR OF PHILOSOPHY
in

ENVIRONMENTAL SCIENCES AND RESOURCES - BIOLOGY

Portland State University

1978 
TO THE OFFICE OF GRADUATE STUDIES AND RESEARCH:

The members of the Committee approve the dissertation of Richard B. Stieh1 presented 24 February 1978.
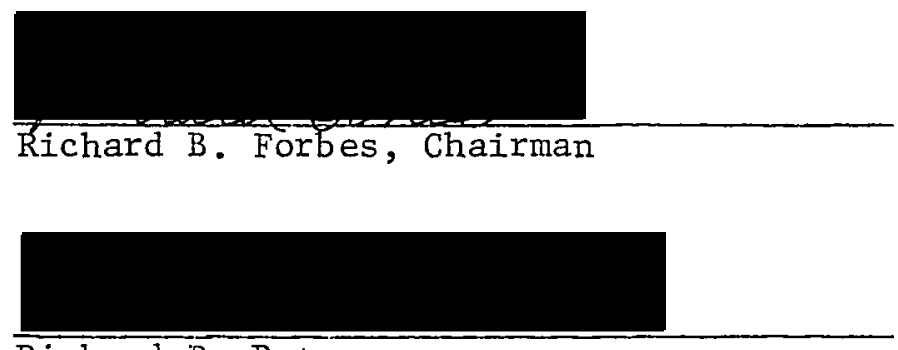
Richard R. Petersen

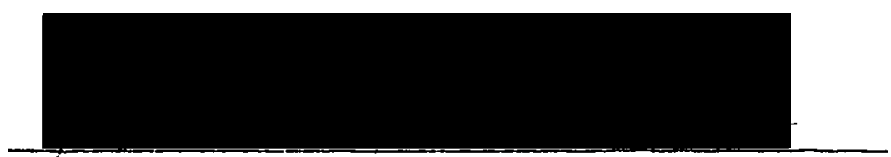
Robert 0. Tinnin

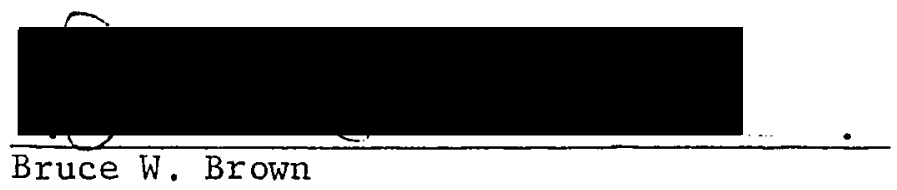

APPROVED :

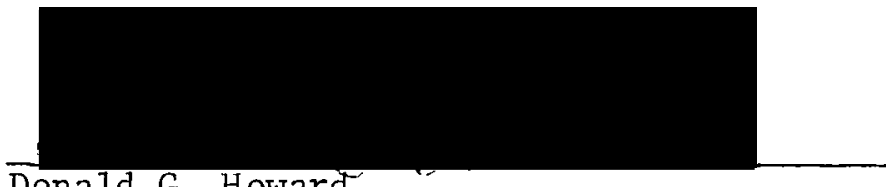

Donald G. Howard

\section{APPROVED:}
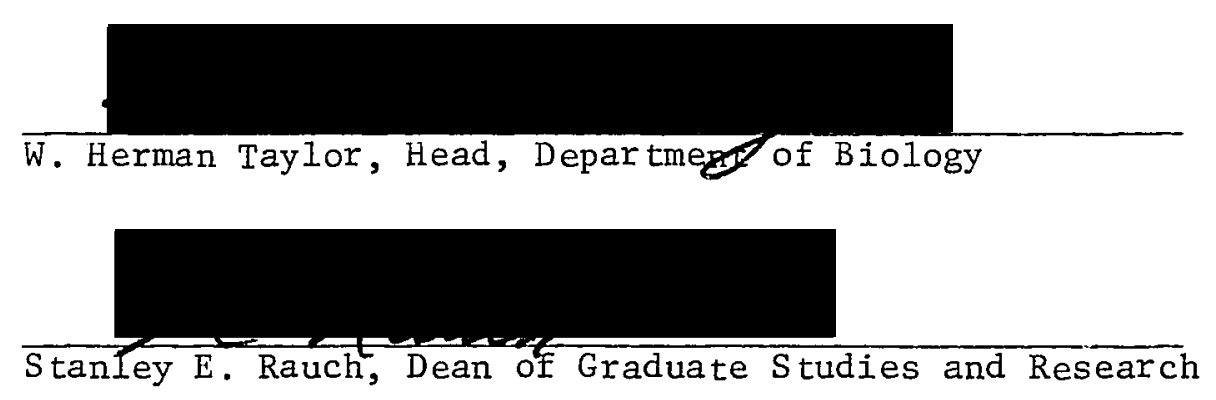
AN ABSTRACT OF THE DISSERTATION OF Richard B. Stiehl for the Doctor of Philosophy in Environmental Sciences and Resources - biology presented on 24 February 1978.

Title: Aspects of the Ecology of the Common Raven in Harney Basin, Oregon

APPROVED BY MEMBERS OF THE DISSERTATION COMMITTEE:

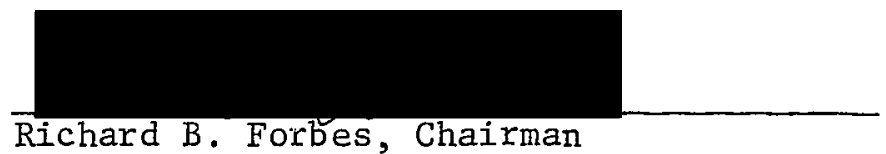

Richard B. Forbes, Chairman

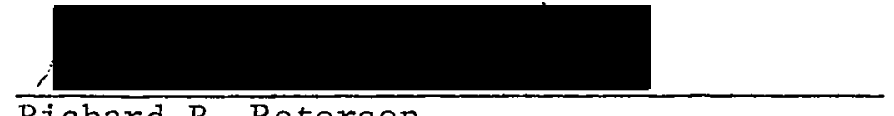

Richard R. Petersen

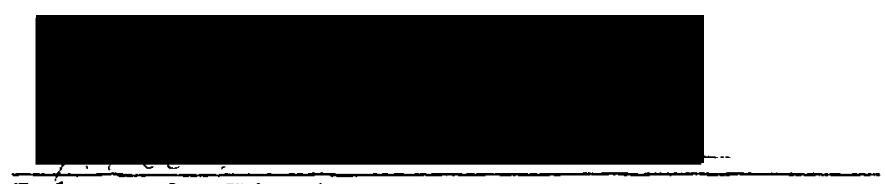

Robert 0. Tinnin
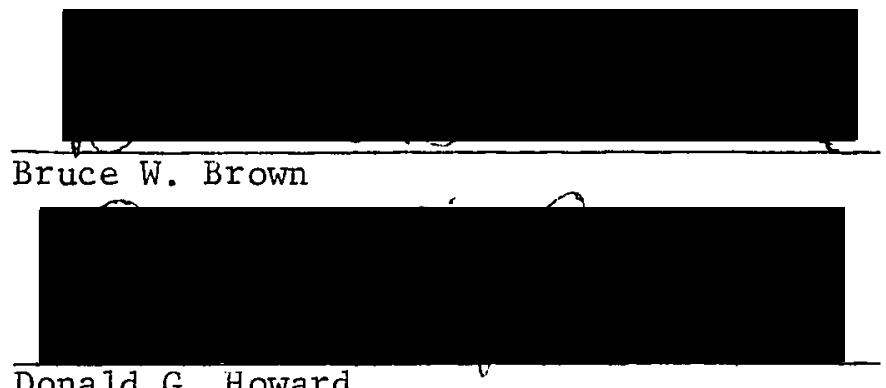

Ex-Officio:

Dr. Marvin Beeson, Graduate Council Representative 
ABSTRACT

Comnion Ravens (Corvus corax $L_{\text {. }}$ ) have been implicated as significant predators on the eggs of waterfowl and shorebirds on Malheur National Wildlife Refuge. Malheur Refuge, located in southeastern Oregon on the northern edge of the Great Basin, is one of the largest waterfowl refuges in the United States and is an important breeding area for waterfow1. In order to provide fundamental information on which a sound raven management plan could be based, research was conducted from 1975-1977 on aspects of population density, brood phenology, nesting success, seasonal use of the study area, roosting behavior, and food habits of ravens on and near the refuge.

Nesting density was determined to be one pair per approximately $25 \mathrm{~km}^{2}$. Most nests occurred in rimrocks, but trees and abandoned human structures were also used. Investigation of 87 nests revealed that the incubation period was $21 \pm 1$ days. Incubation began with the laying of the first egg; hatching was asynchronous. Nesting period was $41 \pm 3$ days. An original method of age-classing ravens is described.

A total of 266 ravens was marked with patagial tags. Observation of marked individuals as far as $480 \mathrm{~km}$ from the study area suggests considerable mobility in the population. Population numbers vary seasonally, peaking in the winter. The Harney Basin is the location of an exceptionally large winter roost for ravens. 
Analysis of food remains, collected from 34 nests, indicates that ravens have varied diets and that there are significant differences in the diets of ravens nesting in different habitats. A correlation exists between the proportion of the diet that is avian material and the proximity of the raven nest to waterfowl production areas.

Based on these findings, suggestions are offered for a management plan for Common Ravens on Malheur National Wildlife Refuge. 


\section{ACKNOWLEDGEMENTS}

A number of people have assisted in the research reported in this dissertation. I would like to take this opportunity to thank them.

Professor Richard B. Forbes, under whose supervision this research was conducted, has encouraged and supported the work since its conception. His consultation and helpful attitude are greatly appreciated.

I would also like to acknowledge the other members of my research committee: Bruce Brown, Don Howard, Richard Petersen, and Robert Tinnin for their assistance and numerous suggestions in the preparation of this dissertation.

I am grateful to Joe Mazzoni and the staff at Malheur National Wildlife Refuge for their assistance in time, suggestions, critical discussions, and explanations throughout the field study.

The ranchers of the Sod House district, especially Marcus Haines, Buck Taylor, and Rex Taylor were of great help during the study. For their assistance in providing access, equipment, numerous discussions, and direct help, I offer my sincere thanks.

Finally, I am deeply appreciative of the patience, encouragement and companionship of my wife, Kachy. Her help in the field, her suggestions during preparation and her assistance with the manuscript were indispensible and will always be remembered. 
The research reported herein was supported by an assistantship from Portland State University and a research grant from the U.S. Fish and Wildlife Service. 
ACKNOWLEDGEMENTS .................. . . . LIST OF TABLES . . . . . . . . . . . . . . . v vii LIST OF FIGURES . . . . . . . . . . . . . . . v viii INTRODUCTION . . . . . . . . . . . . . . . 1

Description of the Area .............. 1

Justification of the study . . . . . . . . . 5

Environmental Relatedness ............ 8 MATERIALS AND METHODS ................... 11 Trapping .................... 17 Hand Capture Rocket Net Drop-In Trap

Patagial Marking .............. 22

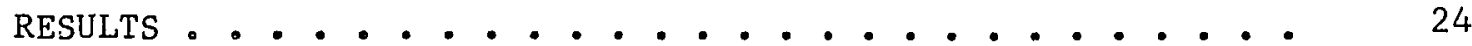

Age Determination . . . . . . . . . 24

Brood Phenology ............... . . 24

Nest Location

New Nest Construction

Nest Reuse

Egg Laying

Hatching

Renesting

Fledging and Post-fledge Activity

Fledge Success

Post Fledge Behavior Patterns

Communal Roosting ............... 
PAGE

Food Habits . . . . . . . . . . . . . . . .

Spring Food Habits

Results

Summer and Fall Food Habits

Winter Food Habits

Food Habits of Non-nesting Ravens

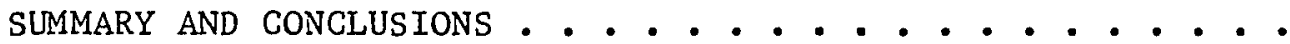

MANAGEMENT CONSIDERATIONS AND RECOMMENDATIONS • • • • • • •

Management Considerations . . . . . . . . . . . 73

Management Methods • . . • • . • . . . . . 75

Destruction of Specific Nesting Pairs of Ravens

Reduction in the Numbers of Non-breeding Ravens

Habitat Improvement

LITERATURE CITED •. . . . . . = = = . . . . . . . .

APPENDIX A

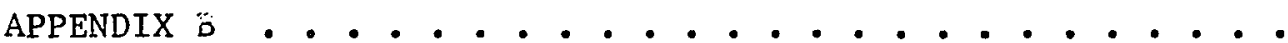




\section{LIST OF TABLES}

TABLE

PAGE

I Nesting Success of Ducks, Sandhill Cranes, and

Canada Geese on Malheur National Ẅildlife

Refuge 1964-1977 •............ 6

II Active Raven Nests 1976-1977 . . . . . . . 12

III Rocket Net and Drop-In Trap Locations : . . . . 18

IV Summary of Nesting Activity 1976-1977 . . . . 32

V Table Used to Determine the Weighted Food Scores

for Items in the Diet of C. corax ...... 53

VI Analysis of Pellets from Nests . . . . . . . 55

VII Analysis by Group of Raven Food Scores . . . . . 56

VIII Analysis of Variance of Grouped Food Scores . . . . 60 


\section{LIST OF FIGURES}

FIGURE

PAGE

1. Location of Study Area . . . . . . . . . .

2. Map of Active Raven Nests 1976 . . . . . . . .

3. Map of Active Raven Nests 1977 . . . . . . .

4. Map of Trapping Locations . . . . . . . .

5. Diagram of Drop-In Trap .............

6. Diagram of Patagial Mallicl . . . . . . . . .

7. Attachment of Patagial Marker . . . . . . . 24

8. Group Food Scores of Nesting Ravens . . . . . . 57

9. Comparison of Food Scores of Ravens Nesting in 


\section{INTRODUCTION}

\section{DESCRIPTION OF THE AREA}

Malheur National Wildlife Refuge, located in the Harney Basin, Harney County, Oregon, between about $118.5^{\circ}$ and $119.5^{\circ} \mathrm{W}$ 1ongitude and $42.7^{\circ}$ and $43.4^{\circ} \mathrm{N}$ latitude (Figure 1 ), is an important resting and breeding area for migratory waterfowl. The refuge was established in 1908 when 32,370 ha $(80,00$ a) wure set aside as a Federal Bird Sanctuary. A major portion of the Blitzen Valley was added in 1935, and the Double-0 Ranch area, in the lower Warm Springs Valley, was added in 1942 , to form the present $\mathrm{T}$-shaped refuge of approximately 73,250 ha (181,000 a) (United States Department of the Interior 1974). Gabrielson (1943) provided a brief general history of the refuge and a description of some of the early conditions that existed there.

The Harney Basin encompasses portions of the high lava plains and the basin-range physiographic divisions of Oregon (Dicken 1955). The lava plains area is a relatively undeformed region of lava flows, lava buttes, cinder cones, tuffs and alluvium of Pliocene and Pleistocene origin. The basin-range area is characterized by fault block mountains oriented north-south, and basins of internal drainage (Baldwin 1959).

The refuge is at an elevation of approximately $1,350 \mathrm{~m}$ $(4,100 \mathrm{ft})$. It is characterized by dry summers with temperatures rarely exceeding $32^{\circ} \mathrm{C}\left(90^{\circ} \mathrm{F}\right)$ and cold winters with average 


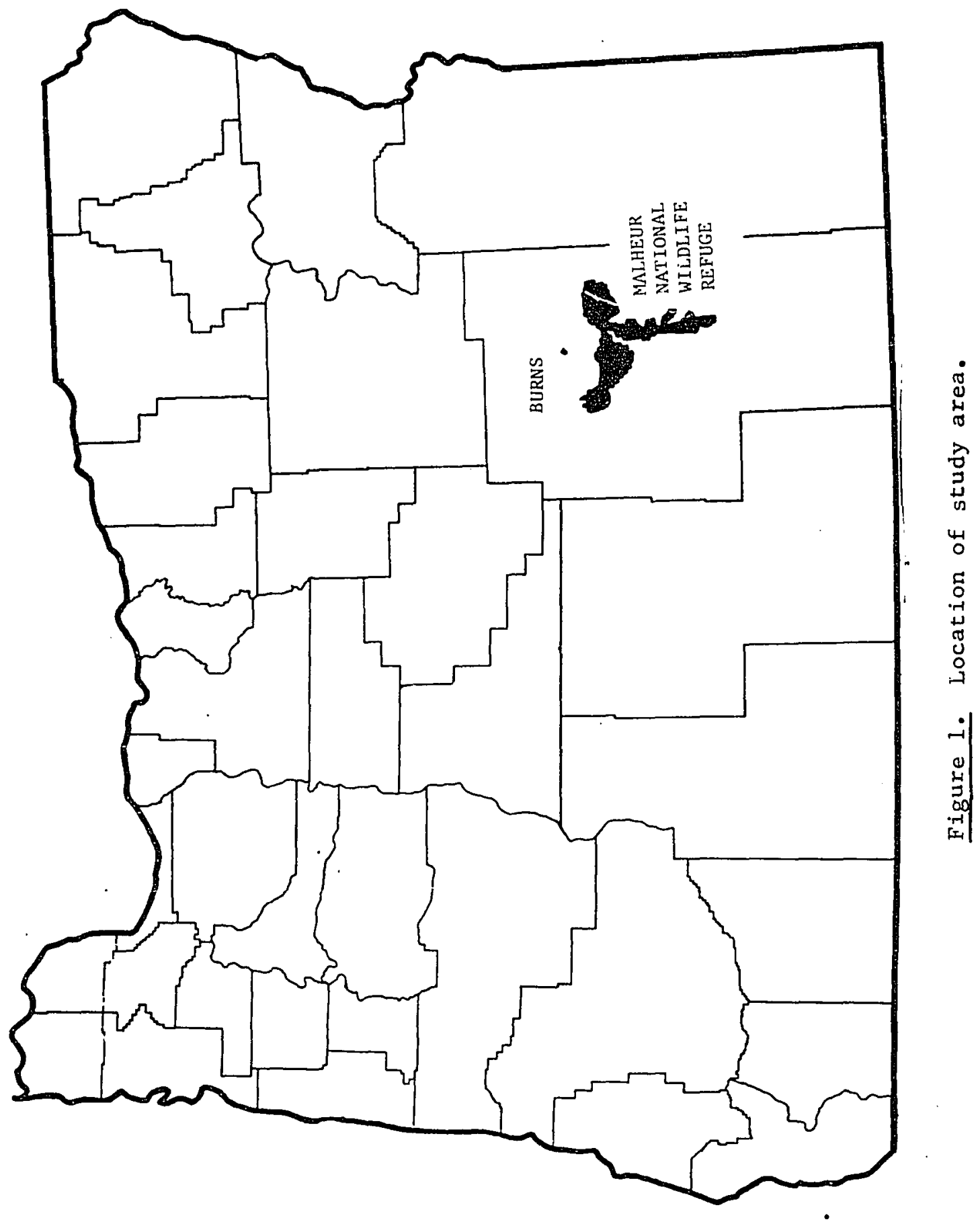


temperatures of $-6.6^{\circ} \mathrm{C}\left(20^{\circ} \mathrm{F}\right)$. The average annual precipitation is $22.9 \mathrm{~cm}(9.0 \mathrm{in})$; much occurs as snowfall (Meteorology Committee, Pacific Northwest River Basins Commission 1969).

Major drainages into the Harney Basin and the refuge are the Silvies River and Silver Creek, flowing southward from the Blue Mountains, and the Donner und Blitzen River, flowing northwestward from the Steens Mountain highlands (Lindsey et al. 1969). The Silvies River drains approximately $3,500 \mathrm{~km}^{2}\left(1,350 \mathrm{mi}^{2}\right)$ and flows into the north side of Malheur Lake; Silver Creek discharges into Harney Lake. The Donner und Blitzen River drains approximately $2,600 \mathrm{~km}^{2}\left(1,000 \mathrm{mi}^{2}\right)$ and empties into the southern portion of Malheur Lake, providing the major source of water for the refuge (USDI 1957).

Harney Lake, a shallow, alkaline lake nearly devoid of vegetation, is the lowest part of the drainage and usually covers about 12,140 ha $(30,000$ a). Malheur Lake, a shallow, alkaline marsh of about 20,240 ha $(50,000 \mathrm{a})$, supports dense, interspersed stands of emergent vegetation including Scirpus acutus, Typha latifolia and Juncus balticus as well as submerged aquatic plants, particularly Potomogeton pectinatus, Zannichellia palustris, and Mymaphyllum exalbescens (Duebbert 1969). Both lakes vary in the size of their surface areas, depending on the availability of water, and both may become dry during extended periods of drought.

Beside Harney and Malheur Lakes, a high proportion of the refuge consists of valley wetlands vegetated primarily by Carex and submerged and emergent wetland flora. Drainage is usually poor on 
these wet, alluvial soils (Lindsey et $a$. 1969), and approximately 8,090 ha $(20,000$ a) of this bottomland is under cultivation (U.S. Soil Conservation Service, unpublished data). Rimrock areas above the valley floor support mainly Artemisia tridentata, Sarcobatus vermiculatus, and the exotic annual Bromus tectorum.

The earliest faunal information from the Harney Basin was recorded by Peter Skene Ogden, who led a party of fur trappers to the area in 1826 (Elliott 1910). In the early 1900's, various members of the Bureau of the Biological Survey collected birds and mammals in the Harney Basin (Lewis 1912, Willett 1918, Jewett 1922) and referred to the Common Raven (Corvus corax hereafter referred to as raven). Ravens have been regularly mentioned in annual narrative reports from the refuge due to the interaction between them and waterfowl which nest in the area. As early as 1937, ravens were killed on the refuge in attempts to alleviate depredations of eggs of ducks and other waterfowl (Refuge Narrative 1937). In February 1972 the use of chemical toxicants such as Compound 1080 (sodium monofluoroacetate) as a method of reducing predators was terminated on the refuge in accordance with Executive Order: Environmental Safeguards on Activities for Animal Damage Control on Federal Lands. The toxicity of Compound 1080 is related to a metabolic derivative, fluorocitrate, which inhibits citrate and succinate metabolism, and thereby blocks the Krebs cycle (Rudd and Genelly 1956). Compound 1080 is highly stable in tissue and therefore allows secondary poisoning (Robinson 1948, Rudd 1964, and Cain 1972). Rudd and Gene1ly ( I956) reported ravens and other birds have been 
found in the areas of Compound 1080 bait stations, and further point out that they regularly feed on poisoned carcasses. Whether through primary or secondary poisoning, the use of poisons was thought to be responsible for the low number of ravens on the refuge in 1947 (Refuge Narrative 1947). It has been assumed that ravens were important in determining the nesting success of waterfowl on the refuge (Jarvis 1964, Clark 1977). Therefore, concern was expressed over the effect of the curtailment of predator management on refuge waterfowl production (Refuge Narrative 1973).

JUSTIFLLATION OF THE SIUDY

Jarvis (1964) found that avian predators destroyed 28\% $(n=93)$ of the duck nests (includes Mallard (Anas platyrhynchos), Cinnamon Teal (A. cyanoptera), Gadwall (A. strepera), Greenwing Teal (A. carolinensis), Shoveler (A. clypeata), American Wigeon (Mareca americona), Redhead (Aythya americana) and Ruddy Duck (Oxyura jamaicensis)) he examined on the refuge in 1964. Although Blackbilled Magpies (Pica pica), and California and Ring-billed Gulls (Lams califomicus and $L$. delawarensis) were present in the areas and may have destroyed some nests, ravens were believed to be the most destructive avian predator. Clark (1977) determined avian predators destroyed $30 \%(n=223)$ of the duck nests he examined during 1974 and 1975. Although Common Crows (Corvus brachyrhynchos) and Black-billed Magpies were present in small numbers, ravens were once again believed to be the major avian predator present on his study plots (Table I). 
TABLE I

NESTING SUCCESS OF DUCKS, SANDHILL CRANES, AND CANADA GEESE

ON MALHEUR NATIONAL WILDLIFE REFUGE 1964-1977

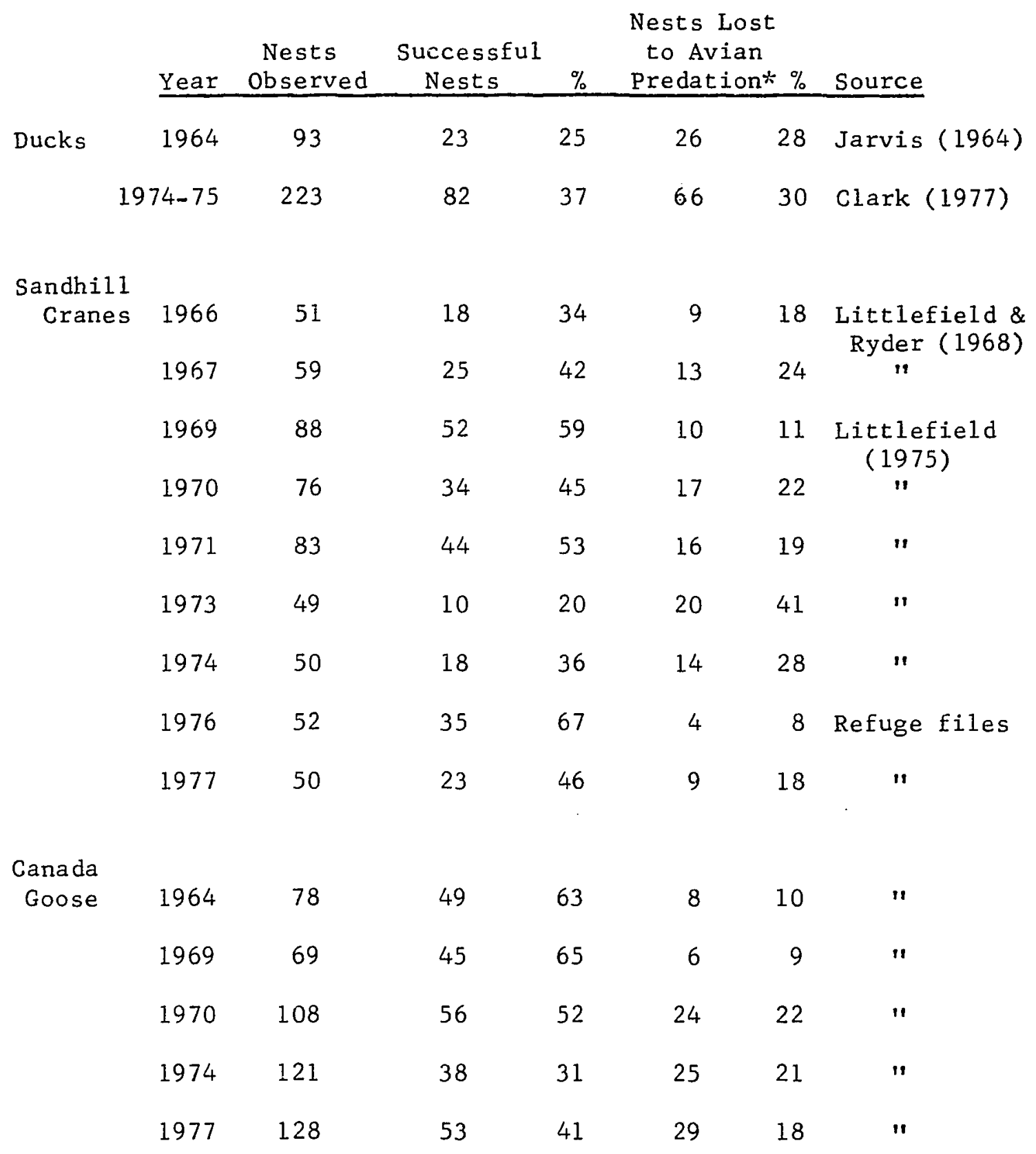

* Includes Raven, Crow, Magpie, Ringbill Gull and California Gull 
The nesting success of Greater Sandhill Crane (Gms canadensis tabida) on the refuge has been tabulated since 1966 and is summarized on Table I. Although there was a significant $\left(X^{2}=13.33\right.$, I df, $\left.P \leq 0.01\right)$ increase in raven depredation in 1973 immediately after control activities were terminated, raven depredation decreased thereafter and reached its lowest recorded levels in 1976.

Several years of nest success studies were conducted by refuge personnel for Canada Geese (Bronta canadensis) on the refuge. These are also summarized in Table I.

Table I shows that raven management on the refuge has not achieved any significant decrease in the amount of nest depredation. However, a proposal for the management of predator populations, including ravens, on the refuge was drafted in June 1.975 (Refuge files, Malheur NWR). In order to provide data leading to a raven management policy, I studied the ecology of ravens on and near the refuge from 1975 to 1977 . Several parameters of raven ecology needed to be better understood so that attempts to manage the raven population would be ecologically acceptable, and in accord with long-term refuge objectives. I determined that certain population phenomena including brood phenology and nesting success, the relationship of ravens nesting on the refuge to those inhabiting other parts of the Northern Great Basin, and seasonal variation in the abundance of ravens on the refuge, were germane to this understanding. Knowledge of the food habits of ravens nesting on the refuge was essential. Further, I suspected that determination of the diets of individual pairs of ravens would be particularly important in 
order to learn whether the entire population was functioning as egg predators, or if nest depredation was primarlly perpetrated by particular pairs of birds.

\section{ENVIRONMENTAL RELATEDNESS}

The research was conducted because of the economic and aesthetic aspects of waterfowl as a resource, interest in the activities of ravens as protected predators, and the opportunity to contribute to a sound and effective predator management plan.

Bellrose (1976) estimated the number of waterfowl hunters in the United States in the early $1970^{\prime} \mathrm{s}$ at 2.2 million, based on the average number of Federal Migratory Waterfowl Stamps sold. Johnsgard (1975) estimated 1.7 million based on a four-year average and further suggested an annual expenditure of over $\$ 1$ million by waterfowl hunters, and an annual harvest of 15 million ducks and geese in the United States alone. Waterfowl are an important economic resource.

The number of visitors on Malheur National Wildlife Refuge has increased 46\% from 1973 to 1976 (Refuge Files, Malheur NWR). Eighty-five percent of the visitors in $1976(28,000)$ indicated that their reason for visiting was non-consumptive use (Refuge Files, Malheur NWR). Malheur W1ldlife Refuge is Ilsted in Harrison (1976) and is nationally recognized for tts diverse and abundant waterfowl. As ponds and lakes in the prairte states and Canada continue to be drained, refuges will become more important for producing waterfowl. It is very important that refuge personnel make every effort to reach their wildlife production objectives. The Malheur 
National Wildife Refuge objective for Canada goose production has been set at 3,500 annually (Refuge files, Malheur NWR). The production in 1971 was estimated at about $69 \%$ of this goal. In 1973 and 1974 goose production was estimated to be $19.4 \%$ and $28.6 \%$ of the goals respectively (Refuge Files, Malheur NWR). Increased predator pressure was cited as the primary reason for low production. The production objective for ducks is 50,000 annually. Although the data for production after 1972, when predator management was stopped on the refuge, shows a wide range, the average for $1973-74$ is $40 \%$ lower than the average for 1965-1972 (Refuge Files, Malheur NWR). Again, predator pressure was listed as a fundamental cause.

One of the predators which had been controlled prior to 1972, and had been accused of significant nest predation, was the raven. Many of the basic questions concerning the raven population could not be answered. Refuge personnel did not know the density of ravens, their nest success, or populational movements. The ecological position of the raven on the refuge was considered to be that of an effective predator. The methods and justification for predator management have improved substantially since the period of general, unchallenged control. An important reason for this change is a change in the public attitude toward predators, which has resulted from an increased understanding of the ecological position of predators in an ecosystem and of predator-prey interactions in general.

The raven is a holarctic species and is one of the most widely distributed spectes on earth (Welty 1968). The raven reaches its highest densities in the western United States and is truly common 
only there (Bent 1946). The raven is regarded as a "wilderness species" (Craighead and Craighead 1969), and due to international agreements with Mexico was listed as a protected species in 1974 by the U.S. Fish and Wildlife Service.

This research offered a unique opportunity to investigate the raven and to gather data upon which a sound predator management plan for ravens could be built. 
MATERIALS AND METHODS

Ravens were studied in the field from $1 \mathrm{July} 1975$ to 31 August 1977, except from October 1975 through February 1976, when only five to seven day periods of observation were spent in the field each month. Field notes and sighting records were tape recorded and transcribed to a journal. A systematic search of deserted buildings, trees, and rimrock suitable for raven nesting, was made during July and August 1975. Although positive identification of raven nests was not possible because of their similarity to raptor or owl nests, all possible nest locations on and near the refuge were recorded on maps. Nest locations were marked with bright orange plastic ribbon to facilitate relocation. Each nest location (see Appendix A) was assigned a number (Table II) and recorded on the maps of the area (Figure 2 and 3 ). During the raven nesting season, the status of each nest was determined by examining its contents. Where direct visual observation was obscured, observation of nest contents was facilitated by use of an auto mirror mounted on a one m length of "3/8 inch" copper tubing. The copper handle could be bent so nest inspection was possible with a minimum of nest disturbance. Almost all nests were visited at weekly intervals during the nesting season. Potential nesting sites were examined during daily travels. 
TABLE II

ACTIVE RAVEN NESTS 1976-1977

Nest \# Location Active 1976 Active 1977

\begin{tabular}{|c|c|c|}
\hline 1 & Rock Island Field & $\mathrm{x}$ \\
\hline 2 & Chappo Field & $\mathrm{x}$ \\
\hline $3 a$ & Double-o School & $\mathrm{x}$ \\
\hline $3 b$ & Warbler Pond & \\
\hline $3 c$ & Double-o School R & \\
\hline 4 & Stinking Lake & $\mathrm{x}$ \\
\hline 5 & Derrick Lake & $\mathrm{x}$ \\
\hline 6 & Martha Lake & $\mathrm{x}$ \\
\hline 7 & Pictograph & $\mathrm{X}$ \\
\hline 8 & Shelley Ranch Road & $\mathrm{x}$ \\
\hline 9 & Gibson House & $\mathrm{x}$ \\
\hline 10 & Baccus Lake & $\mathrm{x}$ \\
\hline 11 & Cole Island Dike S & $\mathrm{x}$ \\
\hline $12 \mathrm{a}$ & Cole Island Dike $\mathrm{N}$ & $\mathrm{x}$ \\
\hline $12 b$ & Cole Island Dike N-R & $x$ \\
\hline 13 & Blacky Corner & $\mathrm{x}$ \\
\hline 14 & Sagebrush Field & $\mathrm{x}$ \\
\hline 15 & Davies Ranch & $\mathrm{X}$ \\
\hline 16 & Jenkins Ranch & $\mathrm{x}$ \\
\hline 17 & Power Line & $\mathrm{X}$ \\
\hline 18 & Ramelli Bridge & $\mathrm{x}$ \\
\hline 19 & Diamond Dump & $\mathrm{X}$ \\
\hline
\end{tabular}


TABLE II

ACTIVE RAVEN NESTS 1976-1977

(Cont.)

\begin{tabular}{|c|c|c|c|}
\hline Nest \# & Location & Active 1976 & Active 1977 \\
\hline 20 & Diamond Point-Ditch & $\mathrm{x}$ & \\
\hline 21 & Diamond Point-Fence & $\mathrm{x}$ & $\mathrm{x}$ \\
\hline 22 & Diamond Swamp & $\mathrm{x}$ & $\mathrm{x}$ \\
\hline $23 a$ & Diamond Cut & $\mathrm{x}$ & $x$ \\
\hline $23 b$ & Diamond Cut-R & $x$ & \\
\hline 24 & Hog Wallow seeding \#l & $\mathrm{x}$ & $\mathrm{X}$ \\
\hline 25 & Rock Crusher Point & $\mathrm{x}$ & $\mathrm{x}$ \\
\hline 26 & Krumbo Swamp & $\mathrm{X}$ & $\mathrm{X}$ \\
\hline 27 & Krumbo Valley & $x$ & $\mathrm{x}$ \\
\hline 28 & Krumbo Dam & $\mathrm{X}$ & $\mathrm{x}$ \\
\hline 29 & Boca North* & $\mathrm{X}$ & $\mathrm{x}$ \\
\hline 30 & Boca East & $\mathrm{x}$ & \\
\hline 31 & Bridge Creek Field & $\mathrm{x}$ & \\
\hline 32 & Pelican Island $\mathrm{N}$ & $x$ & $\mathrm{X}$ \\
\hline 33 & Juniper Tree & $\mathrm{x}$ & \\
\hline 34 & Stone Castle & $\mathrm{X}$ & \\
\hline 35 & Dog Mountain & $\mathrm{x}$ & $\mathrm{x}$ \\
\hline 36 & House Field & $\mathrm{x}$ & \\
\hline 41 & Larry's Corral & & $\mathrm{x}$ \\
\hline 42 & Rinrock Field & & $\mathrm{x}$ \\
\hline 43 & East Grain Camp & $\mathrm{x}$ & \\
\hline $44 a$ & Larson Field & $x$ & $\mathrm{x}$ \\
\hline
\end{tabular}


TABLE II

ACTIVE RAVEN NESTS 1976-1977

(Cont.)

\begin{tabular}{|c|c|c|c|}
\hline Nest \# & Location & e 1976 & Active 1977 \\
\hline $44 b$ & Larson Field-R & & $\mathrm{X}$ \\
\hline 46 & Cargill Corral & $\mathrm{x}$ & $\mathrm{x}$ \\
\hline 48 & Big Red S & $\mathrm{x}$ & $\mathrm{x}$ \\
\hline 51 & Hog Wallow seeding \#2* & $x$ & $\mathrm{x}$ \\
\hline 52 & West Grain Camp & & $\mathrm{x}$ \\
\hline 53 & Unit 8 Pond & & $\mathrm{x}$ \\
\hline 55 & Saddle Butte & & $\mathrm{x}$ \\
\hline 56 & Kirk House & $\mathrm{x}$ & $\mathrm{x}$ \\
\hline 58 & South Harney Lake & & $\mathrm{x}$ \\
\hline 59 & Eagle's Nest & & $\mathrm{x}$ \\
\hline 60 & Pelican Island S & & $\mathrm{x}$ \\
\hline
\end{tabular}

* The precise location of this nest shifted slightly from 1976 to 1977; however, I consider the same nest site to be represented. 


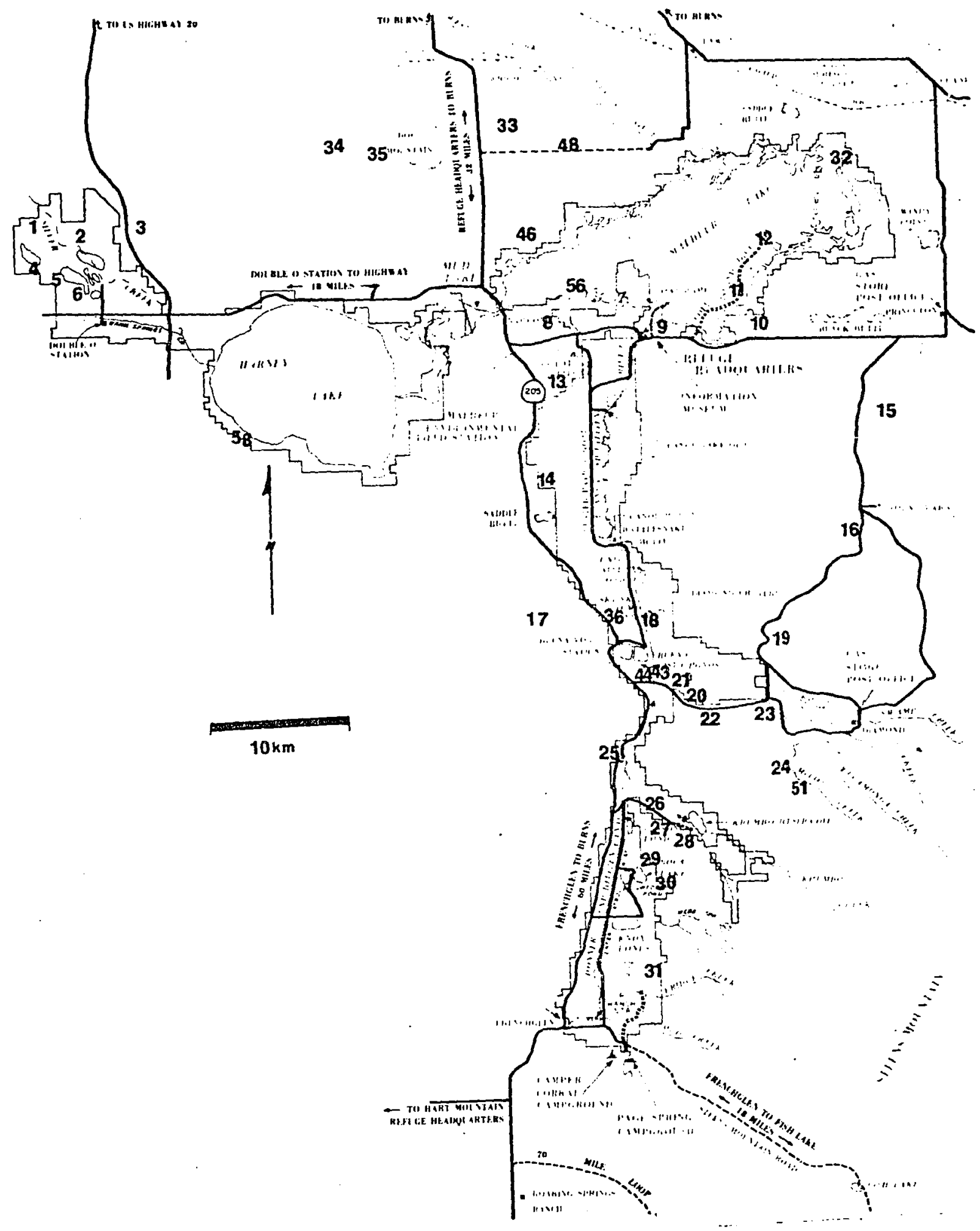

Figure 2. Map of active raven nests - 1976. 


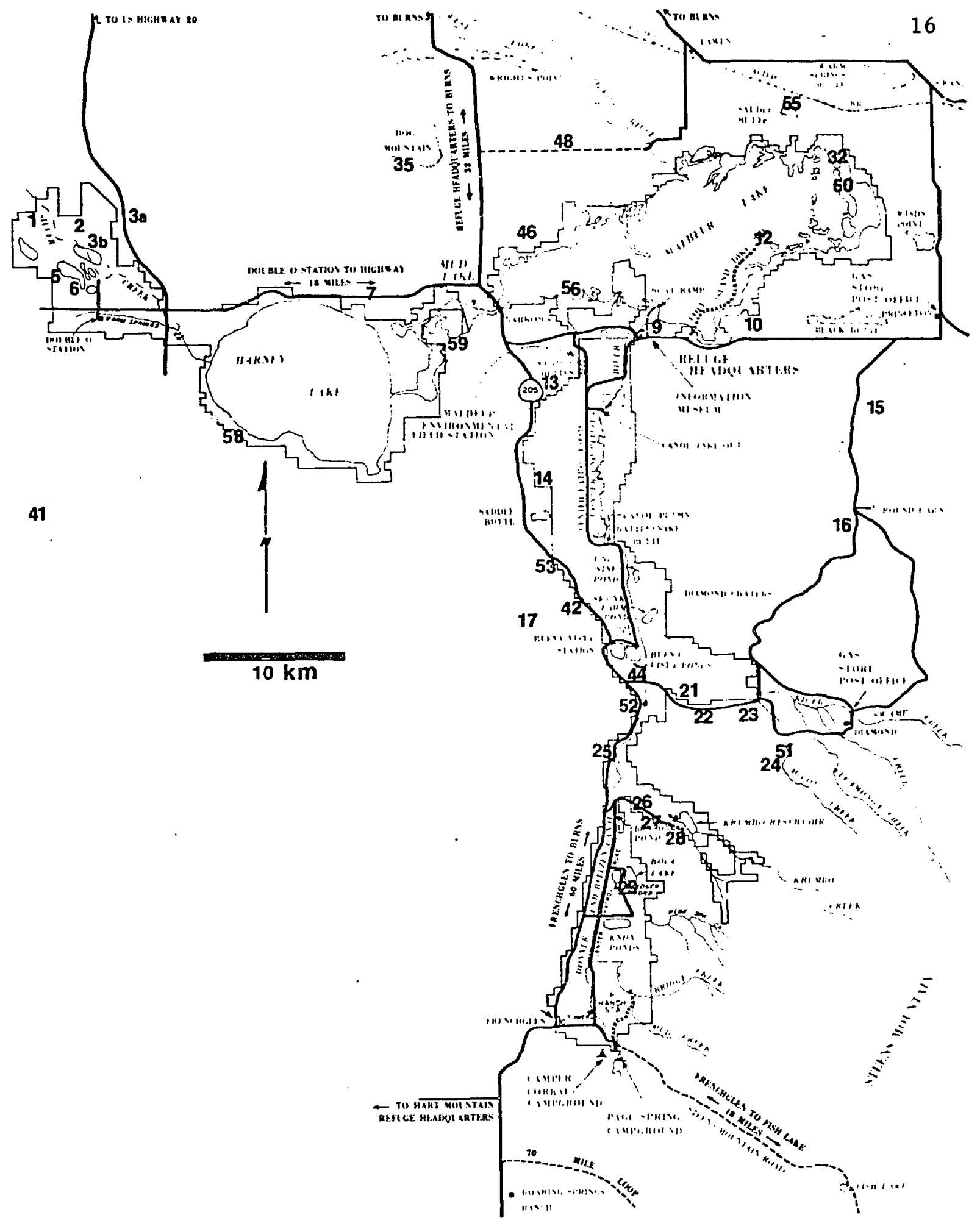

Figure 3. Map of active raven nests - 1977. 
TRAPPING

Three methods were used to capture 266 ravens.

Hand Capture

One hundred forty-five fledgling ravens were captured by hand at their nests about 35 days after hatching and were marked with patagial markers. Sixteen birds younger than 35 days, representing four nests, were similarly captured and marked with patagial markers. This did not appear to impede fledging or alter normal behavior patterns. Early patagial marking facilitated locating and identifying young ravens, including those which died at or immediately after fledging. The early marking provided information as to time of death and age, relative to nest mates, of any dead fledglings.

\section{Rocket Net}

A $9 \mathrm{~m} \times 18 \mathrm{~m}$ rocket net was used on 10 occasions from March to November 1976 in an attempt to capture fledged birds. Locations and dates of operation are given in Table III and Figure 4. Cattle (Bos taurus) carcasses, obtained from local ranchers, were used as bait. To prevent any observation by ravens of human activity near the carcass, the rocket net was set at sundown. In six attempts, the carcasses were moved to locations which were better suited for trap operation. Criteria included sparse vegetation near the net and the proximity of a blind which afforded a view of the trap site. Trapping success by means of rocker netting was poor. It was first thought that lack of success was due to moving the carcasses to 
TABLE III

ROCKET NET AND DROP-IN TRAP LOCATIONS

\begin{tabular}{|c|c|c|c|c|c|}
\hline Number & Trap Type & Location & Period 0 & of & Deration \\
\hline 1 & Rocket & Narrows $^{a}$ & $1-14-76$ & to & $1-17-76$ \\
\hline 2 & Rocket & East Grain Camp ${ }^{a}$ & $1-28-76$ & to & $2-01-76$ \\
\hline 3 & Rocket & Dunn Dam ${ }^{a b}$ & $3-06-76$ & to & $5-20-76$ \\
\hline 4 & Drop-In & Narrows & $3-20-76$ & to & $4-13-76$ \\
\hline 5 & Drop-In & Diamond Point & $4-13-76$ & to & $4-20-76$ \\
\hline 6 & Rocket & Ruby Springs ${ }^{a}$ & $6-14-76$ & to & $6-24-76$ \\
\hline 7 & Rocket & Crane Pond ${ }^{a}$ & $8-18-76$ & to & $8-31-76$ \\
\hline 8 & Rocket & Haines Fiel $\mathrm{d}^{\mathrm{b}}$ & $9-15-76$ & to & $9-20-76$ \\
\hline 9 & Rocket & Taylor Field & $9-21-76$ & to & $11-01-76$ \\
\hline 10 & Rocket & North Malheur Lake & $11-06-76$ & to & $11-07-76$ \\
\hline 11 & Rocket & Cargill Field & $11-07-76$ & to & $11-20-76$ \\
\hline 12 & Rocket & Meadow Field ${ }^{a}$ & $12-15-76$ & to & $1-16-77$ \\
\hline 13 & Drop-In & Sod House & $1-28-77$ & to & $2-05-77$ \\
\hline 14 & Drop-In & Benson Boat Landing & $2-05-77$ & to & $4-19-77$ \\
\hline 15 & Drop-In & Bonhoff Nest & $3-28-77$ & to & $5-26-77$ \\
\hline 16 & Drop-In & Larson Field Nest & $4-19-77$ & to & $5-31-77$ \\
\hline
\end{tabular}

a Indicates carcass was moved
b Indicates success at location 


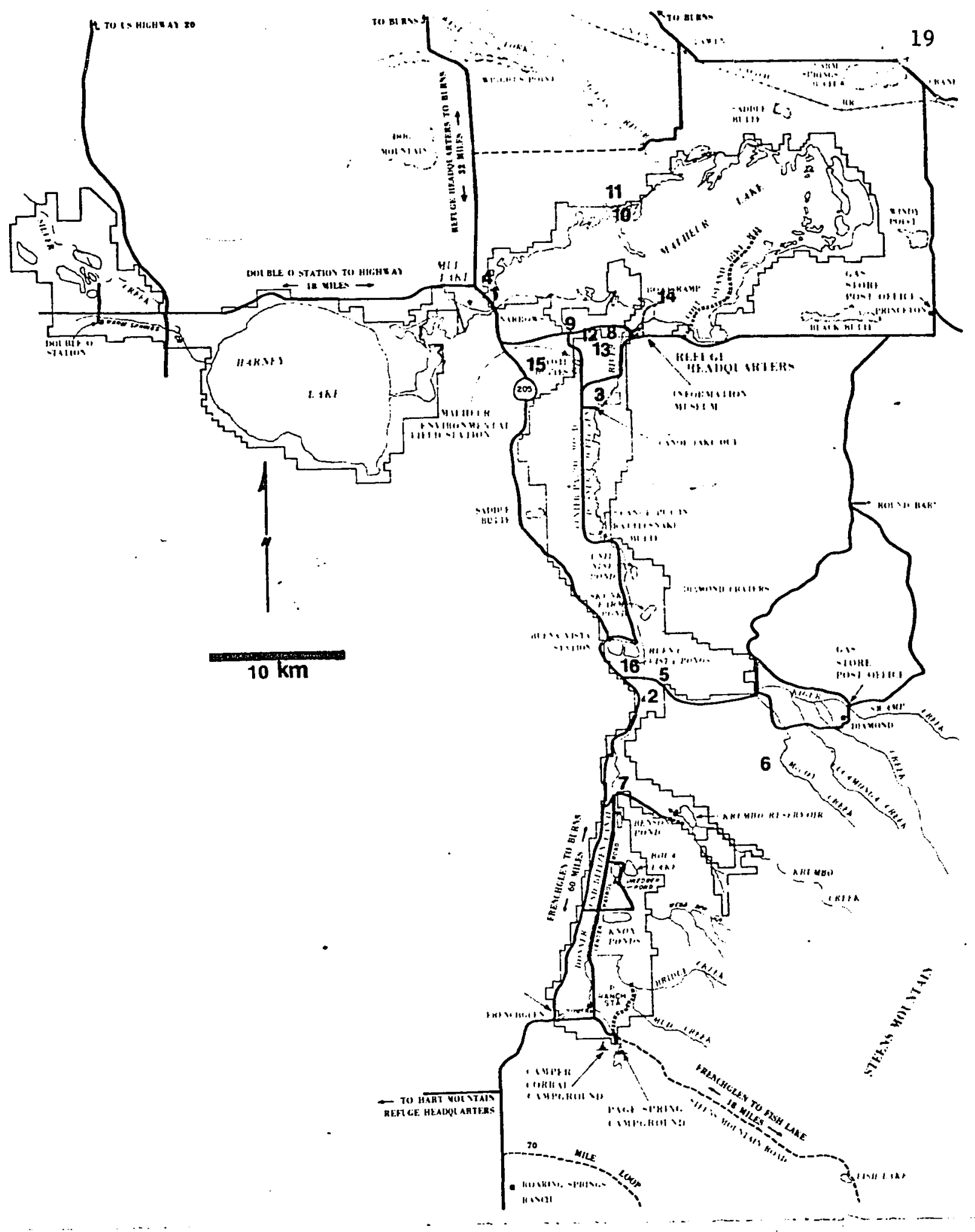

Figure 4. Map of trapping locations. 
locations distant from grazing cattle. Therefore, in four cases in which a carcass was judged to be at an acceptable location, the trap was set without relocating the dead animal. Permission from local landowners was secured and cooperation was obtained in reducing the number of cattle grazing near the carcass. This procedure resulted in similar lack of success. At only two locations were ravens successfully trapped. Six ravens were captured using the rocket net. Observations at trapping sites indicated that ravens perceived the rocket net, rockets, or detonating wire and then avoided the site. At locations 10 and 11 (Figurn 4), ravens had been feeding on the carcasses four to seven days before the net was positioned. In both cases, use of the area by ravens stopped immediately and the ravens were observed flaring directly above the bait at a distance of $20 \mathrm{~m}$. At both locations, ravens were again observed feeding 12 to 16 days after the rocket net and detonating material had been removed.

Drop-in Trap

The most successful method of capturing fledged birds was to use a wire drop-in trap as shown in Figure 5. The basic design is similar to that of Rowley (1968) and Coldwell (1972). The trap was constructed of "2 inch $\times 2$ inch" frame and "l inch" poultry net. Trap locations are indicated in Table III and Figure 4. The drop-in trap was baited with cattle carcasses provided by local ranchers. Initially, unsuccessful operation of the drop-in trap at locations 4 and 5 (Figure 4) discouraged its use until January 1977. At location 13, three ravens, captured as fledglings in 1976, were 


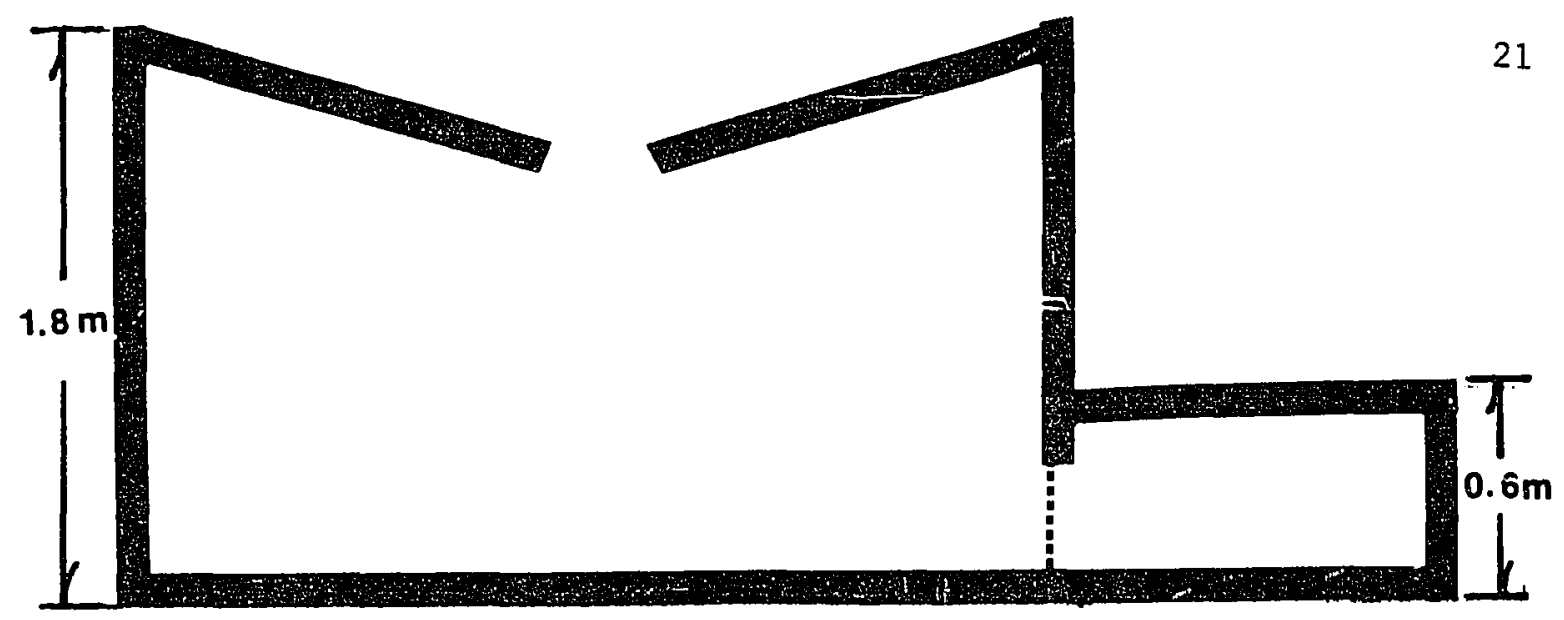

SIDE VIEW

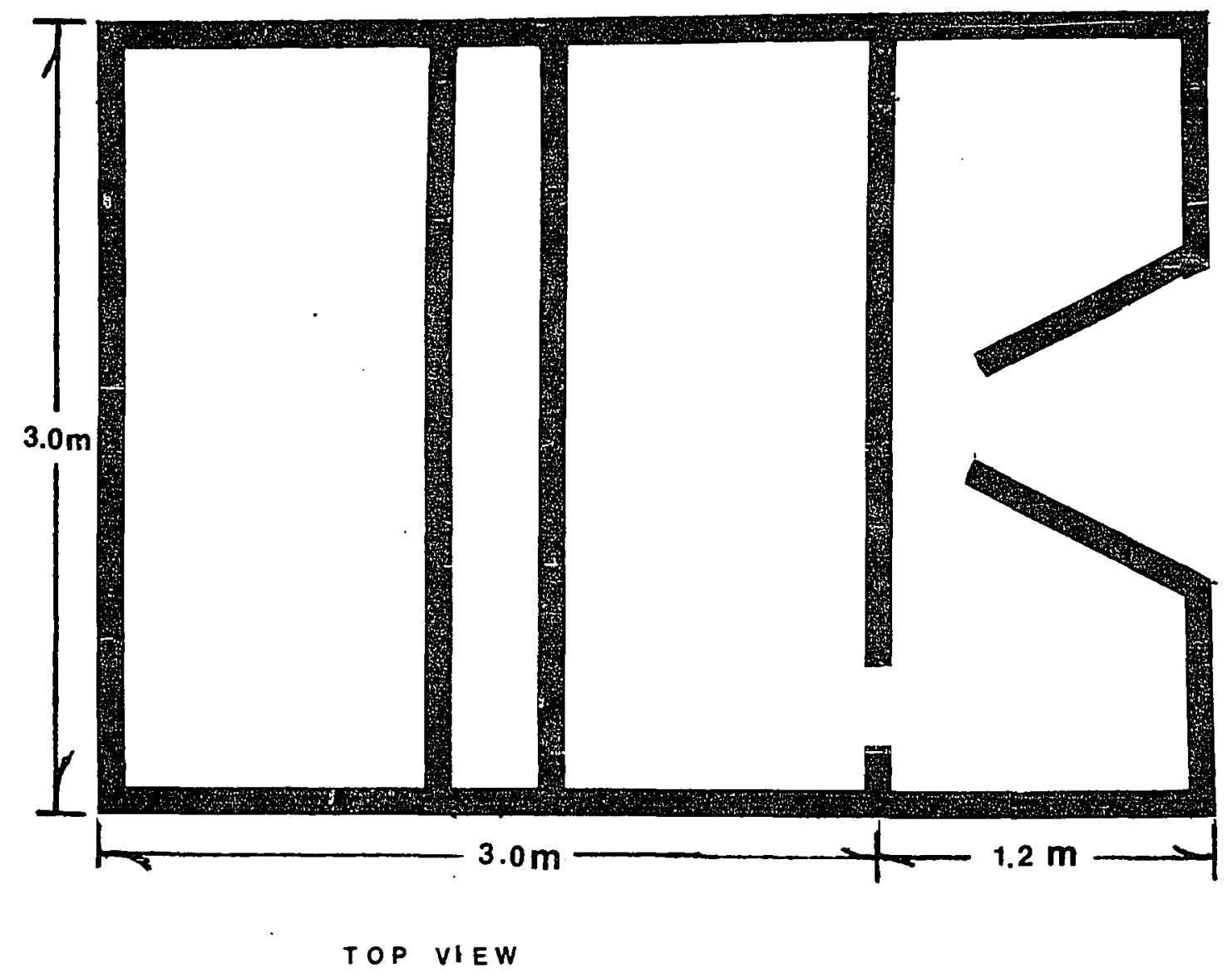

Figure 5. Diagram of drop-in trap. 
used as decoy birds as suggested by Rowley (1968). Although wild ravens were seen near the trap, it was unsuccessful, apparently due to daily human activity in the area. At this time, it was noted that in open habitat, ravens landed 10 to $20 \mathrm{~m}$ from the trap and then hopped or walked to the trap. To facilitate entrance into the trap, a walk-in extension (Figure 5) was added to the trap. The trap was then moved to location 14. The site was selected because it was removed from frequent human activity, adjacent to an all weather road, and frequently visited by ravens. The use of 1ive decoy birds and carcass bait in large quantities produced good trapping results. Twelve carcasses were used during the trapping period. Although several birds escaped through the top opening, 99 birds were trapped in 44 trap days ( 3 February 1977 to 19 March 1977). The trap was inspected at two day intervals thereby minimizing human disturbance. The trap was most successful after periods of snow, but ravens were trapped between almost all inspections. Trapping at this site was terminated when all available color combinations of patagial markers had been used.

The trap was placed at 1ocations 15 and 16 (Figure 4) in an attempt to capture specific nesting pairs as suggested by Rowley (1968). These trapping efforts were unsuccessful.

PATAGIAL MARKING

Ravens were marked for field identification by means of wing markers manufactured of Saflag (Safety Flag Corp. of America, Pantucket, RI) and Herculite (Vaughn Brothers, Portland, OR). The 
material was cut to a dumbbell shape, about $20 \mathrm{~cm} \times 10 \mathrm{~cm}$. Two reinforcement eyelets were attached as indicated in Figure 6 . Use of white, yellow, blaze orange, aurora pink, signal green, light blue, and dark blue material in combination provided a total of 63 different color combinations. A silver colored Saflag strip $(2.5 \mathrm{~cm} \times 10 \mathrm{~cm})$ was attached with Vyna-Bond (Plastic-Dip Int., St. Paul, MN) to some markers to provide an additional 161 color combinations. The use of the silver diagonal caused some confusion in proper identification, especially in overcast weather for inexperienced observers. In cases of questionable sighting reports, the observation was recorded as an unidentified marked bird at a particular location. Personal observation minimized misidentification.

Markers were attached to the wing following the methods suggested by Fentress (1975) by using a hand riveter and $3 \mathrm{~mm}$ diam. $\mathrm{x}$ $9.5 \mathrm{~mm}$ aluminum rivets together with $3 \mathrm{~mm}$ aluminum backup plates on each side ( Figure 7).

Although the marker blocked preening of the area it covered, no other impairment of normal behavior was observed. A patagial marker on an individual recaptured 11 months after tagging was only somewhat faded and frayed. There were no signs of harm to the bird and the weathered marker was still visible and functional. 


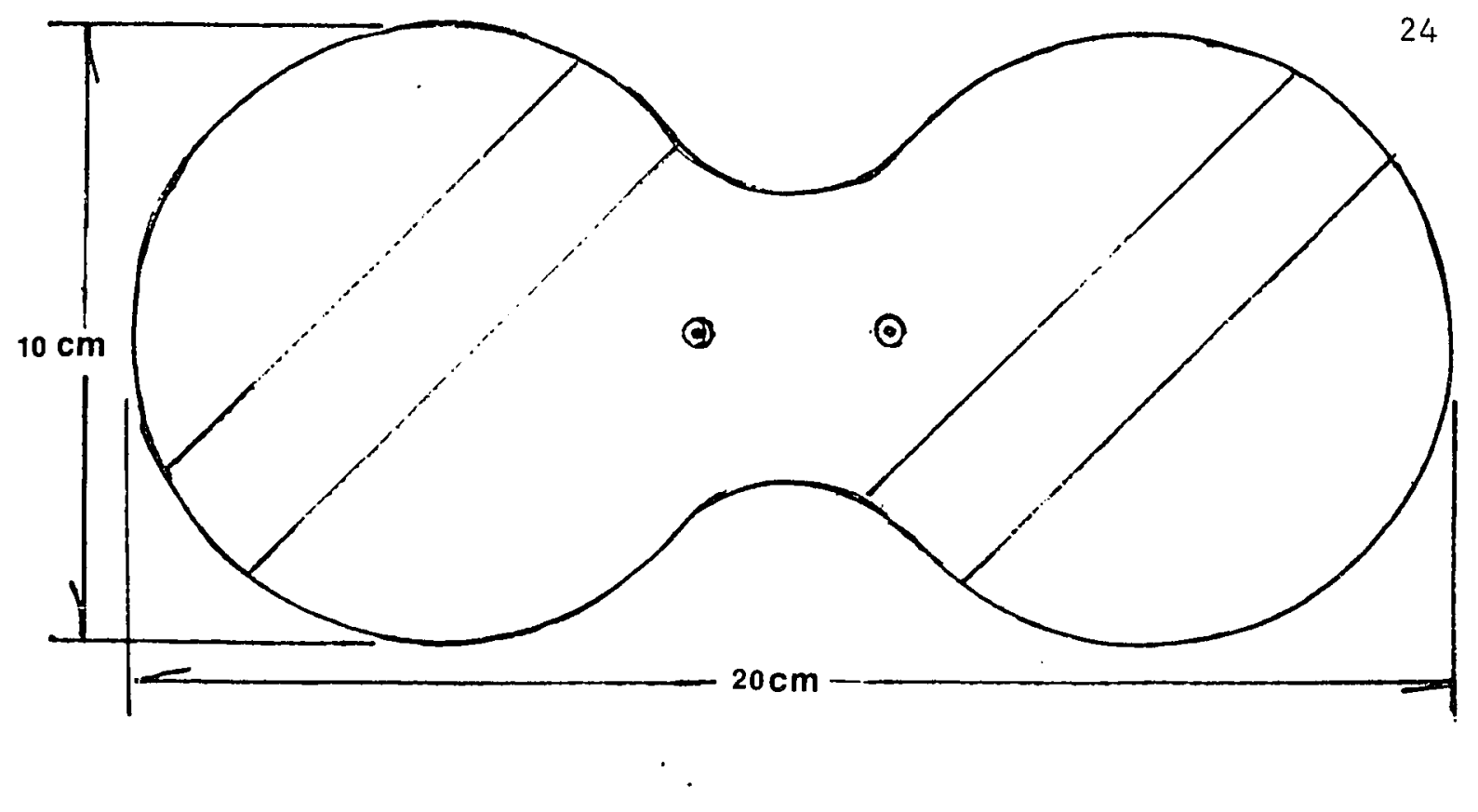

Figure 6. Diagram of patagial marker.

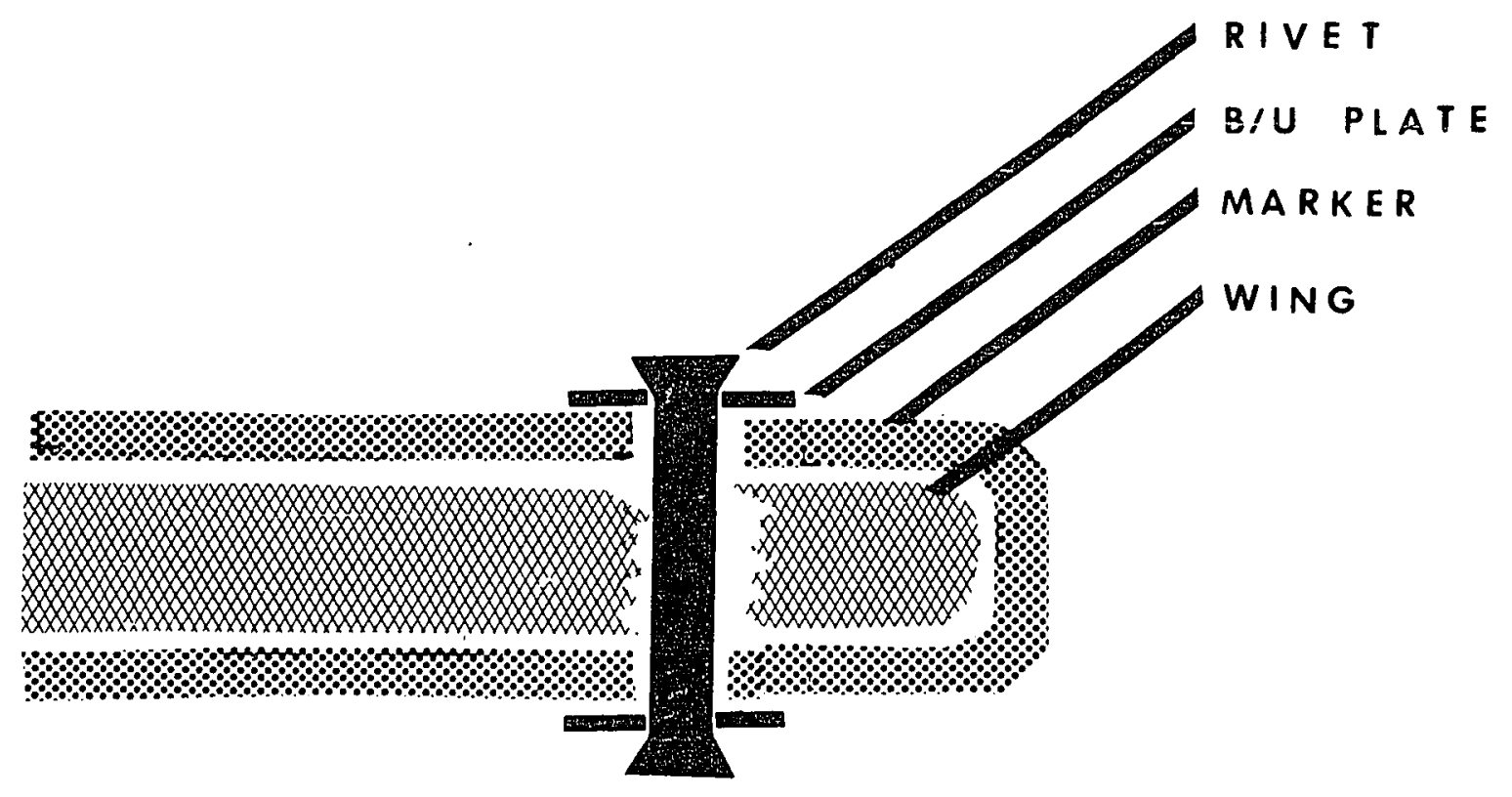

Figure 7. Attachment of patagial marker. 
RESULTS

AGE DETERMINATION

I found that it is possible to assign ravens to different age-classes based on mouth and tongue color. The mouth and tongue of the fledgling raven is bright red. In adult (breeding) birds, the mouth lining and tongue are totally black. There appears to be a gradual change in the color of the mouth and tongue during the first two years. The mouth and tongue of yearling birds in February and March range from a mottled pink-grey to blue. The mouth color of five ravens known to be 16 months old was blue-black.

Aggressive behavior also appeared to increase with age. Fledgling ravens reacted passively to capture, however agonistic behavior of five captive birds, as measured by threat displays (Lorenz 1931) and bill thrusts, increased throughout their captivity. Similar agonistic behavior was also seen in birds of unverified age, but whose mouth and tongue color was dark.

BROOD PHENOLOGY

Harlow (1922) and Coldwell (1972) suggested that ravens establish permanent pair bonds. As ravens were seen as pairs in all seasons during the study, I used the establishment of nesting territory as the initial phase of brood phenology. Nesting 
territories had been established by 6 March in 1976 and were first noted on 28 February in 1977.

\section{Nest Location}

During the study period I observed 87 active raven nests on and near the refuge to determine various aspects of brood phenology. I observed 45 nests in 1976 and 42 nests in 1977. The locations of the nests on the refuge are indicated in Figures 2 and 3 . Nest density for 32 nests on the refuge in 1976 averaged one per $22 \mathrm{~km}^{2}$. In 1977 the nest density for 29 nests occurring on the refuge was one per $25.2 \mathrm{~km}^{2}$. The distribution of nests reflects the heterogenity of habitat types found on the study area. Most nests $(n=64,74 \%)$ occurred in rimrocks. Abandoned buildings and other human structures (windmills and power poles) constituted $23 \%(n=20)$ of the nest sites. The remainder of the nests (3\%) occurred in Juniperus occidentalis and Salix sp.

At any of these types of sites, a nest may be reused for several years, or may be used only once. Great Horned Owls (Bubo virginionus), Red-tailed Hawks (Buteo jamaicensis) and Golden Eagles (AquiZa chrysaetos) use the same nests and nesting sites as ravens. Although I observed no physical conflict over nests or nest sites, one nest used by a paix of Golden Eagles (77-59) and one used by a pair of Great Horned Ow1s (77-21) in 1976 were occupied by ravens in 1977. Conversely, Great Horned Owls occupied two nests in 1977 which had been raven nests in 1976 (76-6 and 76-19). Although unused in 1976 and 1977, a nest in French's Round Barn has been occupied sequentially 
by Red-tailed Hawk, raven, and Great Horned Owl in the three nesting seasons prior to 1976 (John Scharff, Pers. Comm.).

There appears to be no correlation between the success of a pair in a given year and reuse of the nest. Attempts to capture adult nesting ravens were unsuccessful; therefore, none were marked during the study. However, differences in behavior and voice were used to identify eight pairs. Four of these pairs used the same nest in both 1976 and 1977, two pairs changed location during the nesting season after nest depredation, and two changed their nest locations in 1977 after successful nesting in 1976.

Changes in nest location after nest depredation did not necessarily reflect changes in habitat selection, only site selection. Based on chronological sequences, three pairs renested in the same nest; five pairs renested in a different nest, in the same habitat type; and two pairs changed both location and habitat type. Habitat plasticity was reported for Rooks (Taapken 1952) when the population shifted nesting habitat in response to harassment.

\section{New Nest Construction}

Nest construction was similar to that reported by Kulczycki (1973). When a suitable nest location is selected, both pair members participate in nest construction. Large sticks are first stacked for a base and then a loose basket is woven about the perimeter of the base. Most commonly, Artemesia tridentata and Sarcobatus are used for this purpose. These shrubs are relatively abundant in the area and have twisted irregularly shaped twigs. Smaller twigs are then 
placed into the structure until a large basket (18 cm deep) is formed. Smaller sticks are woven into the outer framework. This activity results in a stick basket about $40 \mathrm{~cm}$ in diameter and $20 \mathrm{~cm}$ in depth. Sticks dropped in flight, or which fall while being placed into the nest, are disregarded as nesting material. Over the years, this results in an accumulation of sticks beneath some reused nest sites. If a new nest is constructed close to an old, existing nest, however, the disregarded sticks may be used in the construction of the new nest by the pair.

After construction of the initial basket, a layer of soil $1-3 \mathrm{~cm}$ deep is formed at the bottom of the basket. This phase of nest construction was never observed, and it is not known how the soil is brought to the nest, but soil was found in all nests. Kulczycki (1973) reported clay or dung in the bottom of raven nests, but in this study only soil was found.

This soil-bottomed stick basket is then lined with finer material of types seemingly dictated by availability. The most commonly found materials were cattle hair (available from dead animals, fences, and rubbing posts), shredded Juniperus occidentalis bark, and grasses. Also used were Salix leaves, Black-tailed Jackrabbit fur (Lepus califormicus), discarded human clothing, and, in one instance, a coyote tail (Canis Zatrons).

The diameter of the nest structure appears to be determined by its location. Rimrock nests usually fill the ledge or alcove upon which they are built. Structure and tree nests are generally larger, 
but the size is apparently dependent on the amount of material necessary for proper support.

\section{Nest Reuse}

During the 1977 nesting season $43(51 \%)$ of the raven nests active in 1976 were reused. Local residents have verified that several nests have been reused by ravens for up to six years. During the nesting season, the perimeter of the nest is compacted by the movement of the chicks and adults, and the nest rim and outer edge is fouled by the chicks. The condition of the nest after a nesting season necessitates some reconstruction prior to reuse.

Reconstruction of established nests is similar to new construction. When a nest is reused, a perimeter of larger sticks is placed on the existing base and knit into a loose basket. Investigations of eight nests indicated that five to eight layers of sticks built up the initial framework. Smaller sticks are then added within the basket. The remainder of the nest building is identical to new construction. No additions of mud were observed in reused nests; apparently accumulation from prior use was sufficient.

\section{Egg Laying}

The earliest date of egg laying (calculated by method 1 below) was 7 March 1977 (77-15). Egg laying dates were based on one or more of the following criteria: (1) visual inspection of the nest on at least two consecutive days, with at least one day when no eggs were present, (2) calculation based on date of hatch, or (3) calculation based on date of fledge. 
I observed that, in the Malheur raven population, incubation is 21 days $( \pm 1)$ and hatching is asynchronous. There is considerable controversy concerning hatching synchrony for the raven. Gwinner (1965a) maintained that incubation starts with the last or penultimate egg, whereas Holyoak (1967), while referring to Gwinner's (1965a) data, suggested incubation begins with the first egg. Goodwin (1976) indicated that a parent sits on the nest, without incubating, as soon as the first egg is laid, but also mentions that the beginning of incubation can vary between individuals. Gwinner's (1965a) observations would account for the disparity between the 18-19 day incubation period he suggests and the 20-22 day period observed in this study.

I observed incubation to begin after the first egg is laid; variation in incubation period is ascribed to the amount of nest attendance. Nests which were in areas of heavier public use (e.g., $76-7,77-7,76-27,77-27)$ had longer incubation periods. These nest sites were often disturbed by humans, and the incubating females would leave for a time. I observed that in locations of infrequent human disturbance, female ravens remain tenaciously on the nest when approached by humans, whereas at nest sites of heavy human disturbance the incubating female flushes quickly from the nest.

To ascertain the length of the incubation period, and egg-laying sequence, I sequentially numbered the eggs of four clutches. I observed that egg-laying averaged one egg every 26 hours. In all instances of clutch completion sequences, the first laying period was followed by a refractory period, followed by a period in which 
two eggs were laid. After this initial start/stop sequence, laying then proceeded daily until the clutch was completed. The mean clutch size for 1976 was 5.8, S.D. = 1.1 for 19 nests and in 1977 was 6.1 , S.D. $=0.8$ for 26 nests (see Table IV.)

Holyoak (1967) suggests that clutch size in the Common Raven varies from 3 to 6 . Goodwin (1976) also suggests 3 to 6 , rarely fewer than 3 and very rarely 7 . During this study 15 nests (33\%) were found with a complete clutch of 7 eggs. One nest had a completed clutch of 3 eggs. Ratcliffe (1962) reported an average clutch size of 4.6 for 139 nests. Holyoak (1967) reported a mean clutch size of 5.2 eggs $(\mathrm{N}=67)$ for Common Ravens in Wales and South England. Kochert et al. (1976) reported a mean of 5.20 eggs $(N=10)$ for Common Ravens nesting in the Snake River Birds of Prey Study area in 1976, and $5.38(\mathrm{~N}=21$ ) in the following year (Kochert et al. 1977).

During incubation the nest is seldom left unattended. It appears that only the female incubates. Only the female incubates in Corvus coronoides, C. orm, C. bennetti, C. melzori, and C. tasmonicus (Rowley 1973) and C. brachyrhynchos (Good 1952). Bent (1946) insists that in ravens both sexes assist in incubation, but includes the behavior of the male as an incubation-related activity. Vocal, molting, or physical differences between partners could be established for all nesting pairs I observed. I found that pairs remain firmly bonded throughout incubation and that only the female incubates the eggs.

The male provides food for the incubating female. Feeding was observed on 23 occasions, and two basic patterns were discerned. Direct feeding of the female was initiated by the female as the male 


\section{TABLE IV \\ SUMMARY OF NESTING ACTIVITY \\ 1976-1977}

Range Mean S.D. $\begin{aligned} & \text { No. of } \\ & \text { Nests }\end{aligned}$

\section{Eggs}

$\begin{array}{lllll}1976 & 3-7 & 5.8 & 1.1 & 19 \\ 1977 & 4-7 & 6.1 & 0.8 & 26 \\ \text { Overali } & 3-7 & 6.0 & 0.9 & 45\end{array}$

Hatch

1976

$0-6$

4.0

1.6

25

1977

$0-6$

4.4

1.8

26

Overall

$0-6$

4.2

1.7

51

Fledge

$\begin{array}{lllll}1976 & 0-6 & 2.2 & 2.1 & 25 \\ 1977 & 0-6 & 2.5 & 2.0 & 28 \\ \text { Overall } & 0-6 & 2.3 & 2.0 & 53\end{array}$


approached the nest, by quivering (Goodwin 1976) accompanied by adult food calls (Rowley 1973). The male responded by direct regurgitation into the female's mouth. Alternatively, lower intensity quivering by the female resulted in placement of food on the nest rim or within two meters of the nest by the male.

Occasionally an incubating female was observed to leave the nest for short (ca. $10 \mathrm{~min}$ ) periods. The incidence of such flights increased in the later stages (ca, 15 days) of incubation. When not hunting for food, the male of a nesting pair would "stand guard" near the nest (cf. Bent 1946). Typically the male would position himself in a prominent location with a commanding view of the area. Direct view of the nest was not critical to the lookout location. At three nest locations, a shallow $(5 \mathrm{~cm})$ platform of large sticks was used as the normal male location. Herrick (1935) stated that, in general, such platforms are constructed entirely by males, but their construction was not observed in this study.

Females were also observed to leave nests to assist their mate in nest defense. Such defense was exhibited both intraspecifically and interspecifically. This behavior was directed most frequently at avian predators, such as other ravens, Golden Eagle or Red-tailed Hawk. Initial and more determined aggression was exhibited by the male. After initial aggression by the male, the female would leave the nest to assist in nest defense. She returned to the nest before the male. 
$\underline{\text { Hatching }}$

Normally, although not invariably, one egg of a clutch failed to hatch. This is also reported by Goodwin (1976). This occurred with such regularity that clutch size may be accurately determined from observation of hatchlings at 7-10 days post-hatch. This number was not used in the tabulation of clutch size but may be used as an approximate indicator if data are missing. Attempts were made to determine which of the eggs did not hatch; however, tests conducted on four nests were inconclusive.

Any unhatched eggs remained in the nest for 4-7 days after the hatch of the clutch. Holyoak (1967) indicated that normally all unhatched eggs are removed from the nest within 12 days, after which unhatched eggs would not be removed; Goodwin (1976) indicated that unhatched eggs remain in the nest for at least 7 days before removal. Rowley (1973) suggested that adult C. coronoides, C. mellori, C. orm, and $C$. bennetti may consume their own unhatched eggs, but found no evidence of shells in stomach analysis. Gwinner (1965a) stated that C. corax remove and eat the eggshells of the hatched eggs. Goodwin (1976) suggested that, for corvids in general, the incubating or brood parent consumes any unhatched eggs. In this study, all unhatched eggs were removed by the time the brood was 7 days of age. The fate of unhatched eggs was not determined, but analysis of regurgitated pellets indicated that raven egg shells are consumed by the adults. I could not determine, however, if these shells were from unhatched or hatched eggs. 
For the Malheur population, the average brood size for 1976 was $4.0(n=25)$ and for 1977 was $4.4(n=26)$ (see Table IV). For the nests in which both clutch size and brood numbers were known, $69 \%$ of the eggs hatched in 1976 and $71 \%$ in 1977. Kochert et al. (1976) reported an average brood of $3.66(\mathrm{~N}=21)$ in 1976 and an average of $3.09 \quad(\mathrm{~N}=22)$ for 1977 Kochert et al. 1977).

At hatching, young ravens are orange in color, unfeathered and sightless. No response to calls I made could be elicited at one day post-hatch. The same calls produced begging by the hatchlings at about three days post hatch, indicating possibly, that hearing does not function at hatch, that sound recognition takes several days to develop, and/or many exposures to calls are necessary to elicit a response from chicks. The spinal pteryla is first visible as a grey band at five days post-hatch. Growth is rapid. Eyes are functional between 12 and 14 days post-hatch.

My observations indicated that hatchlings are most vulnerable to predation during the first 14 days post-hatch. Of 17 nests in which the date of depredation was known, 12 (71\%) occurred within this two-week period (see Appendix A).

As indicated, hatchlings, although blind, responded to my presence at three days post hatch. By six days, vocalizations accompanied the begging response. Sight, at 12 to 14 days post-hatch, is correlated with a major change in the behavior of the hatchlings. When approached, 14-day-old chicks would remain silent and crouch low in the nest. Therefore, between 6 and 14 days, a predator may be able to locate raven nests due to indiscriminate vocalizations of the 
hatchlings. Although I was harassed by adults during nest inspections, this nest defense would probably not deter mammalian predators. As hatchlings over 14 days of age were observed begging towards adults, the marked change in behavior would support the suggestion of Bateson (1964) that vision is an important component for species recognition.

$\underline{\text { Renesting }}$

Predation of eggs or hatchlings does not necessarily preclude successful reproduction for the nesting pair. Laying of replacement clutches following destruction of eggs or chicks was observed four times in 1976 and twice in 1977. Additionally, based on normal egg laying dates, it is believed that two additional pairs laid replacement clutches in 1977. This behavior was first reported for Common Ravens by Bowles and Decker (1930). Took (1937) reported renesting in C. corone; Rowley (1973) reported clutch replacement for $C$. meZZom. Renesting after a successful hatch is depredated has not been reported.

The critical period after which renesting would not occur is not known. Predation after 5 May resulted in renesting attempts only once. This pair (77-3) renested in 1977 after the eggs had been destroyed about 28 May, whereas pair 76-8 did not renest in 1976 after predation around 11 May. Perhaps the ability to renest is dependent on the time of year of destruction of eggs or hatchlings, and the reproductive condition of the adults. The latter would be under endogenous (hormonal) control which would in turn be influenced 
by exogenous factors such as photoperiod (Farner 1964, Farner and Follett 1966) and temperature (Farner and Mewaldt 1952).

As already noted, renesting may or may not occur at the same nest location. In one instance the location was moved $2.4 \mathrm{~km}$ and the nest habitat changed from a rimrock to a tree. After the second (tree) nest was depredated, the pair then returned to the original nest site (rimrock) where a brood was successfully fledged. This was the only record of three nesting attempts during the study. The first nest predation occurred very early while eggs were still being incubated. In all other cases of renesting, only two attempts were recorded. If the second nesting attempt was at a location other than the original site, the new nest (with the exception noted above) was within $0.8 \mathrm{~km}$ of the original nest. Construction of a second nest is faster than that of the original nest. The shortest time I recorded for renesting was less than 11 days from predation to nest completion and egg laying as compared with 14-20 days on the first attempt as measured from the establishment of nesting territories to the completion of the nest and egg laying.

Fledging And Post-Fledge Activity

Ravens fledged at about 41 days $( \pm+3)$ of age. No hatchlings were marked for individual identification until near fledging and, because hatching is asynchronous, precise fledging dates were not ascertained. Sustained flight is not possible for young ravens; young ravens forced from the nest at 35 days post-hatch, were observed to glide to a location up to $150 \mathrm{~m}$ away but were back in the nest the next day. 
Young ravens, although capable of limited flight, accomplished most movement by gliding from a higher point to a lower point and then walking or hopping back to a higher location. Short flights (ca. $10 \mathrm{~m}$ ) seem to be accomplished with some difficulty, as determined by a high frequency of wing beats, and an extended ( 2 to $4 \mathrm{~min}$ ) recovery period. The recovery pertod is characterized by frequent calls, gaping, and panting. The duration, distance, and frequency of flight periods increase with time.

\section{Fledge Success}

The mean number of fledges per pair in 1976 was 2.2 (S.D.=2.1, $\mathrm{n}=25$ ) and in 1977 was 2.5 (S.D. =2.0, $\mathrm{n}=28$ ) (Table IV). Kochert et al. (1976) reported a mean of 2.55 for 40 pairs in 1976 and $2.11 \quad(\mathrm{~N}=36)$ the following year (Kochert et al. 1977).

Of the 85 nesting attempts observed during the study period, 51 $(60 \%)$ were successful in fledging one or more young. Hooper et al. (1975) found $63 \%$ of their raven nests were successful, whereas Allin (1968) reported $80 \%$ success, and Dorn (1972) observed $58 \%$ success. Factors which decreased the success of fledging in this study include depredation (20 cases), food supply ( 7 cases), human disturbance ( 5 cases), and two instances in which the nest fell from its location. Human interference was suspected in one of the nest topplings, but in one case (77-14), the falling coincided with a period of strong wind, and therefore natural climatic factors are considered responsible. Cons1dering 1osses as 1isted above, $74 \%$ of the hatched young survived to fledge (see Appendix A). 
Most predation occurred within one week of hatch of the brood, but two nests (76-36 and 77-1) were destroyed at about 35 days post-hatch. No nest predations were observed, but signs at depredated nests were examined and according to Rearden (1951) possible predators include Coyote, Raccoon (Procyon Zotor), Weasel (Mustela sp.), Great Horned Owl and man. Ratcliffe (1962) and Holyoak (1967) reported that humans were involved in a high proportion of nest failures. One nest (76-23) was probably destroyed by man when the brood was about 16 days post-hatch. The female of the pair was found dead on the slope below the nest. The male had, however, remated and the new pair renested in the same nest and successfully raised a brood.

Lack (1947) and Lockie (1955) suggested that asynchronous hatching may confer a selective advantage which reflects an evolutionary history of varying food supply. Ricklefs (1965) further suggested hatchling mortality is a function of asynchronous hatch. Mishaga (1974) linked asynchronous hatching and nest mortality in $C$. cryptoleucus. My observations, especially in 1977, tend to support Mishaga's hypothesis.

At fledging, the young, although able to fly for short distances, are fully dependent on the adults for food. It is safe to assume that the increased activity results in increased food required by the young. For some pairs avian eggs form a high proportion of the diet (see Appendix B). In 1977 the peak period for waterfowl nesting in the Harney Basin was delayed for about 14 days, probably by drought (Refuge Narrative 1977). However, the nesting period for ravens in 1977 was about the same as the 1976 period. The 
late waterfowl nesting period in 1977 is believed to have decreased the normal food supply for these pairs and their broods. This resulted in a food stress for the young at a critical stage in development. A comparison of the ratios of hatching success to fledging success, discounting predation, may reflect the food stress in 1977; in $1976,22 \%$ of the hatchlings died prior to fledge, whereas in $197733 \%$ failed to fledge. Palpation and observations of general development of eight fledglings withia 36 hours of death when compared to healthy birds indicated that malnutrition was the probable cause.

\section{Post Fledge Behavior Patterns}

Two distinct post-fledging behavior patterns were observed, dependent on whether fledging occurred early or late in the season. The fledging date is determined by the date of initiation of a successful nesting attempt. Depending on whether the date of incubation is early or late, the length of the post fledging period varies from six weeks down to one week, respectively, on the average. The post fledge period ends when changes in food availability and preference precipitate a change in feeding patterns.

Early Success Nests. Young ravens and the adults were seen in the vicinity of the nest up to six weeks after fledging. During this period it was observed that, although the fledglings became adept at flying, the adults continued to bring food to them. After four to five weeks the young accompanied the adults on feeding flights away from the nest site, but the center of activity was still the nest site. Early in the period, the young ravens were commonly observed 
within $200 \mathrm{~m}$ of the nest, either on the rimrock (rimrock nests) or on buildings or structures (structure nests). The single successful tree nest in two nesting seasons was not in a location advantageous for extended observation, but linited sightings indicate that the tree (Junipems occidentalis) or nearby Artemesia tridentata were normally used as fledgling perches. With rim-nesting pairs, the behavior pattern of fledglings was quite consistent. Young would make short lateral flights, roughly paralleling the face of the rim with a total descent of up to $10 \mathrm{~m}$. The flight of one of the brood would then be mimicked by the others, although not always to the same location on the rim. The birds would then proceed to work their way back to the edge of the rim by walking and hopping.

Both male and female feed the fledglings and when an adult arrived with food, all fledgling behavior was directed toward that adult. Intensive begging and calling occurred and the young would quickly move toward the adult. All young were fed several times during each four hour observation period, although some of the young appeared to receive food more frequently than did others. The success of a feeding appeared to be a result of the begging intensity of the young; no fledgling, however, was neglected during any of the observation periods. Food was either regurgitated directly into the gaping mouths of young fledglings or placed on the substrate near older fledglings. In the latter type of feeding, food was either regurgitated or, with larger food items such as eggs, which were carried in the beak, simply placed near the begging bird. 
As flight skills increase, fledgling birds accompanied their parents on feeding flights. Due to terrain, the full extent of these flights could not be observed; however, both adults were with the brocd, and young were observed with food items which occurred more comnonly in the adult diets (see Food Habits). There were too few observations to infer any learning on the part of the fledglings, but the pattern of fledglings being led by adults on feeding flights, and the observations of young with the same food item as their parents, suggests strongly the possibility of early formation of food preferences.

Late-success Nests. The behavior of fledglings in late-success nests was similar to that for the early success nests, except that the total period of nest-centered behayior was temporally compressed. The initial stages in which the fledglings remain near the nest was shortened to five to seven days, as opposed to five to six weeks for early-success nests. The fledglings followed the adults from the nest earlier. Less "practice" flying was observed, and, although the fledglings had no more rapidly developing flying ability than their early-success counterparts, they attempted to follow the adults much earlier. Observations of young $500 \mathrm{~m}$ to $800 \mathrm{~m}$ from the nest were not uncommon at seven days post-fledge for the late-success nests. Two factors may be responsible for the accelerated behavioral development. These are: (1) shifts in food preferences in mid-July, and (2) food stress early in July. In July the food for ravens shifts from carrion, small mammals, and avian eggs to insects, probably grasshoppers. The accelerated behavioral development of the late 
success nests was associated with reduced fledgling success of the late nesting pairs. The highest known mortality of fledged young (age 40-50 days post-hatch) was $80 \%(N=5)$ which occurred in a late-success nest $(77-12)$. Further research is necessary to determine if the cause of high mortality is food stress per se or the change in food habits which occurs for most ravens in mid-July or another factor. The change in food preference was not universal for the raven groups; the adults and young from one late nest in 1976 (76-25) did not change feeding habits as did the majority of the populatior.

Therefore, for most ravens, the nest site remains the center of activity until mid-July when a change in food availability or food preference alters that location. In response to the change in diet, the family groups form into increasingly larger feeding flocks and leave the Blitzen Valley. Eighty birds were counted in one such flock. In 1976, the staging area for the emigration was near the Blitzen River at Diamond Point. Groups remained in this area for four days and flocks were observed departing the valley to the west. The flocks were not observed from 28 July to 12 August 1976 when a flock of 120 birds was observed in Catlow Valley $67 \mathrm{~km}$ south of Diamond Point. Throughout the remainder of August this flock continued to both increase in size (to $200 \mathrm{birds}$ ) and move south, east and then north, remaining in the Catlow Valley and Alvord Desert. The flock was last observed on 28 August near Juniper Lake, north of the Alvord Desert, east of Steens Mountain. 
From late August until early November the activity and location of the majority of the Malheur raven population remains unknown.

\author{
COMMUNAL ROOSTING
}

Communal winter roosting behavior is a common feature of corvid biology. Large communal roosts of Common Crows in the midwestern United States have been described by Good (1952) and Madson (1976). Post (1967) discussed pre-roost gatherings and roosts of Fish Crows (C. osifragus) in South Carolina, Ludin (1962) and Tast and Rassi (1973) the roosts of Jackdaws (C. moneduZa) in Finland, and Burns (1957) and Coombs (1961) the roosts of Rooks (C. frugitegus) and Jackdaws in England. Coombes (1948) mentioned roosting of British Ravens ( C. corax). Temple (1974) noted the roost of 10 Common Ravens in Alaska. Harlow et al. (1975) described a roost of at least 60 Common Ravens in Virginia, and Cushing (1941) observed a roost of about 200 Common Ravens in Marin County, California. Lucid and Conner (1974) and Temple (1974) suggest that locations of communal winter roosts of Common Ravens are stable from year to year.

A communal roost used by ravens for at least the last two years (1975-76 and 1976-77) was located on the western edge of Malheur Lake, in Sections 25 and 26 of R3IE, T27S (Willamette Meridian). The roost differs in both physiognomy and size from other roosts of Common Ravens reported. Local residents have indicated that the area has been an active roost for 10 to 15 years. Additionally, John Scharff, retired refuge manager at Malheur National Wildlife Refuge, located a raven roost to the east of Malheur Lake near Princeton, $30 \mathrm{~km}$ east 
of the current roost, in the late $1940^{\prime} \mathrm{s}$. Other local residents have indicated that a communal raven roost in the area of Princeton or Crane was used by ravens in the 1930 's, suggesting that although the exact location may have changed, the Harney Basin has historically been a wintering area for ravens.

Historical and current land use practices may contribute to the location of the large winter roost in the Harney Basin. Cattle ranching operations based in the Harney Basin annually winter thousands of head of cattle in the valley. Grazing allotment on the refuge during the $1976 / 77$ season was 66,800 Animal Unit Months, most occurring in the winter months. The presence of large numbers of cattle on the refuge provide potential food resources through carrion, feces, and placentae and may be responsible for the location and size of the roost (see Food Habits and Management Considerations and Recommendations).

Winter roosts of Common Ravens have been reported in trees (Cushing 1941, Lucid and Conner 1974, Harlow et al. 1975) and in abandoned buildings (Temple 1974). Coombes (1948) suggested coastal cliffs as roost sites, but his observations were made in the fall, possibly on migrating birds. The Malheur Lake roost, however, is within dense growths of Scirpus acutus. Birds roost either directly on the frozen substrate of the dry and frozen marsh or slightly elevated $(1-2 \mathrm{dm})$ on broken and bent $S$. acutus stems.

The Malheur Lake raven roost is located $300 \mathrm{~m}$ north of a low ridge oriented in a southwest-to-northeast direction. In the Harney Basin adverse weather is often accompanied by strong south- 
southeasterly winds. The low elevation and dense vegetation of the roost may provide protection for the ravens from adverse weather. The roost site is an amorphous area covering several hundred square meters. The location of the birds varied within a 100 ha area of homogenous habitat on any particular evening, and appeared to depend on weather conditions (e.g., wind direction and velocity, and precipitation), location of earliest arrivals within the roosting area, and presence of cattle or humans in the area near the roost. Physiognomically, the dense mats of $S$. acutus meet the requirements of a communal' roost as described by Zahavi (1971).

The Malheur Lake roost is associated with several pre-roost areas located within one kilometer of the roost area. The preroosting sites are either dry alkali lake beds devoid of vegetation, or areas of short vegetation such as Eleocharis sp., Juncus balticus, and Distichlis stricta. The function of pre-roosts has been discussed by Zahavi ( 1971) and Stewart (1973). The behavior of ravens in the Malheur Lake roost suggests that the pre-roost sites function as exposed areas advertising the roost location to other ravens in the area. The hypothesis of advertisement is supported by Lack's (1968) suggestion that enhanced predator protection is a major function of the communal roost. Zahavi (1971) extends the anti-predator advantage to the pre-roost. His idea, however, is challenged by Stewart (1973). If one accepts Lack's (1968) thesis, then it would follow that the value of advertisement is naximized only when the individuals using the roost have precise knowledge of its location. The position of the roost area in a homogenous habitat would be more difficult to 
ascertain than would a large tree or group of trees or structure as is the case in other raven roosts. Because the location of the roost is mobile within a larger area, protection might be nullified by moving into the roost area before sunset. Thus, the pre-roosts appear to function both as staging areas close to the roost and as exposed areas where visual contact can encourage aggregation.

Flights to the roost may or may not include stops at a pre-roost site. Individuals arriving early (ca. $1600 \mathrm{hr}$ ) fly at low altitudes (less than $30 \mathrm{~m}$ ) into the pre-roost areas. Occasionally, unison flights (cf. Rowley 1973) are observed, but more commonly, flights are straight and direct. Later arrivals at the roost (ca. $1645 \mathrm{hr}$ ) fly directly to the roost without stopping at a pre-roost. Ravens were observed feeding on carrion $16 \mathrm{~km}$ southeast of the roost as late as $1630 \mathrm{hr}$. This may indicate that individuals feeding on concentrated food sources arrive later than most of the flock. It is possible that other birds arriving late had not been feeding in the same manner as birds returning to the roost from the east were regularly the last birds into the roost. At the pre-roost, ravens turned over dry cow dung and were observed to feed on insects. Food calls (Gwinner 1965b) were heard from the pre-roost, and begging (Lorenz 1940, Gwinner 1965b) was observed on several occasions. Flights from the pre-roost area to the roost were low $(10-15 \mathrm{~m})$ and direct. When over the roost site, the birds appeared to collapse into the vegetation. The wings folded and the individual tumbled into the $S$. acutus. Flights to the roost area began 15 to 20 minutes before civil sunset, usually with a few single birds or pairs. 
0ccasionally a more orderly "string" of pairs typical of the roosting flight of Common Crows (Madson 1976) would begin the flight from the pre-roost to roost. Movement from the pre-roost peaked near civil sunset when large flocks of 80 to 130 individuals rose nearly simultaneously from a single pre-roost and flew to the communal roost.

Once a bird settled into the roost, no further movement was seen, although flyups and unison soars were common activity of birds at the pre-roost. Some individuals flew from one pre-roost area to another in the same evening, occasionally making a circuit of pre-roosts. These flights mainly involved pairs, but interactions of five to eight birds were also seen. A pre-roost site was occasionally vacated by its entire population. This abandonment was observed to be caused by local disturbances associated with the activity of cattle, with Coyote howls, or with the close approach of a large raptor.

The Malheur Lake roost was active in $1975 / 76$ and again in 1976/77 beginning in mid-October 1976 . It was disbanded by mid-March 1977. This roost is believed to have attracted ravens from virtually the entire Blitzen Valley, as birds were tracked traveling both into and out of the roost up to $45 \mathrm{~km}$ north and south of the roost. Counts of ravens arriving indicate that this winter roost is the largest such assemblage reported. Other investigators have reported large winter roosts of 200 ravens, and Jay Sheppard (U.S. Fish and Wildlife Service, Bird Banding Laboratory, Patuxant, MD) observed a roost in Southern California of 400 individuals (pers. comm.). Arrival counts throughout the period indicated that the number of birds using the roost increased to a maximum in early January. On 4 January 1977 , 
836 ravens were counted coming into the roost. Over 400 individuals were counted on six occasions between 7 December 1976 and 22 January 1977. After the 23 January count, there was a rapid decline in the use of the area.

Apparently the Blitzen Valley is a winter refuge for ravens residing throughout southeastern Oregon during other seasons of the year. Individual ravens which I banded in the winter of 1976 are known to have traveled from the Blitzen Valley to Prineville, OR (200 km northwest), Corval1is, OR (480 km northwest), Jordan Valley, OR (145 km east-southeast), Starkey, OR (160 km north), Vale, OR (150 km northeast), McDermitt, NE (165 km south-southeast), and Winnemucca, NE (265 km south).

Morning activity in the roost began before sunrise. Croaks and buzzes signal sunrise about 10 minutes before first 1ight. Shortly after the vocalizations, the ravens begin to fly from the roost. First flights are probably before dawn, since by the first 1ight of day ravens are already flying. Short flights of $400-1,000 \mathrm{~m}$ take the ravens away from the roost area. Small groups of 20-35 individuals form in areas clear of vegetation. These areas are possibly the morning counterparts of the evening pre-roost sites. From these staging areas, long, almost continuous, flight lines take the ravens to graln fields and carrion sites within the Blitzen Valley which are among their customary winter feeding locations (see Food Habits).

The location of this winter roost in the Harney Basin is an important aspect of the ecology and management of the raven population of Malheur National Wildlife Refuge. The number of birds that use 
the Malheur Lake roost during the winter suggests that there could be considerable exchange of birds among the different nesting populations of ravens in the Northern Great Basin. Some individuals from other breeding populations which first arrive in the Harney Basin in the late fall and use the Malheur Lake roost remain in the Harney Basin at least through the following spring and, together with local birds, form into large non-breeding flocks. Coombes (1948), Mylne (1961) and Ratcliffe (1962) also have reported similar flocks. The roost might indirectly serve to increase the size of the non-breeding raven population present during waterfowl nesting and therefore, since some individuals of this non-breeding flock are believed to be egg predators (see Food Habits), serve to increase predation of waterfowl eggs on Malheur National Wildlife Refuge.

FOOD HABITS

One of the most important aspects of this study was investigation of the food habits of ravens in the Harney Basin, particularly with regard to their effects on waterfowl production. Nelson (1934) investigated the food habits of ravens in southeastern Oregon, but his study was limited to collections of stomach contents of 18 adults and 66 fledglings (10 nests) during June 1933. According to Clark (1977), waterfowl nesting in the Harney Basin extends from early March to late July and peaks in early June. Therefore, collection of raven food data was undertaken for the raven nesting periods of 1976 and 1977. Additionally, observations were made throughout the year to determine the diet throughout the non-nesting period. 
Spring Food Habits

A total of 1413 collections was made from 34 nests during the study. Regurgitated pellets, consisting of nondigested food items and any other fragments collected near the nests (eggshells, bone fragments, and skulls) were sealed in plastic bags and were marked according to location and date of the collection. The materials were therefore associated with a particular pair of ravens, and hence food habits within the entire sample population could be compared to determine if any differences in feeding habits existed among different pairs and different areas.

Pellets were separated and their contents identified with the aid of a $30 \mathrm{x}$ binocular microscope. Hair and bones were identified by comparison with reference material from the Portland State University Collection of Vertebrates, castings from captive wild ravens fed local small mammals, and hair from identified mammals collected in the study area. Eggshell fragnents were identified by comparison with eggshells from the George Benson Museum at Malheur National Wildlife Refuge Headquarters, and from descriptions by Reed (1965).

The total number of items in each pellet was recorded, and each item was assigned a rank based on its volume within the pellet. As 1413 records were obtained, a computer-assisted numerical analysis was necessary to compare the data. The contents of each pellet along with collection date, habitat type, and location of the collection were entered on standard computer cards and analyzed with an SPSS program (Nie et al. 1970) on the Xerox Sigma 6 computer at the University of Wisconsin-Green Bay. 
The method of organization differed slightly from the methods of Harlow et al. (1975) where individual food items were quantified for each casting. Quantification of my heterogeneous samples was impossible because of such dissimilarities as the volume of a rodent mandible and a volume of feathers. Both indicate that a particular individual had been at least partially consumed, but it is difficult to compare the importance value of dissimilar items by precise volume alone. Likewise, eggshell fragments in pellets were difficult to compare volumetrically with hair or fur samples. Therefore, each casting was examined and the items were ranked in order by volume. The rankings allow for a comparison of food habits and may be used to indicate differences in the feeding habits of each nesting pair (see Appendix B). To permit a comparison of the diets of different pairs or pairs from different habitat types, a weighting based on the rank of the item and the total number of items in a pellet was devised by which the item could be assigned a food score (Table V). By averaging the records from a particular nest, the relative importance (as determined by rank) of each item in the diet could then be assessed. It should be stressed that the food score is not a percent occurrence. Food score numbers were assigned so that each pellet score equalled 100 and each score reflected the relative importance of a particular item based on its rank in a pellet. Also, the mean food scores of different items for a nest could be compared to similar data for other nests. These data present a representative overall picture and should be adequate for general comparisons. The 


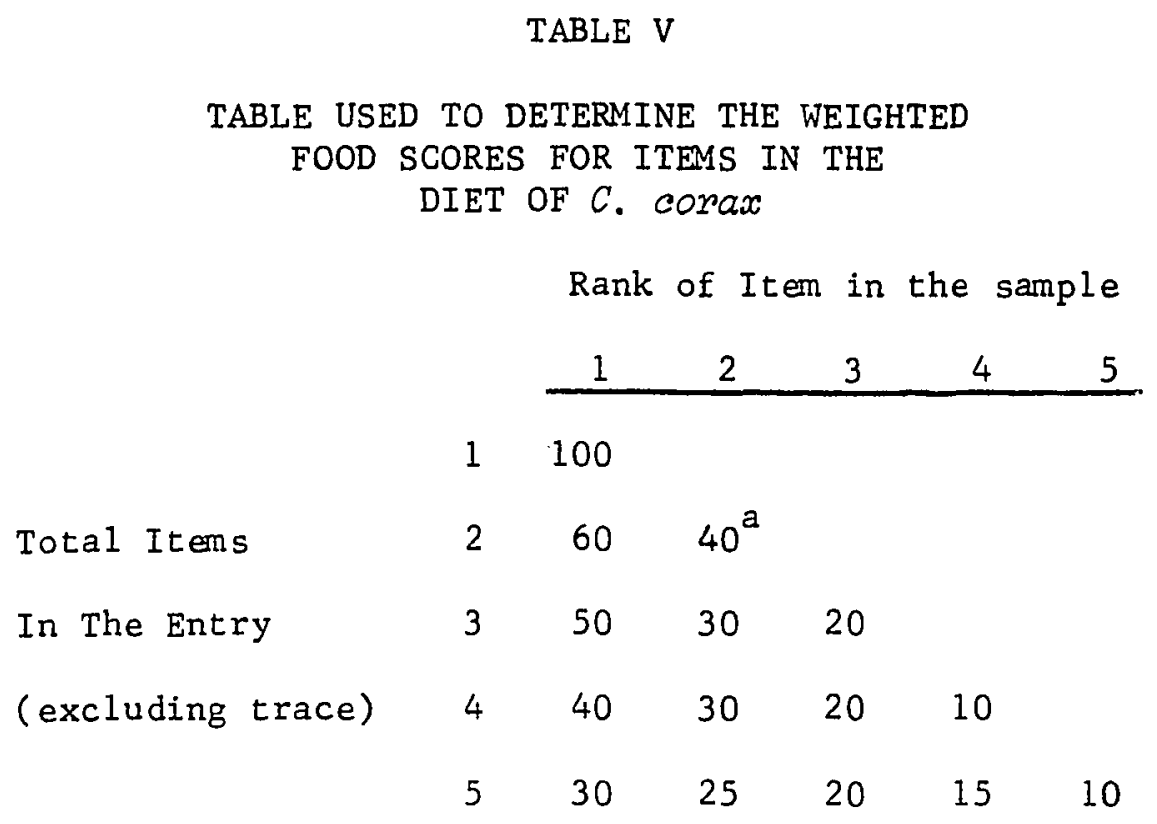

a (example) An item which was ranked second in a two item pellet would be given a food score of 40 . 
technique, however, is simply a method of normalizing the rankings of complex heterogeneous samples and presumably includes some bias.

Some important items in the diet, such as carrion from large

mammals (è.g., Bos taumus), are probably not proportionally

represented in this type of food study, as most of this food is easily digestable with a minimum of nondigestable remains which would occur in pellet examination. Likewise, whole eggshells collected at the nest site received a higher value by virtue of being a homogeneous sample. Thus, an analysis based on pellets and other nondigestable materials contains an inherent bias that must be remembered when forming conclusions.

\section{Results}

The number of items for a given pellet ranged from one to five. A total of 2202 food items found in castings and debris near nests are listed in Table VI. This table summarizes the total occurrence, percent occurrence (number of records for each item divided by total items $\mathrm{x}$ 100), and weighted food score for each item in the diet of the population. Table VII and Figure 8 further summarize the diet of the population by combining the specific food items into the general categories of avian eggs; feathers, down, and avian body parts; remains of mammals, reptiles, fish, and insects; and vegetation. The data indicate that for the portion of the nesting raven population which was sampled, mammals formed the most important food category (Table VII) with a foodscore of 46.1. Avian eggs were second in importance with a food score of 25.6. Avian parts (feathers, down, 
ANALYSIS OF PELLETS FROM NESTS

Species/Item

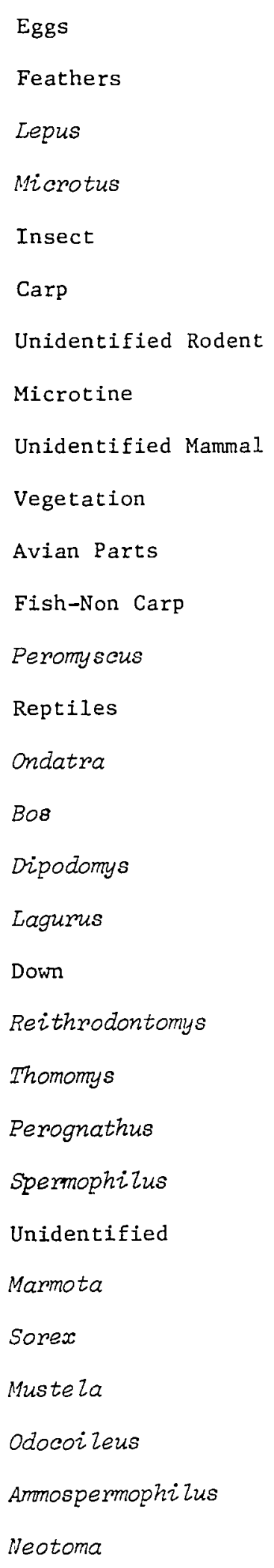

Occurrence

$\%$ Occurrence

Food Score

535

245

244

208

188

131

115

90

82

78

52

42

40

25

22

17

14

13

13

13

12

9

3

3

2

2

1

1

1

1
24.3

11.1

11.1

9.4

8.5

5.9

5.2

4.1

3.7

3.5

2.4

1.9

1.8

1.1

1.0

0.7

0.6

0.6

0.6

0.6

0.5

0.4

0.1

0.1

0.1

0.1

0.0

0.0

0.0

0.0
25.61

10.56

12.81

10.63

5.52

4.44

5.81

4.90

4.00

2.37

2. 71

1.11

1.97

0.92

1.40

0.63

0.64

0.80

0.63

0.63

0.74

0.49

0.16

0.10

0.14

0.06

0.07

0.07

0.04

0.04 
TABLE VII

ANALYSIS BY GROUP OF RAVEN FOOD SCORES

Food Group Total Pop. Wetlands Wetland/Road Sage Sage/Road

$\begin{array}{lrrrrr}\text { Avian Eggs } & 25.6 & 29.3 & 37.6 & 7.1 & 1.5 \\ \text { Avian Parts } & 13.9 & 15.1 & 14.8 & 14.6 & 9.2 \\ \text { Mammal } & 46.1 & 40.2 & 36.5 & 59.1 & 74.2 \\ \text { Reptile } & 0.9 & 0.3 & 1.2 & 0.3 & 2.3 \\ \text { Fish } & 5.6 & 8.5 & 3.5 & 2.1 & 1.0 \\ \text { Insect } & 5.5 & 4.5 & 3.6 & 10.6 & 10.2 \\ \text { Vegetation } & 2.4 & 2.1 & 2.5 & 6.2 & 1.9\end{array}$




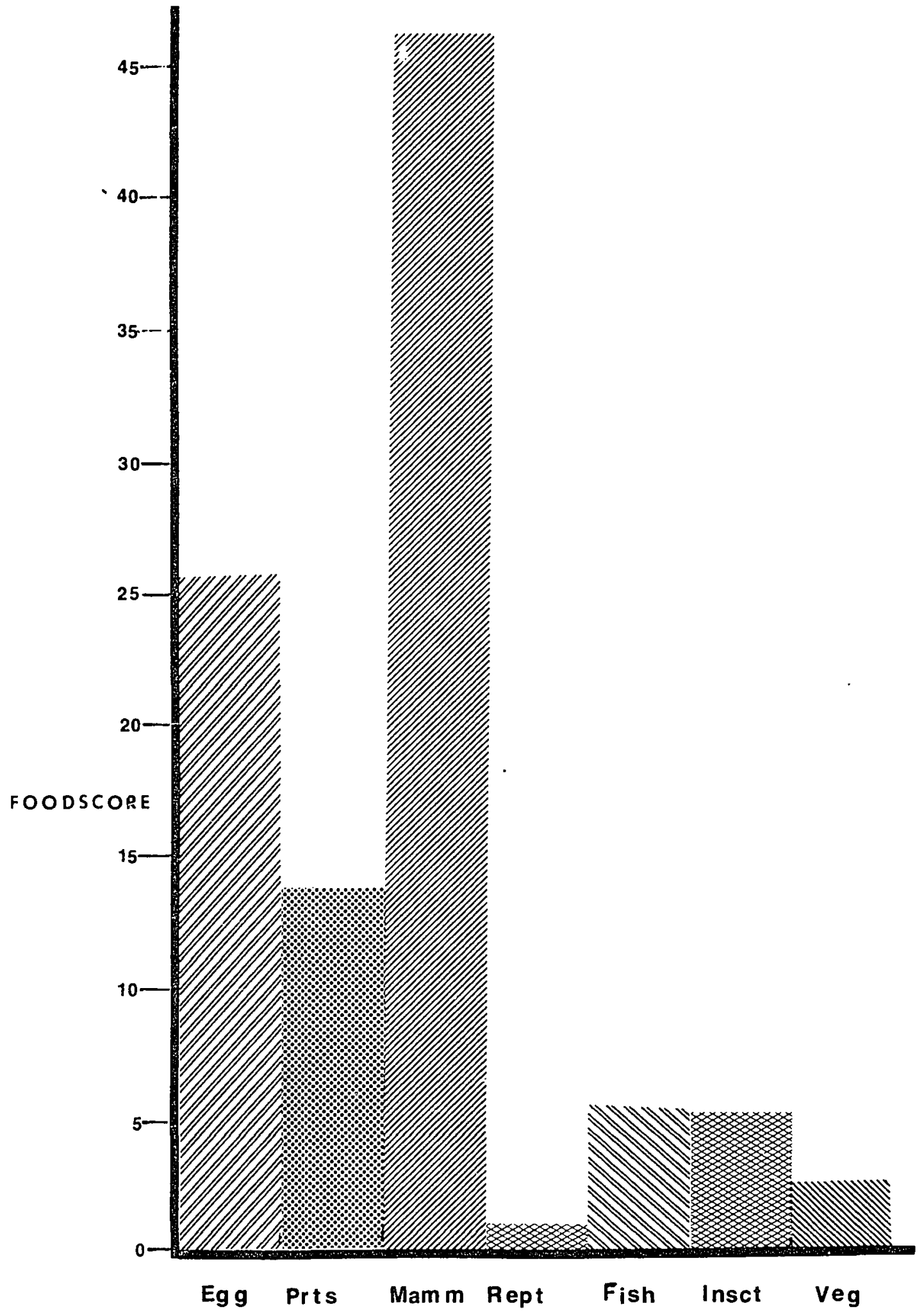

Figure 8. Group food scores of nesting ravens. Egg=avian eggs; Prts=avian parts; Manm=mammal; Rept=reptile; Fish=Fish; Insct= insect; Veg $=$ vegetation. 
and body parts) had a food score of 13.9. The separation of avian items into eggs and parts (feather, down and body parts) is useful in assessing the diets of individual nesting pairs. Analysis indicates that for some nests, avian food sources are of prime importance (e.g., Nests 1, 5, 20, and 26, Appendix B). The data further indicate that for the sample population, fish (food score 5.6) and insects (food score 5.5) are of equal importance, and vegetation (food score 2.4) and reptilian material (food score 0.9), are relatively less important to the total diet. The total food score for all items other than avian and mammalian is 14.4 .

Each nest site of the sample population had been assigned to one of four major habitat types - sagebrush, sagebrush near a road, wetland, and wetland near a road. The division of road and non-road areas is important because extensive carrion feeding was observed by pairs nesting near roads. Carrion feeding was also considered important by Feilden (1909a, 1909b), Nelson (1934), Mylne (1961) Radcliffe (1962), Temple (1974), and Harlow et al. (1975). Figure 9 and Table VII summarize food scores from these four habitats. The grouped food score data were tested for significance with one-way analysis of variance. The results are presented in Table VIII. Although non-randon sampling procedures may contribute a bias in this statistical analysis, $94 \%$ of the refuge population of nesting ravens was sampled. The analysis is one of the best available under the circumstances. Avian eggs, mammal remains, and $f i s h$ remains as represented in the samples are significantly different at 0.01 , and 


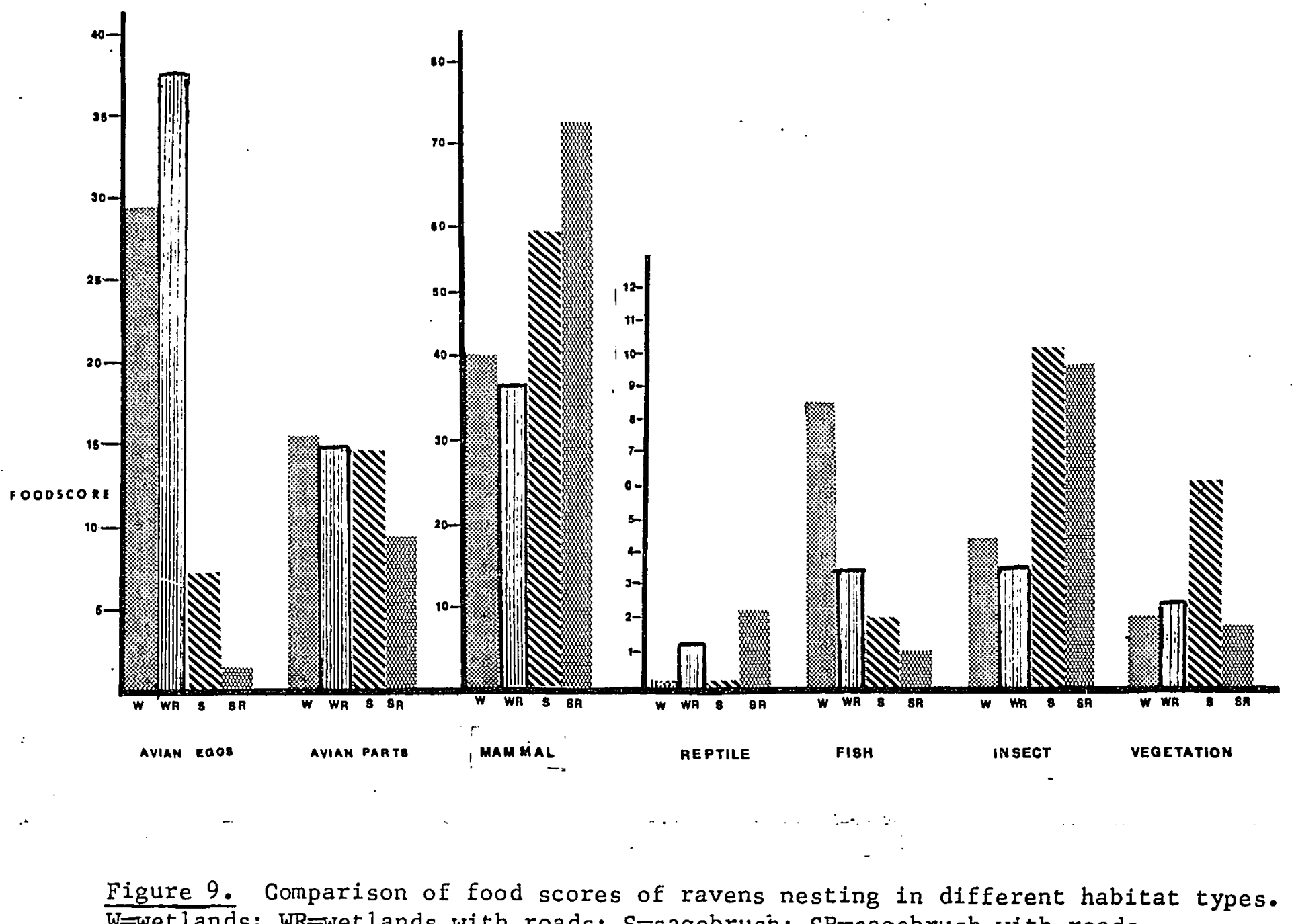

Figure 9. Comparison of food scores of ravens nesting in different habitat types. $W=$ wetlands; WR=wetlands with roads; $S=$ sagebrusin; $S R=$ sagebrush with roads. 
TABLE VIII

ANALYSIS OF VARIANCE OF GROUPED FOOD SCORES

\begin{tabular}{lcc} 
& Fratio & $\begin{array}{c}\text { F probability } \\
(\text { d.f. }=3) *\end{array}$ \\
\cline { 2 - 3 } Avian Eggs & 55.48 & 0.00 \\
Avian Parts & 2.57 & 0.05 \\
Mammal & 53.39 & 0.00 \\
Reptile & 3.62 & 0.01 \\
Fish & 15.54 & 0.00 \\
Vegetation & 2.55 & 0.05
\end{tabular}

$* \mathrm{~d} . \mathrm{f} .=$ number of habitats -1 
reptile and vegetation are significantly different at 0.05 and 0.10 respectively.

These data Indicate that, with a high degree of significance, the diets of ravens nesting in a particular habitat (i.e., sagebrush, sagebrush/road, wetland, and wetland/road) are different from each other.

Summer And Fall Food Habits

As Indicated earlier, raven food habits generally changed abruptly in July. At that time, most ravens migrated south from the Blitzen Valley to the Catlow Valley. Another group of about 60 ravens was seen throughout August in the Crane-Buchanan area, $45 \mathrm{~km}$ northeast of refuge headquarters. In both areas, the ravens were concentrated in areas of either Agropyron cristatum or cultivated cropland of Medicago sativa, or Avena sativa. Al1 ravens appeared to be feeding on insects. Inspections of the feeding areas indicated the presence of dense populations of grasshoppers (Melanoplus sp.). Repeated observations were made of the feeding behavior. The ravens walked or hopped a few meters, pecked at the ground several times, then hopped a meter or so and pecked again. This feeding behavior was observed to last up to two hours, when the birds then flew, in groups of four to seven, to a nearby perch (fenceline or tree). Perching lasted from 5 to 20 minutes, after which feeding resumed.

Although no observations were made of the food in castings or stomach samples, it is suspected that grasshoppers are the dietary staple of these ravens for the sumner (late July through September). 
During several observation periods, an attempt was made to measure the frequency of successful food capture. Seven hours of observation indicated an average of one peck per 14 seconds of feeding time, but the success of pecking was not ascertained.

Carrion was utilized by ravens in all seasons of the year. Its use in the summer months, however, was less than in other seasons. On several occasions, large feeding flocks were located within $5 \mathrm{~km}$ of carrion (road kills), yet the relative numbers of ravens in fields as opposed to those on carrion indicated a strong summer preference for insects as a food source. In late summer, carrion feeding increased as the numbers of grasshoppers declined.

Temple (1974) stated that Common Ravens are opportunistic feeders. My observations in late summer of the Harney Basin ravens supported his findings. Normal agricultural practices both on the refuge and private farmland adjacent to the refuge, allowed additional food sources to be exploited late in summer. The annual mowing of meadow grass for winter cattle feed exposed such foods as eggs of late or abandoned waterfowl nests and small birds, rodents and insectivores not previously available. Ravens were regularly observed in areas where meadow grasses or planted crops were being harvested; often the birds followed the machinery. One observation was made of a raven caching small mammals in a pile in the corner of a large Medicago sativa field. Food-hiding is a common behavioral trait in ravens and has been reported in captive Common Ravens by Lorenz (1931) and Gwinner (1965b). Feeding in recently cut areas usually diminished over a three to five day period after mowing was complete. The persistence 
of this feeding behavior was dependent on the duration of the mowing period and the size of the area mowed. Most mowing near the refuge was completed by mid-September.

Some canals of the extensive irrigation system had a reduced water flow in late sumer. These reduced flows had both immediate and future consequences. Immediately, carp were concentrated, and in some locations, exposed and suffocated, providing widespread, but concentrated food resources for the ravens in the area. Future consequences are discussed under winter food habits.

Late in the fall (October, November) ravens began to concentrate their feeding in harvested grain fields. Observations, and some castings collected, indicated that there was an increased use of grain such as Triticum aestivum and Hordeum vulgare residues in these fields. Carrion also became an increasingly important food source during the period. Overt hunting, presumably for small mammals, with a "head-down" posture (as described by Rowley (1973) for C. coronoides) was also observed with increasing frequency.

\section{Winter Food Habits}

The winter months (December to mid-March) were a period of food stress for Harney Basin ravens. Several interacting factors produced this stress. Mean low temperature for the winter months of 1976/77 was $-12{ }^{\circ} \mathrm{C}$ (Malheur NWR Weather Reports). Scholander et al. (1950) and Veghte and Herreid (1965) have determined the standard metabolic rate of a cold-adapted raven at ambient temperature below $0^{\circ} \mathrm{C}$ was $92 \mathrm{kcal} / \mathrm{day}$. Following the doubling of metabolic rate during activity 
(King and Farner 1961), 60\% efficiency due to urinary and pellet wastes, and heat loss (King and Farner 1961), a raven must consume about $300 \mathrm{kcal} /$ day to maintain active behavior (Temple 1974). During the winter months of $1975 / 76$ and $1976 / 77$, the Blitzen Valley was often snow-covered. Snow cover decreased the efficiency of grain feeding as grain was obscured by snow and more searching was required for each fruit. Immediately after a snowfall, increased concentrations of ravens were observed flying and hunting parallel to major roads, perhaps searching for carrion. Conner and Adkisson (1976) also reported increased concentrations of ravens along the Trans-Canadian Highway and associated the increase with large numbers of migrating songbirds killed by passing vehicles. Periodic snowfall may have prevented ravens from using fooa sources, primarily grain, and forced them to use alternative feeding behavior which was perhaps less energy efficient, as suggested by Temp.le (1974).

Short day length restricted the time period during which ravens may actively feed. My observations indicated that ravens are sighthunters, as has been suggested by Rowley (1973) for C. coronoides, Good (1952) for C. brachyphynchos and Goodwin (1976) for corvids in general. Croze (1970) discussed at length the hunting strategy of C. corone and indicated an inverse relationship between prey density and hunting persistance. As ravens were observed more often in a hunting posture (cf. Rowley 1973) in winter months and appeared to rely more on predation during this period, the short day length limited the time available for foraging. 
As suggested, a main food source for ravens in winter months was cultivated grain wastes. High concentrations (80 to 130 ravens) were often counted on Triticum aestivum and Hordeum vulgare fields. In the winter of 1976-77 ravens were regularly observed feeding in a private grainfield east of Dog Mountain. In 1975-76, the behavior was similar, but the location was in the East Grain Camp grainfields. There was a three-fold increase in the area planted near Dog Mountain in 1976-77, which may account for the increase in use of the area in that season. Observations indicated that each area was visited by ravens in the course of the normal day. The use of the East Grain Camp site, however, indicated the importance of grain in the winter diet of ravens, as the grain field is located $30 \mathrm{~km}$ south of the Narrows roost.

Another food source used by ravens especially in late winter was carp which were concentrated by low water levels in late summer and killed when the canals and ponds had frozen, decreasing the temperature or dissolved oxygen to lethal levels. The carcasses floated to the surface as the water thawed in March. This exposed large numbers of dead carp, and flocks of up to 28 ravens were observed in mid-March feeding on the carcasses in each of several locations. A similar pattern was observed in mid-November on a smaller scale when isolated shallow ponds first froze and then thawed. Ravens also fed on dead range animals, principally cattle, throughout the winter. Additionally, cattle parturition peaked in mid-January. This provided additional food sources for ravens, in the form of placentae, weak or stillborn calves and occasionally cows 
which succumed during birth. Extreme low temperatures in January 1977 (average night temperature $=-14^{\circ} \mathrm{C}$ ) effectively removed carrion as a food source. Dead animals were frozen so solidly that ravens were unable to penetrate the carcasses. An increase in live calf depredation (eye pecking) was reported by ranchers during the period of low temperature.

As a possible reflection of food stress, the only successful trapping I accomplished was in February and March 1977, when I used large volumes of carrion to attract 99 ravens to my drop-in trap. Although it may appear that ravens were not food-stressed in winter, it must be remembered that food sources were widely scattered, highly variable, and therefore not dependable. The problem of unpredictable food sources is compounded by low temperatures which required high energy (food) intake, and short day length, which limited the time available for feeding.

\section{Food Habits of Non-nesting Ravens}

Before 1972 most of the efforts to reduce the number of ravens on Malheur National Wildlife Refuge involved the destruction of eggs, broods, and nests (Refuge Narratives 1937-1972). A comparison of the effectiveness of control efforts, as measured by the level of raven depredation of waterfowl eggs, indicated that, although at one time all known raven nests in the area were destroyed, a concomitant decrease in waterfowl egg predation did not follow (Refuge Narrative 1948). This may indicate that the control effort was inadequate, that the bulk of the waterfowl egg depredation was done by non-nesting 
ravens in the area where control measures were in effect, or that nesting ravens far from the refuge were responsible. Certain pairs of ravens, particularly those nesting near wetiands, fad heavily on waterfowl eggs. My data indicated that from a total of 34 raven nests surveyed, ravens at six nests accounted for $61.9 \%$ of all the avian food items collected (see Appendix B). Observations during the 1977 waterfowl nesting season suggested that non-nesting ravens preyed heavily on waterfowl eggs. At least one flock of 40 to 60 ravens was often seen in prime waterfow 1 nesting areas. Individuals of this flock were observed carrying eggs, and inspection revealed waterfowl nest destruction in areas where this flock had been seen the previous day. The majority of the fledglings from known raven nests near the refuge had been wing-marked in 1976 and 14 of these birds were observed to be members of this flock. Additionally, individuals captured in February and March and identified as yearling birds on the basis of mouth color, were also observed to be members of the flock. No known nesting adults were ever seen to feed communally during the nesting season. The nomal feeding behavior of nesting adults observed during the study period indicated that rarely, if ever, were both adults away from the nest site at the same time, beginning with incubation and extending through brooding. I observed that when responding to distress calls of the brood, the arrival times and directions of each adult were different suggesting further that when both adults were absent from the nest site that both are not members of the flock. Also, the number of unmarked birds in this flock was larger than the population of adults 
nesting in the area. Although not all individuals in the flock were wing-marked, the presence of known and presumed yearling birds and the feeding behavior of nesting adults indicated that this flock consisted mostly of immature, non-breeding ravens. 


\section{- SUMMARY AND CONCLUSIONS}

. The nesting density of ravens on Malheur National Wildlife Refuge averaged one pair per $24 \mathrm{~km}^{2}$ for the two years studied. The highest population densities of ravens were observed in the winter months (November to March). The largest concentration occurred in early January 1977, when 836 birds were counted arriving at the large winter roost near Malheur Lake. Birds which were wing marked in the winter of 1976 have been observed in other areas of Oregon (Corvallis, Prineville, Vale, Jordan Valley, and Starkey) and northem Nevada (Winnemucca and McDermitt) which suggests that the ravens inhabiting a large geographic area use the Harney Basin as a winter refuge. Ravens from other areas of Oregon and northern Nevada together with the birds I studied may form a large panmictic population.

Behavioral and vocal differences allowed recognition of individual ravens which indicated that pair bonding persists for at least two years and also that pairs use the same nesting site for more than one year. Nesting behavior began about 1 March; it is believed that the adult nesting pairs from other areas which winter in the study area return to their nesting areas at this time. Some immature ravens, probably reared in other areas, remain in the Harney Basin and, together with some of the local immature birds, form at least one non-territorial feeding flock of 40 to $60 \mathrm{birds}$. 
Average clutch size of ravens for the 1976 and 1977 nesting seasons was 6.0 eggs per nest. There was no significant difference in the clutch size for these two years. Clutch size ranged from three to seven eggs. Seven-egg clutches were found in $33 \%$ of the nests.

The incubation period ayeraged 21 days, with incubation beginning with the first egg laid. Hatching was determined to be asynchronous, which is contrary to the findings of Gwinner (1965a). Due to the usual failure of one egg in the clutch to hatch, and to nest predation, the average brood was 4.2 hatchlings. There was no significant difference between brood sizes the two study years.

The fledge success for the study period was reduced, probably by predation, disturbance and starvation to the average of 2.3 young per nest. There was no significant difference in the success for the years studied. The overall nesting success (one or more fledged young per nest) was $70 \%$ for both years.

Multiple clutches laid by a single pair were observed six times during the study. On at least two occasions, replacement clutches were laid after depredation of the hatchlings. Clutch replacement was not observed in all cases of depredation. Apparently there is a critical date, after which clutch destruction does not result in another nesting attempt.

Factors limiting the number of nesting pairs are unknown. If the fledge success and nesting densities for the 1976 and 1977 nesting seasons are typical, the nesting population of ravens will vary only slightly. Moreover, factors affecting nesting success and food 
supplies outside the study area could presumably cause unpredictable fluctuations in the population of non-breeding ravens.

The results show that diet of ravens is varied. Certain pairs were more destructive to the waterfowl population than were other pairs. Six of 34 nests studied accounted for $61.9 \%$ of all avian food items. The proportion of avian items in the diet was positively correlated with the proximity of the raven nests to areas of prime waterfowl production. Ravens which nest in areas distant from waterfowl production areas had diets in which the proportion of mammalian (principally rodent) items was greater. Based on weighted analysis of 2202 food items of the nesting population, the types of food, in order of importance, were: mammalian (mainly rodents and hares), avian, fish (principally carp), insects (beetles and grasshoppers), vegetable matter, and reptilian matter.

Based on the analysis of spring food habits of nesting pairs of ravens, not all pairs which nest near waterfowl production areas are detrimental to waterfowl nesting success, and that pairs nesting in locations distant from waterfowl production areas exert a negligible effect on the nesting success of waterfowl. I suggest that the non-nesting ravens present during peak waterfowl nesting periods (mid-March to July) may be responsible for the majority of waterfowl nest predation by ravens.

The immature flock and most locally breeding adults and their broods dispersed from the Blitzen Valley in late July. The majority of the population moved south into the Catlow and Alvord Valleys, although a few small bands remained in the Harney Basin. 
Behaviorally, there was a change in food habits and food availability that was correlated with this exodus, and it is hypothesized that lack of food is causally related to the migration. It appeared that from late July through the middle of September, the ravens rely heavily on insects, especially grasshoppers, for food. Although carrion was consumed, it was consumed in less volume than in other seasons of the year.

Fall and winter food habits reflect the dietary plasticity of the ravens. Most of the feeding behavior appeared to be determined by agricultural practices of the area. Fall feeding included opportunistic scavenging in freshly mown meadows and forage crops (for exposed or killed small mammals and insects, and deserted waterfowl and shorebird nests) and feeding on waste grain in harvested grain fields. Winter feeding included predation on young livestock, feeding on birth tissue of livestock, carrion-feeding on dead livestock, and feeding on insects and/or internal parasites found in livestock feces. 


\section{MANAGEMENT CONSIDERATIONS AND RECOMMENDATIONS}

\section{MANAGEMENT CONSIDERATIONS}

Any management of ravens in the Harney Basin may have an impact on ravens in other regions. Ravens which are known to be the young of birds nesting in the Harney Basin have been observed up to $375 \mathrm{~km}$ from the refuge. Also, adult ravens, which were marked on the refuge in February 1977, have been observed nesting $150 \mathrm{~km}$ from the refuge. This suggests that ravens which nest in the Harney Basin are part of a larger, possibly panmictic population. The proportion of young ravens reared in the Harney Basin, which contribute to other nesting populations and the contribution of other nesting populations to the population of Harney Basin ravens is unknown. However, the majority of the non-breeding ravens present during waterfowl nesting seasons may be reared in distant areas. The wide dispersal of offspring of the Harney Basin ravens in their first two years of life provides at least a potential genetic exchange within different nesting populations. Since the full extent of the population is unknown, the effects of any management measures cannot be completely determined.

The major waterfowl nest predators present on Malheur National Wildlife Refuge include Common Rayen, Coyote, Long-tailed Weasel, and Raccoon. A review of annual refuge narratives from 1942 to 1969 indicates that when extensive pressure was applied to reduce the population of one predator there were corresponding increases in 
predation rates by the other species. It is possible that the levels of nest depredation by a particular species is both a reflection of their density, relative to other predators, and interspecific opportunism. Thus, a selective reduction of the raven population may result in a decrease in waterfowl nest predation by ravens only, unless the entire predator complex is managed. Raven management must not be interpreted as a method of increasing waterfowl nesting success, but only a means of possibly reducing the effects of raven predation. If overall waterfowl nest success is to be increased raven management should be implemented as a part of an integrated predator management plan.

Any attempt to reduce the raven population will have linited carry-over effects from year to year. As indicated, the population of ravens in the Harney Basin appears not to be isolated. There appears to be substantial mobility among different nesting groups. A decrease through management in the number of young in one year will probably be matched by greater recruitment of yearlings from other nesting groups in the area the following year. Thus, any efforts to reduce the non-nesting population will have to be implemented annually to be effective.

Any management technique must be accompanied by a means to evaluate the effects of such measures. Evaluation should include the amount of reduction of waterfowl nest depredation by ravens, a monitoring of the status of the raven population in the Harney Basin, and an appraisal of the cost/benefit ratio. As the management may affect other raven nesting areas, some of these nesting areas (e.g., 
Jordan Valley, Catlow Valley and near McDermitt) should be monitored for any changes in raven activity.

\section{MANAGEMENT METHODS}

Berryman (1972) stated that predator management should be used only to meet planned objectives and suggested that the criteria for need include a combination of political, social, aesthetic, economic, and ecological considerations. He also stated that the methods used in predator control may extend from controlled killing to transplanting to habitat modification.

Destruction of Specific Nesting Pairs of Ravens

Generally, ravens nesting in wetland habitats, near areas of high waterfowl production are more likely to be involved in waterfowl nest depredation. However, the presence of a nesting pair of ravens near waterfowl nesting habitat is not an a priom indication of waterfowl predation. Criteria for control of a particular pair should be based on direct observation of waterfowl predation, analysis of regurgitated pellets and/or collections of debris from around the nest.

As some pairs of ravens account for the majority of the waterfowl egg predation by nesting birds, and a particular nesting site is probably reused by the same pair of ravens for several years, if control of nesting birds is desired it may be necessary that specific offending pairs of ravens be destroyed. Both members of the pair would have to be destroyed, as new pair bonds may be formed late in the raven's nesting season. The nest itself should not be 
destroyed, as its presence may encourage the occupation of the site by Great Horned 0w1 or other raptors which use similar nesting sites. Such use may delay the reoccupation of the area by ravens.

A census of waterfowl nesting success in the areas suspected to be feeding areas for ravens should be made prior to palr destruction so that the effects of the destruction may be measured. The pairs responsible for heavy waterfowl depredations are probably most destructive of waterfowl nests in acceptable habitat close to their nests. These areas should be closely monitored.

Reduction In The Numbers of Noll-breeding Ravens

Since the majority of waterfowl nest predation may be due to non-nesting ravens, destruction of selected pairs may reduce but not eliminate nest predation by ravens. Steps should be initiated to reduce the size of the population of non-nesting birds. Based on my observations, the following methods may be effective in reducing the non-nesting raven population.

Reduction In Food Availability. Reduction in food availability may be accomplished through frequent burning of the county dump on Sod House Lane, and removal or disposal of other concentrated food sources, such as winter-killed cattle, from December through February. As a small fraction of the grain production in southern Harney Basin is on federal land, very little can be done to reduce the availability of grain. Moreover, the reduction of grain availability to other winter residents (e.g., Canada geese and some ducks) would off-set the advantage from raven management. The current refuge plan which 
includes carp management should be continued so that the availability of carp as a winter and early spring food is reduced.

Monitoring the effectiveness of food reduction may be accomplished by ground or aerial transect suryeys conducted at regular intervals to census the raven population in the area. If aerial transects are made, locations of carrion and raven concentrations should be noted so that additional corrective measures can be taken. Live Trapping of Ravens From December Through Apri1. Successful trapping indicates that it is possible to capture ravens in substantial numbers during this period. To trap successfully, it is necessary to have both live decoy ravens and large volumes of carrion as bait. Traps should be constructed as indicated in Figure 5 . Captured individuals could be humanely destroyed or transported to other areas. At least five trapping locations should be maintained in the Blitzen Valley from late December through May, including locations near Sod House Field, Kado Field, Jones Field, Wrango Field, and Unit 1.

If captured birds are transported out of the refuge, a banding program of these birds should be included as part of the project to indicate the duration and success of the transplanting. A minimum displacement of $200 \mathrm{~km}$ is recommended due to the known dispersal patterns of these ravens. Trapping and relocation may circumvent problems associated with destruction of this protected species. As ravens are found in other areas of the Great Basin, the relocation would not constitute a species introduction. Areas of northern Nevada may be acceptable for relocation. 
The Blitzen Valley is an "island" of waterfowl production, therefore relocation of ravens outside the valley should have minimal impact on waterfowl production. However, an Inventory of wildlife in the area of relocation should be made prior to transport, so that the impact of increased raven densities may be assessed. Local residents of the Blitzen Valley did not consider the raven to be a threat to either livestock or grain crops. Based on this information, the impact of the translocation should be minimal.

Direct Shooting. Direct shooting of non-breeding birds would have a minimal effect in reduring the population. Ravens appear to be too suspicious of humans for such a plan to have value. Further, this tnethod of management may be difficult to implement in a manner which has measurable results as there may be a tendency to be non-selective in shooting. This would violate the principles of sound wildlife management and conflict with U.S. Fish and Wildlife Service predator control policy.

Chemical Toxicants. Use of a selective poison, such as DRC-1339 (Larsen and Dietrich 1970), would affect only those ravens which are predators on waterfowl nests and would have minimal effect on non-target species. However, ravens which are scavengers or only occasionally consume eggs (hence, are considered to have minimal impact on waterfowl production) would also be affected by the method. Simulated nests (Hammond and Forward 1956) with eggs injected with one $\mathrm{ml}$ of water containing $15 \mathrm{mg}$ DRC-1339 (Larsen and Dietrich 1970) would be effective in selectively reducing the population of ravens involved in waterfow1 egg predation. 
The use of poisons in raven management may pose insurmountable procedural problems because of restrictions on toxicants on federal land and adverse public reaction. Although non-target species should be minimally affected with DRC-1339, there are inherent risks with the use of any poison and all possible effects on all non-target species should be considered prior to iniplementation. Balser et al. (1968) reported an elimination of a breeding population of Marsh Hawks (Circus cyaneas) as a direct result of the use of poisons. The authors attributed a decrease in crow predation to a negative reaction by the crows to the few that were poisoned and exposed.

Evaluation of this management method would include comparison of pre-management nest predation rates with the post-management predation rates, and an evaluation of nest predation on the management area compared to a control (non-management) area. It is necessary to have an accurate census of waterfowl nests in each area and to know the levels of nest predation. Experimental areas should be chosen on the basis of comparable predation rates. The decision to continue chemical control should be based on achieving a reduction in nest predation. The acceptable level of production should be set prior to management implementation. The environmental cost of the technique must be considered. In addition to waterfowl nest success, the effects of any chemical control must be assessed on all of the possible predator species. This assessment would be particularly difficult for non-nesting avian species. Perhaps intensive, frequent transect surveys over prescribed routes would indicate the impact on the predator complex. If chemical control is implemented as a management 
technique, the method should be used only from early March to late April to minimize the effects on other populations of ravens which are usually absent during the waterfowl nesting season.

\section{Habitat Improvenent}

Errington (1942) indicated that a high annual waterfowl nest success may be possible despite heavy depredation, due to the renesting behavior of most waterfowl species. Cartwright (1952) explained this theory further, indicating a $43 \%$ failure of first nests and $19 \%$ failure of renesting birds results in only $6 \%$ reduction in the total population at the end of the breeding season. The indication is that, due primarily to renesting, overall waterfowl production may not be proportional to predation.

Clark (1977) stated that raven sightings on his study area (Upper Blitzen Valley) decreased sharply after late June. This may reflect the considerations of Craighead and Craighead (1969) and Errington (1967) that predator pressure decreases as vegetative cover in the area improves. Smith (1971) and Stoudt (1971) reported higher crow predation on duck nests earlier in the duck nesting season. Errington (1967) suggested that habitat management is more important in increasing nesting success than is predator management. Harrison (1967) showed a $700 \%$ increase in a Mallard population through habitat improvement. Schrank (1966, 1972) reported a significant correlation between increased duck nest success and increased cover density, and Newton (1970) stated that habitat management can have both short term and long term gains far greater than can be obtained by predator management. 
In view of these findings, I suggest that refuge personnel first concentrate management efforts on habitat improvement before any attempts are made to reduce the non-breeding raven population. This approach has the advantage of improving nesting success without the long-term expenses associated with an annual reduction of the raven population. The wide fluctuations in predation on Sandhill Crane nests (Table 1) between 1973 and 1977 indicate that environmental conditions such as weather, water levels, and vegetative cover may be much more important in alleviating nest predation than is predator management. 
Allin, E. K. 1968. Breeding notes on Ravens in North Wales. Br. Birds. 61: 54l-545.

Baldwin, E. M. 1959. Geology of Oregon. Eugene, Univ, of Ore.

Balser, D. S., H. H. Dill and H. K. Nelson. 1968. Effect of predator reduction on waterfowl nesting success. J. Wildl. Manage. 32: 669-682.

Bateson, P. P. G. 1964. Effect of similarity between rearing and testing conditions on chicks' following and avoidance responses. J. Comp. Physiol. Psychol. 57: 100-103.

Bellrose, F. C. 1976. Ducks, geese and swans of North America. Harrison, $\mathrm{Pa}$. Stackpole Books.

Bent, A. 1946. Life histories of North American Jays, Crows and Titmice. New York, Dover Pub.

Berryman, J.H. 1972. Principles of predator control. J. Wildl. Manage. 36: 395-400.

Bowles, J. H. and F. R. Decker, 1930. The Ravens of the State of Washington. Condor. 32: 192-201.

Burns, P. S. 1957. Rook and Jackdaw roosts around Bishop's Stortford. Bird Study. 4: 62-71.

Cain, S. A. 1972. Predator Control - 1971 Report to the Council on Environmental Quality and the Department of the Interior. Washington D.C., U.S. Government Printing Office.

Cartwright, B. W. 1952. A comparison of potential with actual waterfowl production. Trans. No. Am. Wild1. Conf. 17:131-137.

Clark, J. P. 1977. Effects of experimental management schemes on production and nesting ecology of ducks at Malheur National Wildlife Refuge. Unpublished M.S. thesis. Corvallis, Ore. St. Univ.

Coldwell, C. 1972. Raven banding in Nova Scotia. Bird-Banding. 43: 288. 
Conner, R. N. and C. S. Adkisson. 1976. Concentration of foraging Common Ravens along the Trans-Canada Highway. The Can.

Field-Nat. 90: 496-497.

Coombes, R. A. H. 1948. The flocking of the raven. Br. Birds. 41: 290-294 and 386 .

Coombs, C. J. F. 1961. Rookeries and roosts of the Rook and Jackdaw in South-west Cornwa11. Bird Study. 8: 55-70.

Craighead, J. J. and F. C. Craighead. 1969. Hawks, Owls and Wildlife. New York, Dover Pub.

Croze, H. 1970. Searching image in Carrion Crows. Z. Tierpsychol. Supp. 5. 1-86.

Cushing, J. E. 1941. Winter behavior of ravens at Tomales Bay, California. Condor. 43: 103-107.

Deubbert, H. F. 1969. The Ecology of Malheur Lake, U.S. Department of the Interior. Leaflet $\$ 412$.

Dicken, S. N. 1955. Oregon Geography. Eugene, Univ. of Oregon.

Dorn, J. L. 1972. The Common Raven in Jackson Hole, Wyoming. Unpublished M.S. Thesis, Laramie, Univ. Wyoming.

Elliott, T. C. 1910. Editorial notes on the Peter Skene Ogden journal of Snake Expedition 1826-7. Ore. Hist. Soc. Quart. 11: 201-222.

Errington, P. L. 1942. On the analysis of productivity in populations of higher vertebrates. J. Wildl. Manage. 6: 165-181.

Errington, P. L. 1967. Of predation and life. Ames, Iowa St. Univ. Press.

Farner, D. S. 1964. The photoperiodic control of reproductive cycles in birds. Am. Sci. 52: 137-156.

Farner, D. S. and B. K. Follett. 1966. Light and other environmental factors affecting avian reproduction. J. Anim. Sci. 25 SuppI. 90-118.

Farner, B. K. and L. R. Mewaldt. 19.52. The relative roles of photoperiod and temperature in gonad recurdescence in male Zonotrichia leucophrys gambelii. Anat. Rec. 113: 612-613.

Feilden, H. W. 1909a. Some Sussex Ravens. Br. Birds. 2: 279-280. 
Feilden, H. W. 1909b. Ravens as scavengers. Br. Birds. 3: 57-58.

Fentress, C. 19.75. Pop rivet fasteners for color markers. Inland Bird Banding News. 47: 3-9.

Gabrielson, I. N. 19.43. Wildlife Refuges. New York, The MacMillan Co.

Good, E. E. 1952. The life history of the American Crow. Ph.D. thesis. Ohio State Univ. University Microfilms. Pub. No. 23,690. AnnArbor, Mich.

Goodwin, D. 1976. Crows of the world. Ithica, New York, Cornell Univ. Press.

Gwinner, E. 1965a. Beobachtungen uber Nestbau und Brutpflege des Kolkraben in Gefangenschaft. J. Ornithol. 106: 145-178.

Gwinner, E. 1965b. Uber den Einflus des Hungers und anderer Faktoren auf die Versteck-Aktivitat des Kolkraben (Corvus corax). Vogelwarte. 23: 1-4.

Hammond, M. C. and W. R. Forward. 1956. Experiments on causes of duck nest predation. J. Wild1. Manage. 20: 243-247.

Harlow, R. C. 1922. The breeding habits of the Northern Raven in Pennsylvinia. Auk. 39: 399-410.

Harlow, R. C., R. G. Hooper, D. R. Chamberlain and H. S. Crawford. 1975. Some winter and nesting season foods of the Common Raven in Virginia. Auk. 92: 298-306.

Harrison, H. 1976. Roger Tory Peterson's Dozen Birding Hot Spots. New York, Simon and Schuster Inc.

Harrison, J. 1967. A wealth of wildlife. London.

Herrick, F. H. 1935. Wild birds at home. New York, D. AppletonCentury Co.

Holyoak, D. 1967. Breeding biology of the Corvidae. Bird Study. 14: 153-168.

Hooper, R. G., H. S. Crawford, D. R. Chamberlain and R. F. Harlow. 1975. Nesting density of Common Raven in the Ridge-Valley region of Virginia. Am. Birds. 29: 931-935.

Jarvis, R. L. 1964. Relationship between land use patterns and waterfow1 production at Malheur National Wildlife Refuge. Refuge Files, Malheur National Wildlife Refuge. 
Jewett, S. G. 1922. Report on Malheur Lake Birds Reservation. Refuge files. Malheur National Wildlife Refuge.

Johnsgard, P. A. 1975. Waterfowl of North America. Bloomington, Ind. Univ. Press.

King, J. R. and D. S. Farner. 1961. Energy metabolism, thermoregulation and body temperature. IN: A. J. Marsha11, Ed., Biology and comparative physiology of birds. Vo1. 2 . New York, Academic Press.

Kochert, M. N., A. R. Bammann and J. H. Doremus. 1976. Snake River Birds of Prey Research - Quarterly Report. Vo1. 2, No. 3, $36 \mathrm{pp}$.

Kochert, M. N., A. R. Bammann and J. H. Doremus. 1977. Snake River Birds of Prey Research - Quarterly Report. Vo1. 3, No. 2, $38 \mathrm{pp}$.

Kulczycki, A. 1973. Nesting of the members of the Corvidae in Poland. Acta. Zoo1. Cracov. (Eng1. Trans1.) 18: 583-657.

Lack, D. 1947. The significance of clutch-size. Ibis. 87: 302-352.

Lack, D. 1968. Ecological adaptations for breeding in birds. London, Oxford Press.

Larsen, K. H. and J. H. Dietrich. 1970. Reduction of a Raven population on lambing grounds with DRC-1339. J. Wildl. Manage. 34: 200-204.

Lewis, L. A. 1912. Report on Malheur Lake Bird Reservation. Ref uge files, Malheur National Wildlife Refuge.

Lindsey, M. G., B. B. Lovell, J. A. Norgren, G. N. Simonson, B. R. Thomas and D.W. Anderson. 1969. Oregon's long-range requirements for water. State Water Resource Board.

Littlefield, C. D. 1975. Production of Greater Sandhill Cranes on Malheur National Wildlife Refuge, Oregon. Proc. Int. Crane Workshop. 1: 86-92.

Littlefield, C. D. and R. A. Ryder. 1968. Breeding biology of the Greater Sandhill Crane on Malheur National Wildlife Refuge. Oregon. Trans. N. Am. Wildl. Nat. Resource Conf. 33: 444-454.

Lockie, J. D. 1955. The breeding and feeding of Jackdaws and Rooks with notes on Carrion Crows and other Corvidae. Ibis. 97: $341-369$. 
Lorenz, K. 1931. Beitrage zur Ethologie sozialer Coryiden. J. Ornithol. $79: 67-127$.

Lorenz, K. : 1940. Die Paarbildung beim Kolkraben. Z. Tierpsychol. 3: $278-292$.

Lucid, V. J. and R. N. Conner. 1974. A communal Common Raven roost in Virginia. Wilson Bull. 86: 82-83.

Ludin, A. 1962. Observations on the habits of Jackdaws (Comvus monedula) at their wintering and roosting quarters. Var. Fagelvarld. 21: 81-95.

Madson, J. 1976. The dance on Monkey Mountain and other crow doings. Audubon. 78: 52-59.

Meteorology Committee, Pacific Northwest River Basins Commission. 1969. Climatological handbook Columbia Basin States. 2 vol. $802 \mathrm{pp}$.

Mishaga, R. 1974. Asynchronous hatching and nestling mortality in White-necked Ravens. Wilson Bull. 86: 174-176.

Mylne, C. K. 1961. Large flocks of Ravens at food. Br. Birds. 54: 206-207.

Nelson, A. L. 1934. Some early summer food preferences of the American Raven in Southeastern Oregon. Condor. 36: 10-15.

Nie, N. H., C. H. Hull, J. G. Jenkins, K. Steinbrenner, D. H. Bent. 1970. Statistical Package for the Social Sciences. New York, McGraw Hill.

Post, W. 1967. Fish Crows gathering before going to roost. Chat. $31: 75-76$.

Ratcliffe, D. A. 1962. Breeding density in the Peregrine (Falco peregrinus) and Raven (Comus corax). Ibis. 104: 13-39.

Rearden, J. D. 1951. Identification of waterfowl nest predators. J. Wildl. Manage. 15: 386-395.

Reed, C. A. 1965. North American bird eggs. New York, Dover Pub.

Refuge Narratives. 1937-1977. Refuge files, Malheur National Wildlife Refuge, Burns, Oregon. 
Ricklefs, R. E. 1965. Brood reduction in the Curve-billed Thrasher. Condor. 67: 505-510.

Robinson, W. B. 1948. Thallium and Compound 1080 impregnated stations in coyote control. J. Wildl. Manage. 12: 279-295.

Rowley, I. 1968. The ABC of crow catching. Aust. Bird Bander. $6: 47-55$.

Rowley, I. 1973. The comparative ecology of Australian corvids. CSIRO Wild1. Res. 18: 1-169.

Rudd, R. L. 1964. Pesticides and the living landscape. Madison, Univ. of Wis. Press.

Rudd, R. L. and R. E. Gene11y. 1956. Pesticides: Thelr use and toxicity in relation to wildlife. California. Dept. Fish and Game. Game Bulletin 非4.

Scholander, P. F., R. Hock, V. Walters and L. Irving. 1950. Adaptation to cold in arctic and tropical mammals and birds in relation to body temperature, insulation and basal metabolism rate. Biol. Bul1. 99: 259-271.

Schranck, B. W. 1966. Waterfowl nest-sites and nest predation. Unpublished M.S. thesis. Univ. of Missouri.

Schranck, B. W. 1972. Waterfowl nest cover and some predation relationships. J. Wildl. Manage. 36: 182-186.

Smith, A. G. 1971. Ecological factors affecting waterfowl production in Alberta Parklands. USDI. Resource Pub. 98 of Bureau of Sport Fisheries and Wildife.

Stewart, P. A. 1973. Basis for pre-roost gatherings of Starlings and Brown-headed Cowbirds. Bird-Banding. 44: 315-316.

Stoudt, J. J. 1971. Ecological factors affecting waterfowl production in the Saskatchewan Parklands. USDI. Resource Pub. 99 of Bur@au of Sport Fisheries and Wildlife.

Taapken, J. 1952. Breeding of the Rook on buildings in the Netherlands in 1952. Ardea. 40: 155.

Tast, J. and P. Rassi. 1973. Roosts and roosting flights of wintering Corvus monedula at Tampere, Finland. Ornis. Fenn. $50: 29-45$.

Temple, S. A. 1974. Winter food habits of Ravens in the Arctic slope of Alaska. Arctic, 27: 41-46. 
Took, G. E. 1937. Carrion Crow laying twice in same nest. Br. Birds. $30: 80$.

United States Department of the Interior. 1957. Carp control project at Malheur Lake, Oregon 1955-1956. Portland, Oregon.

United States Department of the Interior. 1974. Malheur National Wildlife Refuge. RF 1351700-1. Loose leaf.

Veighte, J. H. and C. F. Herreid. 1965. Radiometric determinations of feather insulation and metabolism of Arctic birds. Physiol. Zool. 38: 267-275.

Welty, J. C. 1968. The life of birds. Philadelphia. Pa., W.B. Saunders.

Willett, G. 1918. Report on Malheur Lake Bird Reservation. Refuge files, Malheur National Wildilfe Refuge.

Zahavi, A. 1971. The function of pre-roost gatherings and communal roosts. Ibis. 113: 106-109. 
APPENDIX A

NESTING SEQUENCE AND BANDING DATA

FOR INDIVIDUAL NESTS 


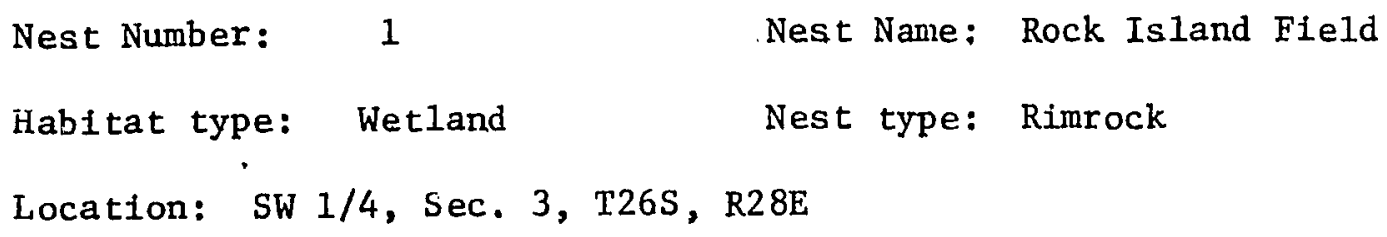

1976

Nest destroyed prior to 5-27-76

$$
\text { Date Number }
$$

$\begin{array}{lcc}\text { Eggs } & 5-07-76 & 7 \\ \text { Hatch } & - & \mathrm{X}^{\mathrm{b}} \\ \text { Fledge } & -- & 0\end{array}$

1977

Nest destroyed prior to 6-10-77

Date Number

$\begin{array}{lcc}\text { Eggs } & 4-01-77 & 7 \\ \text { Hatch } & 4-22-77 & 5 \\ \text { Fledge } & -- & 0\end{array}$

a all dates refer to date of first observation of eggs, hatch, or

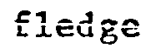

$\mathrm{b} \quad \mathrm{X}=$ number unknown 


\author{
Nest Number: 2 Nest Name: Chappo Field \\ Habitat type: Wetland Nest type: Structure \\ Location: NW 1/4, Sec. 12, T26S, R28E
}

1976

Date Banded: 6-17-76

Date Number Patagial Colors Federal Band No.

$\begin{array}{lllll}\text { Eggs } & 4-23-76 & 6 & \mathrm{Y} / \mathrm{LB} & 1017-80220 \\ \text { Hatch } & 5-14-76 & 4 & \mathrm{LB} / \mathrm{Y} & 1017-80221 \\ \text { Fledge } & 6-20-76 & 3 & \mathrm{Y} / \mathrm{DB} & 1017-80222\end{array}$

1977

Date Banded: 6-26-77

Date Number Patagial Colors Federal Band No.

$\begin{array}{lllll}\text { Eggs } & 4-26-77 & 6 & \mathrm{LB} / \mathrm{DB} * & 1017-80419 \\ \text { Hatch } & 5-17-77 & 5 & \mathrm{LB} / \mathrm{G}^{*} & 1017-80416 \\ \text { Fledge } & 6-26-77 & 4 & \mathrm{LB} / \mathrm{G}^{*} & 1017-80417 \\ & & & \mathrm{LB} / \mathrm{G} * & 1017-80418\end{array}$

Patagial Colors (left wing/right wing)

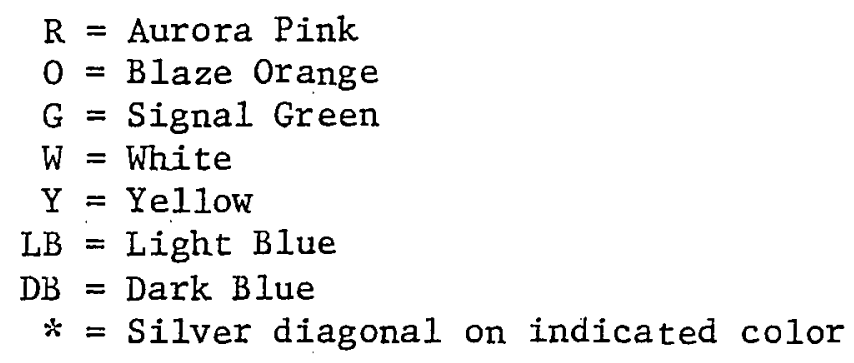




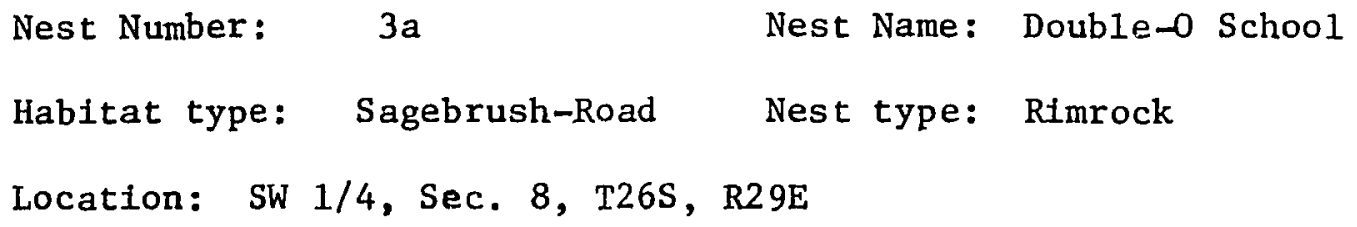

1976

Fledges not banded

$\begin{array}{lcc} & \text { Date } & \text { Number } \\ \text { Eggs } & - & \mathrm{X} \\ \text { Hatch } & -- & \mathrm{X} \\ \text { Fledge } & 5-29-76 & 3\end{array}$

1977

Nest destroyed prior to 4-13-77

Date Number

$\begin{array}{lll}\text { Eggs } & -- & X \\ \text { Hatch } & - & 0 \\ \text { Fledge } & -- & 0\end{array}$


Nest Number: $3 b$

Habitat type: Wetland

Location: NE 1/4, Sec. 13, T26S, R28E
Nest Name: Warbler Pond

(Double-0 School Renest)

Nest type: Tree

1976

Unused

1977

Nest destroyed prior to 5-28-77

Date Number

Eggs $4-19-77 \quad X$

Hatch - $\quad 0$

Fledge -- $\quad 0$ 
Nest Number: $\quad 3 c$

Nest Name: Double-0 School

(Warbler Pond Renesting)

Habitat type: Sagebrush-Road .Nest type: Rimrock

Location: SW 1/4, Sec: 8, T26S, R29E

1976

See Nest $3 a$

1977

\begin{tabular}{lcccc} 
& & \multicolumn{3}{c}{ Date Banded: } \\
& Date & Number & Patagial Colors & Federal Band No. \\
Eggs & $5-08-77$ & $\mathrm{X}$ & LB/LB* & $1017-80420$ \\
Hatch & $5-29-77$ & 4 & LB/LB* & $1017-80421$ \\
Fledge & $7-06-77$ & 4 & LB/LB* & $1017-80422$ \\
& & & LB/LB* & $1017-80423$
\end{tabular}

Patagial Colors (left wing/right wing)

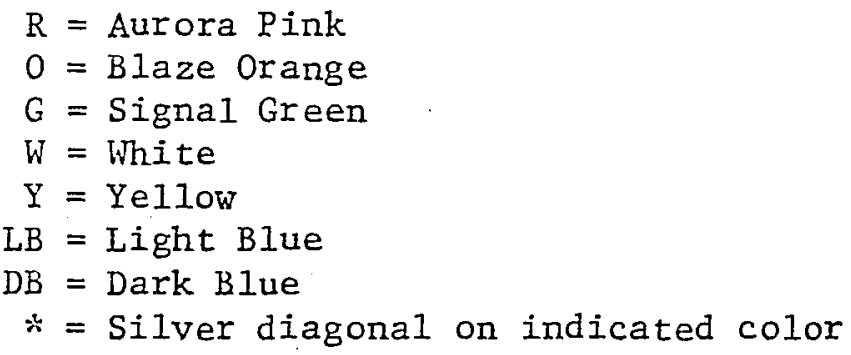




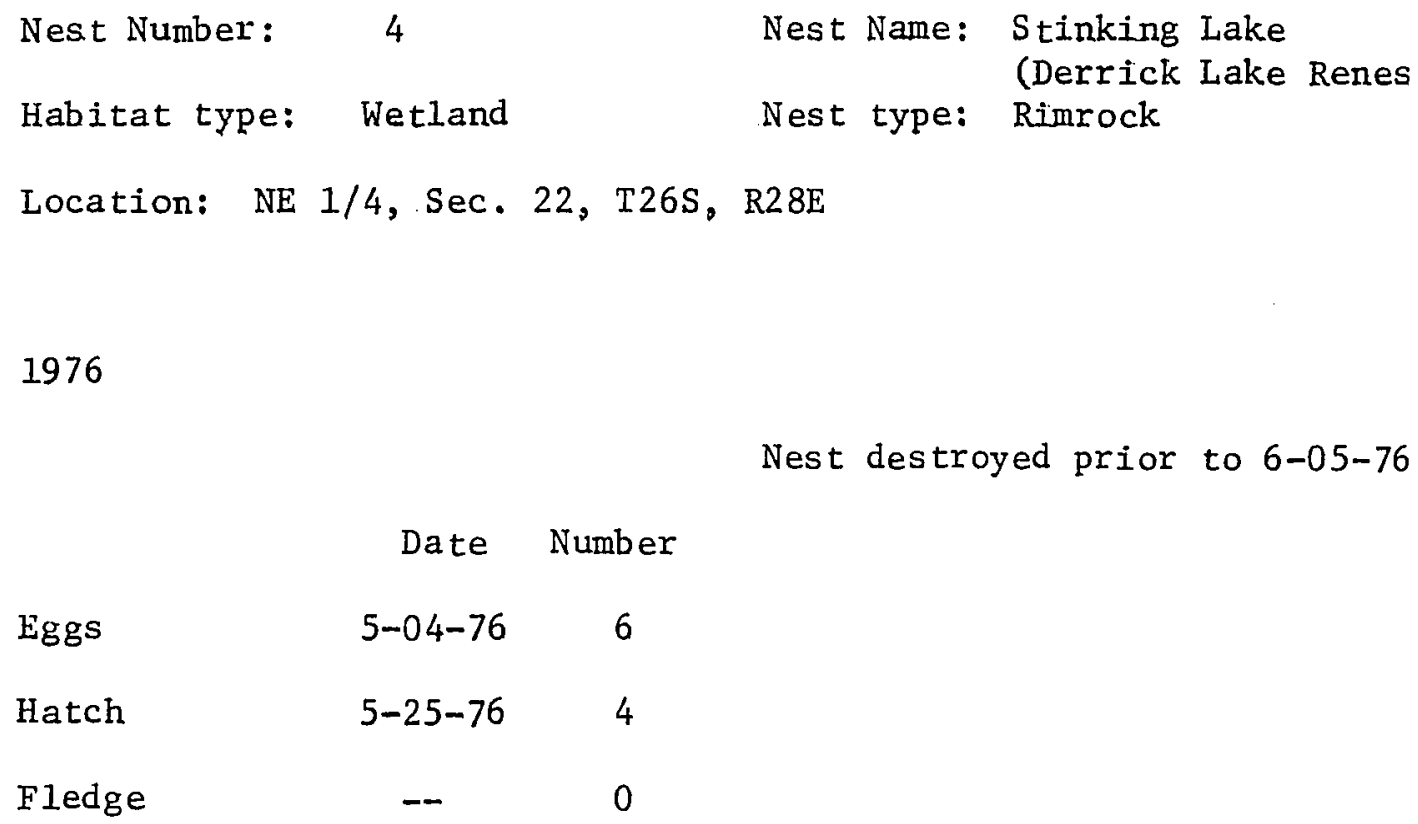

1977

Unused 


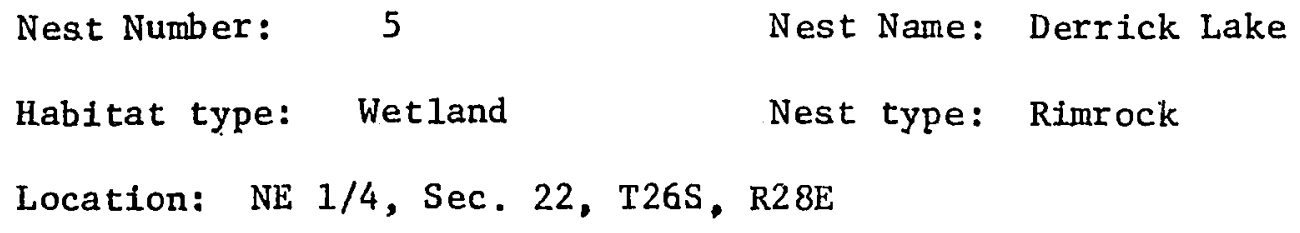

1977

Nest destroyed prior to 5-28-77 Date Number

$\begin{array}{lcc}\text { Eggs } & 4-23-77 & 6 \\ \text { Hatch } & -- & 0 \\ \text { Fledge } & -- & 0\end{array}$




\author{
Nest Number: 6 Nest Name: Martha Lake \\ Habltat type: Wetland Nest type: Rimrock \\ Location: SW $1 / 4$, Sec. 23, T26S, R28E
}

1976

\begin{tabular}{lcccc} 
& & \multicolumn{4}{c}{ Date Banded: } & $5-21-76$ \\
& Date & Number & Patagial Colors & Federal Band No. \\
Eggs & $4-01-76$ & 6 & W/W & $776-57167$ \\
Hatch & $4-21-76$ & 6 & $0 /-$ & $776-57168$ \\
Fledge & $6-01-76$ & 5 & $-/ 0$ & $776-57169$ \\
& & & $0 / 0$ & $776-57170$
\end{tabular}

1977

Date Number Nest destroyed prior to 5-28-77

Eggs $\quad 4-13-77 \quad 6$

Hatch 0

Fledge $\quad 0$

Patagial Colors (left wing/right wing)

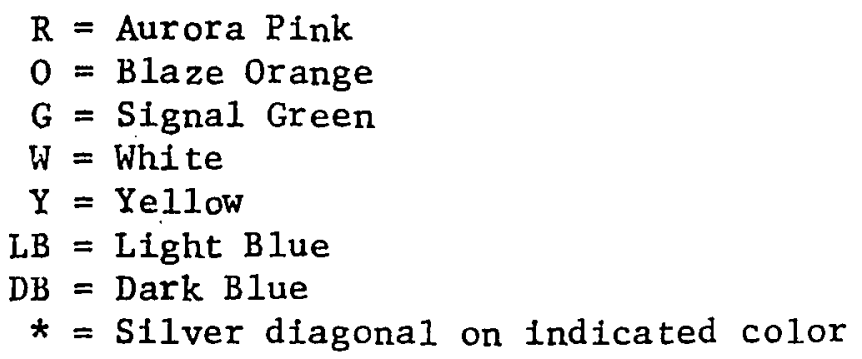




\begin{abstract}
Nest Number: 7 Nest Name: Pictograph
Habitat type: Sagebrush-Road Nest type: Rimrock

Location: NW 1/4, Sec. 25, T26S, R30E
\end{abstract}

1976

Date Banded: 5-18-76

Date Number Patagial Colors Federal Band No.

$\begin{array}{lllll}\text { Eggs } & 3-21-76 & 6 & -/ D B & 817-71693 \\ \text { Hatch } & 4-10-76 & 5 & \text { G/DB } & 817-71694 \\ \text { Fledge } & 5-20-76 & 2 & & \end{array}$

1977

\begin{tabular}{lcccc} 
& & \multicolumn{4}{c}{ Date Banded: } & 5-11-77 \\
& Date & Number & Patagial Colors & Federa1 Band No. \\
Eggs & $3-15-77$ & 5 & LB*/R & $1017-80352$ \\
Hatch & $4-05-77$ & 5 & LB*/R & $1017-80353$ \\
Fledge & $5-11-77$ & 4 & $L B * / R$ & $1017-80354$ \\
& & & $L B * / R$ & $1017-80355$
\end{tabular}

Patagia1 Colors (left wing/right wing)

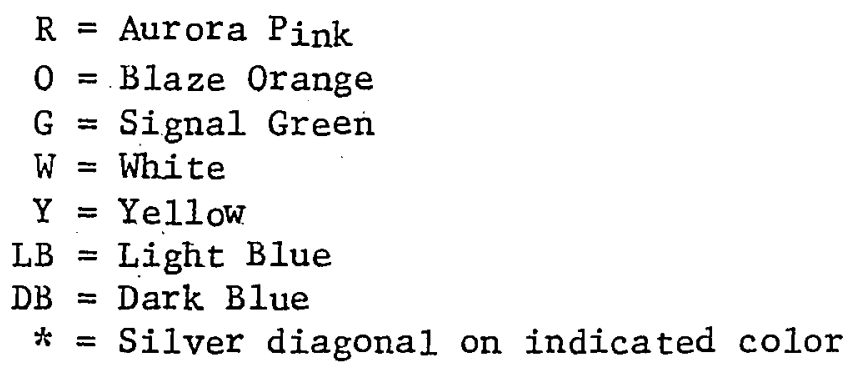




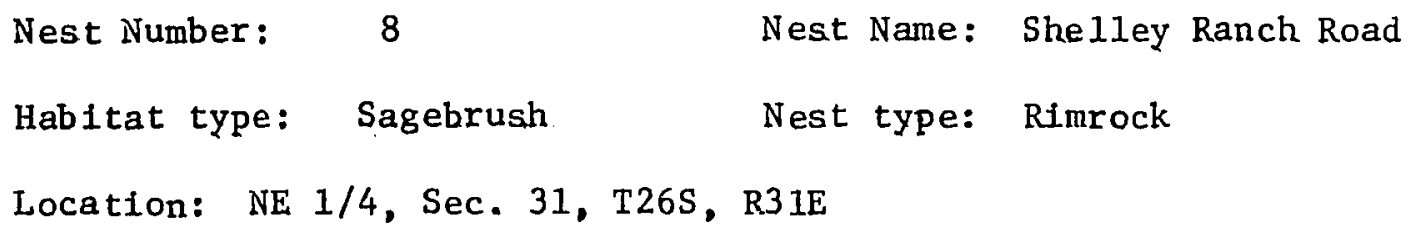

1976

Nest destroyed prior to 5-11-76

Date Number

Eggs

$5-05-76 \quad 7$

Hatch

$-$

0

Fledge

$-$

0

1977

Unused 
Nest Number: 9 Nest Name: Gibson House

Habitat type: Wetland Nest type: Building

Location: NE 1/4, Sec, 36, T26S, R31E

1976

Date Banded: 6-23-76

Date Number Patagial Colors Federal Band No.

$\begin{array}{lllrl}\text { Eggs } & 4-30-76 & 5 & -/ \mathrm{DB} * & 1017-80227 \\ \text { Hatch } & 5-20-76 & 5 & \mathrm{G} / \mathrm{DB} * & 1017-80228 \\ \text { Fledge } & 7-04-76 & 5 & \mathrm{DB} * / \mathrm{G*} & 1017-80229 \\ & & & \mathrm{DB} * / \mathrm{LB} * & 1017-80230 \\ & & & \mathrm{LB} * / \mathrm{DB} * & 1017-80231\end{array}$

1977

Date Banded: 5-17-77

Date Number Patagial Colors Federal Band No.

$\begin{array}{lllll}\text { Eggs } & 3-24-77 & 7 & L B * / D B & 1017-80365 \\ \text { Hatch } & 4-13-77 & 6 & L B * / D B & 1017-80366 \\ \text { Fledge } & 5-17-77 & 5^{a} & L B * / D B & 1017-80367 \\ & & & L B * / D B & 1017-80368 \\ & & & L B * / D B & 1017-80369\end{array}$

Patagial Colors (left wing/right wing)

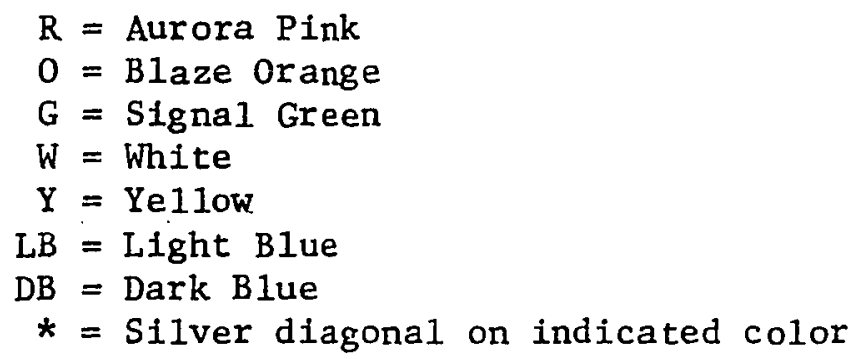

a one marked fledgling found dead 5-18-77 


\author{
Nest Number: 10 \\ Nest Name: Baccus Lake \\ Habitat type: Wetland \\ Nest type: Building \\ Location: NW 1/4, Sec. 34, T26S, R32E
}

1976

Date Banded: 5-18-76

Date Number Patagial Colors Federal Band No.

$\begin{array}{lllll}\text { Eggs } & 3-12-76 & \mathrm{X} & \text { LB } / \mathrm{LB} & 817-71691 \\ \text { Hatch } & 4-02-76 & 6 & \text { DB/- } & 817-71692 \\ \text { Fledge } & 5-12-76 & 5 & & \end{array}$

1977

\begin{tabular}{lcccc} 
& & \multicolumn{3}{c}{ Date Banded: } \\
& Date & Number & Patagial Colors & Federa1 Band No. \\
Eggs & $4-04-77$ & 7 & DB/W* & $1017-80396$ \\
Hatch & $4-25-77$ & 5 & & \\
Fledge & $5-31-77$ & 1 &
\end{tabular}

Patagial Colors (left wing/right wing)

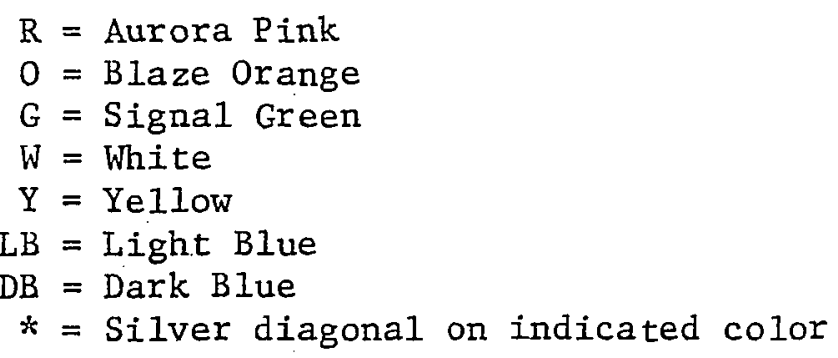




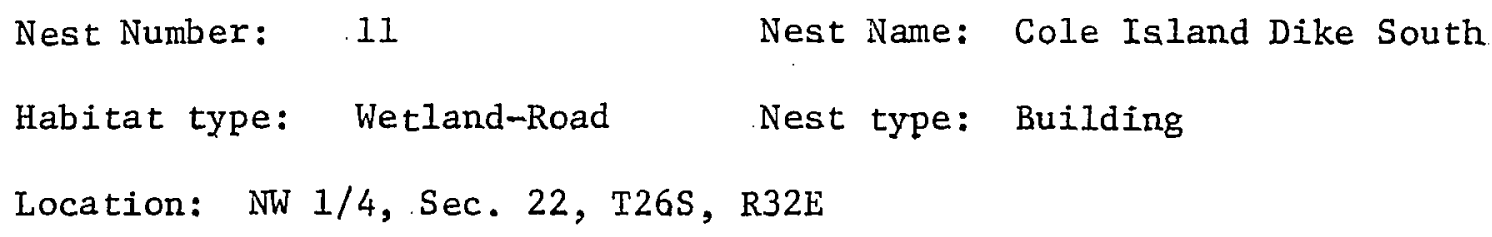

$\begin{array}{lcc} & \text { Date } & \text { Number } \\ \text { Eggs } & 4-04-76 & 6 \\ \text { Hatch } & 4-25-76 & 5 \\ \text { Fledge } & -- & 0\end{array}$

1977

Unused 
Nest Number: 12a Nest Name: Cole Island Dike North Habitat type: Wetland-Road Nest type: Building Location: SW 1/4, Sec. 2, T26S, R32E

1976

Nest destroyed prior to 5-03-76

Date Number

$\begin{array}{lcc}\text { Eggs } & 4-04-76^{a} & X \\ \text { Hatch } & -- & X \\ \text { Fledge } & -- & 0\end{array}$

1977

Date Banded: 6-17-77

Date Number Patagial Colors Federal Band No.

Eggs 4-20-77 X $\mathrm{LB} * / \mathrm{G}$ $1017-80408$

Hatch $5-11-77 \quad x$ $G * / L B$ 1017-80409

Fledge $6-20-77 \quad 1$ $\mathrm{G} * / \mathrm{LB}$ 1017-80410

$\mathrm{G} * / \mathrm{LB}$ 1017-80411

$G * / L B$ 1017-80412

a Nest occupied - contents not obseryed

Patagial Colors (left wing/right wing)

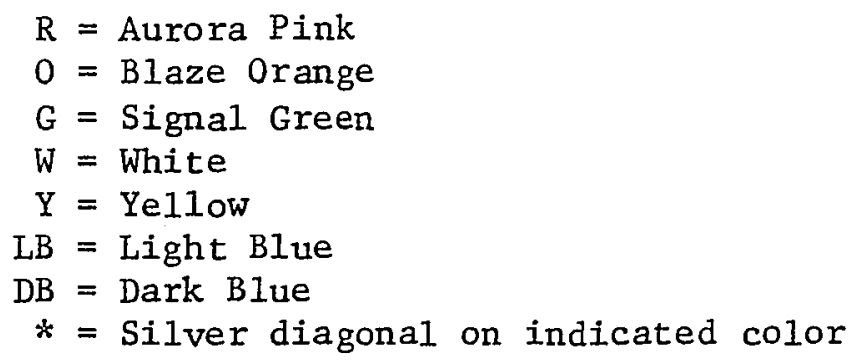




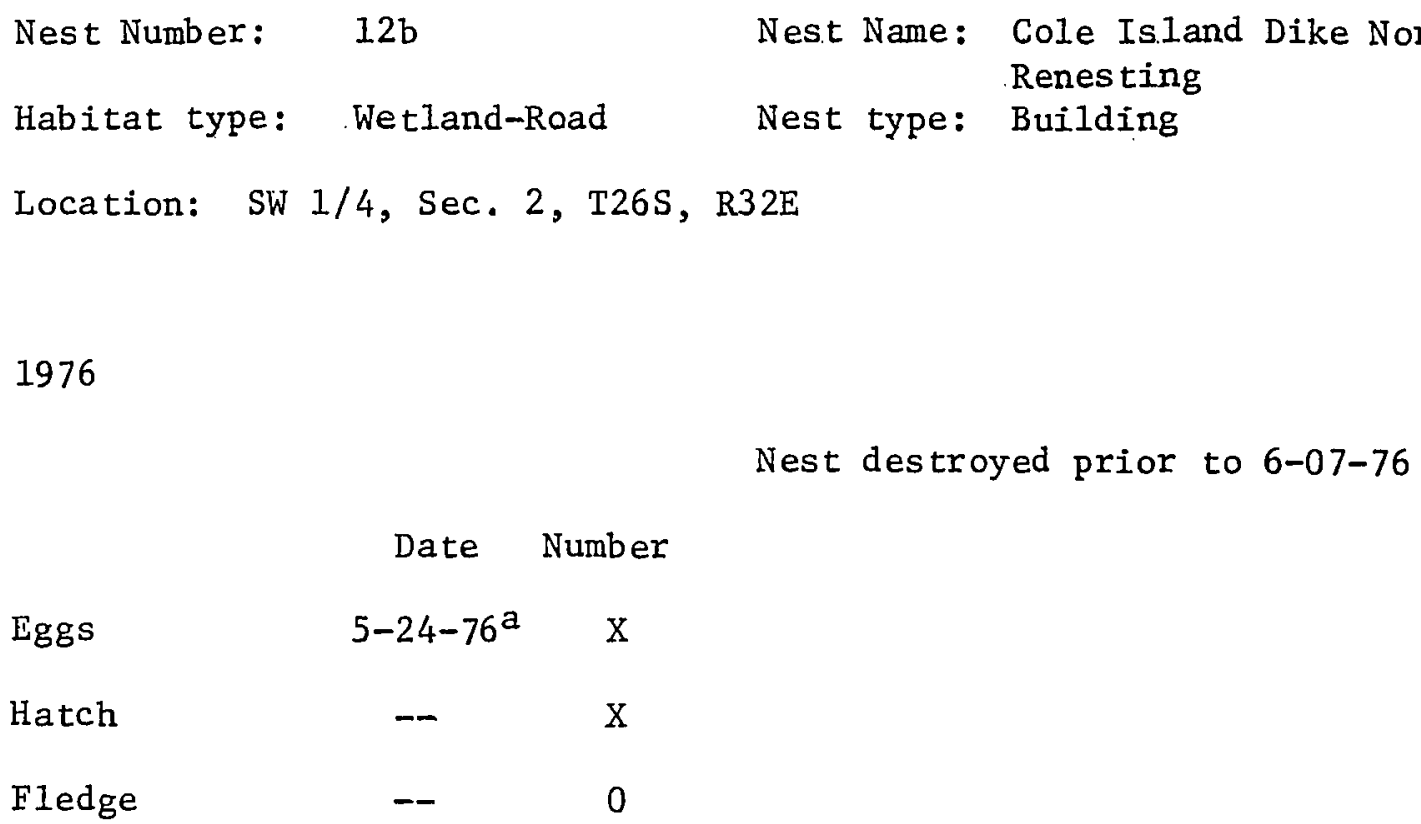

1977

See Nest $12 a$

a Nest occupied - contents not observed 


Nest Number: 13
Habitat type: Sagebrush-Road Name: Blacky Corner
Location: NW 1/4, Sec. 12, T27S, R30E

1976

Date Banded: 5-15-76

Date Number Patagial Colors Federal Band No.

$\begin{array}{lllll}\text { Eggs } & 3-22-76 & X & \text { G/ } & 817-71685 \\ \text { Hatch } & 4-12-76 & 5 & \text { G/G } & 817-71686 \\ \text { Fledge } & 5-22-76 & 4 & -/ L B & 817-71687 \\ & & & \text { LB/ } & 817-71688\end{array}$

1977

Date Banded: 5-26-77

Date Number Patagial Colors Federal Band No.

$\begin{array}{lllll}\text { Eggs } & 3-25-77 & 7 & \mathrm{DB} * / 0 & 1017-80377 \\ \text { Hatch } & 4-18-77 & 5 & \mathrm{DB} * / 0 & 1017-80378 \\ \text { Fledge } & 5-26-77 & 5 & \mathrm{DB} * / 0 & 1017-80379 \\ & & & \mathrm{DB} * / 0 & 1017-80380\end{array}$

Patagial Colors (left wing/right wing)

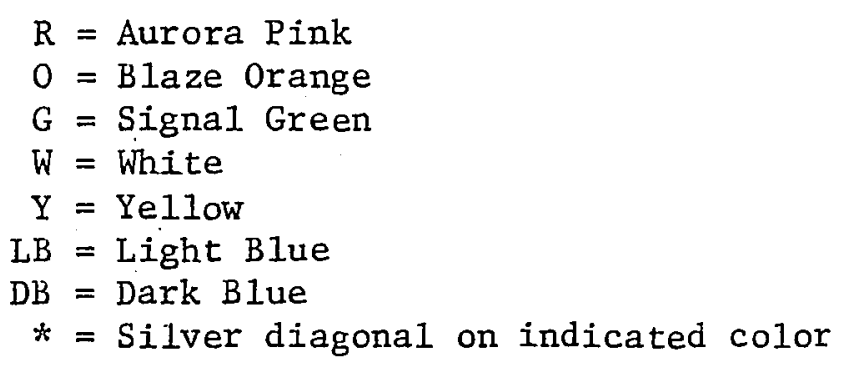




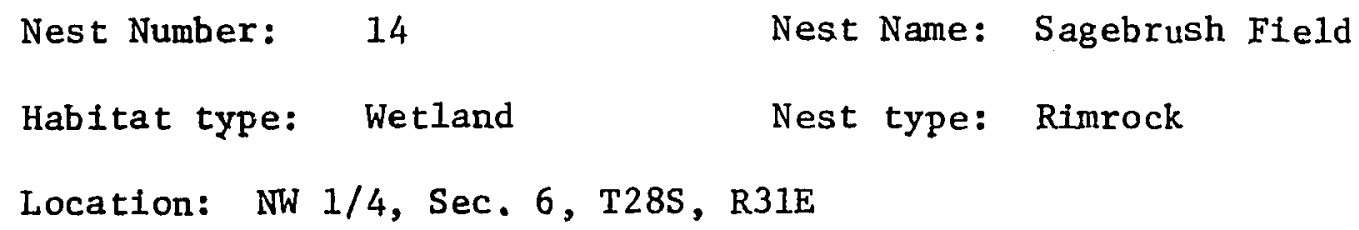

1977

Nest destroyed prior to 5-19-77

Date Number

$\begin{array}{lll}\text { Eggs } & 4-01-77 \quad 6\end{array}$

Hatch 4-21-77 5

Fledge $\quad--\quad 0$ 
Nest Number: $\quad 15$

Habitat type: Sagebrush-Road Nest type: Rimrock
Nest Name: Davies Ranch

Location: T27S, R33E

1976

Date Banded: $5-25-76$

Date Number Patagial Colors Federal Band No.

$\begin{array}{lllll}\text { Eggs } & 4-01-76 & X & \text { LB/O } & 776-57176 \\ \text { Hatch } & 4-21-76 & X & \text { DB/O } & 776-57177 \\ \text { Fledge } & 5-30-76 & 3 & \text { W/O } & 776-57178\end{array}$

1977

Date Banded: 5-10-77

Date Number Patagial Colors Federal Band No.

$\begin{array}{lllll}\text { Eggs } & 3-07-77 & 7 & G * / G & 1017-80341 \\ \text { Hatch } & 3-28-77 & 6 & G * / G & 1017-80342 \\ \text { Fledge } & 5-08-77 & 5 & G * / G & 1017-80343 \\ & & & G * / G & 1017-80344 \\ & & G * / G & 1017-80345\end{array}$

Patagial Colors (left wing/right wing)

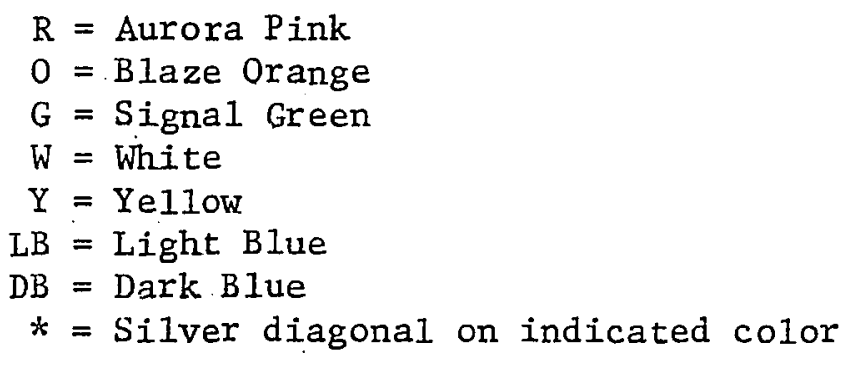


Nest Number: $\quad 16$

Habitat type: Sagebrush

Location: T28S, R33E

1976

$\mathrm{N}$ est used but inaccessable
Nes.t Name: Jenkins Ranch

Nest type: Rimrock

1977

Nest used but inaccessable 


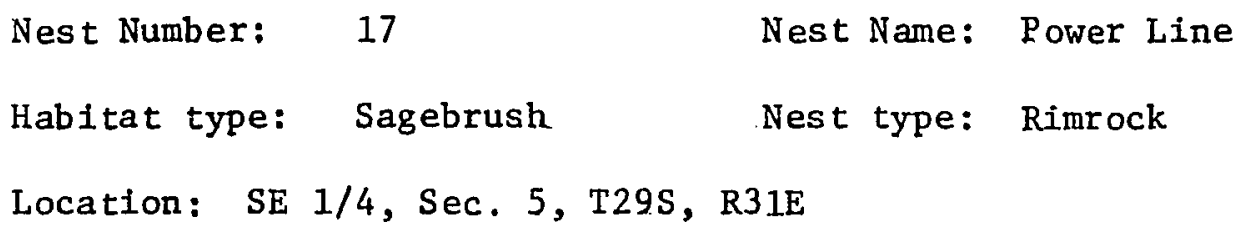

$\begin{array}{lcc} & \text { Date } & \text { Number } \\ \text { Eggs } & - & \mathrm{X} \\ \text { Hatch } & - & \mathrm{X} \\ \text { Fledge } & 5-31-76 & 6\end{array}$

1977

Nest used but inaccessable 
Nest Number: $\quad 18$

Habitat type: Wetland-Road

Location: SW 1/4, Sec, 35, T28S, R31E

1976
Nest Name: Ramelli Bridge

Nest type: Tree

Nest destroyed prior to 5-22-76

\begin{abstract}
Date Number
\end{abstract}
Eggs

$4-13-76 \quad 6$

Hatch

$5-04-76 \quad 5$

Fledge

0

1977

Unused 


$\begin{array}{lll}\text { Nest Number: } & 19 & \text { Nest Name: Diamond Dump } \\ \text { Habitat type: } & \text { Wetland } & \text { Nest type: Rimrock } \\ \text { Location: NE 1/4, Sec. 15, T29S, R32E }\end{array}$

1976

Date Banded: $5-25-76$

$\begin{array}{lcccc} & \text { Date } & \text { Number } & \text { Patagial Colors } & \text { Federal Band No. } \\ \text { Eggs } & 3-25-76 & \mathrm{X} & \mathrm{LB} / \mathrm{O} * & 1017-80428 \\ \text { Hatch } & 4-15-76 & \mathrm{X} & \mathrm{G} * / \mathrm{W} & 1017-80429 \\ \text { Fledge } & 5-25-76 & 6 & \mathrm{G} * /- & 1017-80244 \\ & & & \mathrm{LB} * /- & 1017-80245 \\ & & \mathrm{DB} * /- & 1017-80246\end{array}$

1977

Unused

Patagial Colors (left wing/right wing)

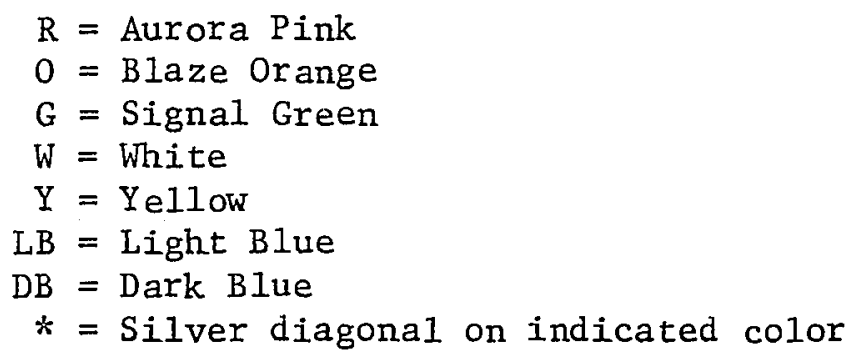




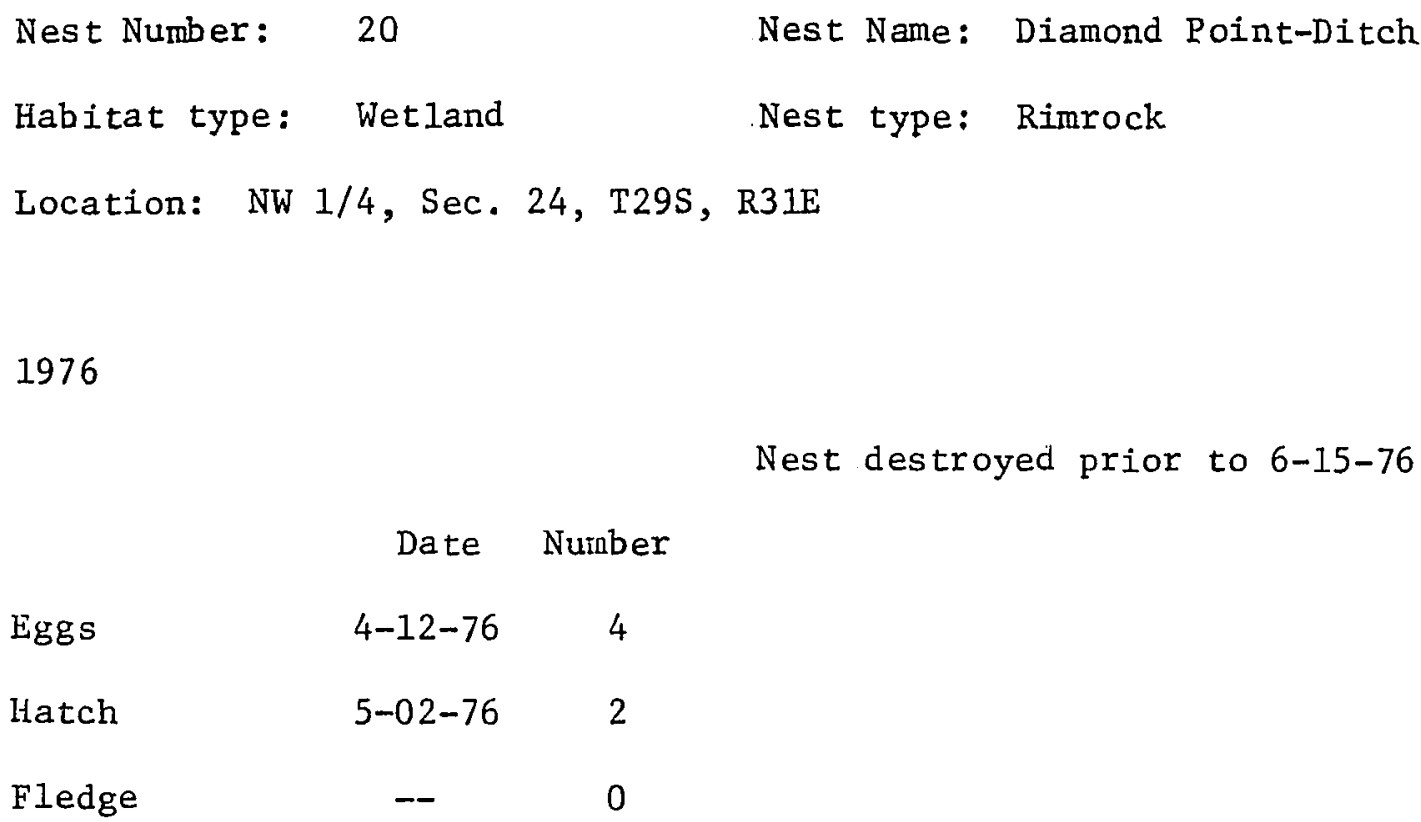

1977

Unused 


\begin{abstract}
Nest Number: 21 Nest Name: Diamond-Point-Fence
Habitat type: Wetland-Road Nest type: Rimrock

Location: SE 1/4, Sec. 24, T29S, R31E
\end{abstract}

1976

Date Banded: 6-03-76

Date Number Patagial Colors Federal Band No.

$\begin{array}{lllll}\text { Eggs } & 4-09-76 & X & R /- & 776-57179 \\ \text { Hatch } & 4-30-76 & X & -/ R & 776-57180 \\ \text { Fledge } & 6-08-76 & 4 & R / R & 776-57181 \\ & & & R / G & 776-57182\end{array}$

1977

Date Banded: 6-01-77

Date Number Patagial Colors Federal Band No.

$\begin{array}{lllll}\text { Eggs } & 4-02-77 & 7 & \mathrm{G} / 0 * & 1017-80398 \\ \text { Hatch } & 4-26-77 & 6 & \mathrm{G} / 0 * & 1017-80399 \\ \text { Fledge } & 6-07-77 & 2 & & \end{array}$

Patagial Colors (left wing/right wing)

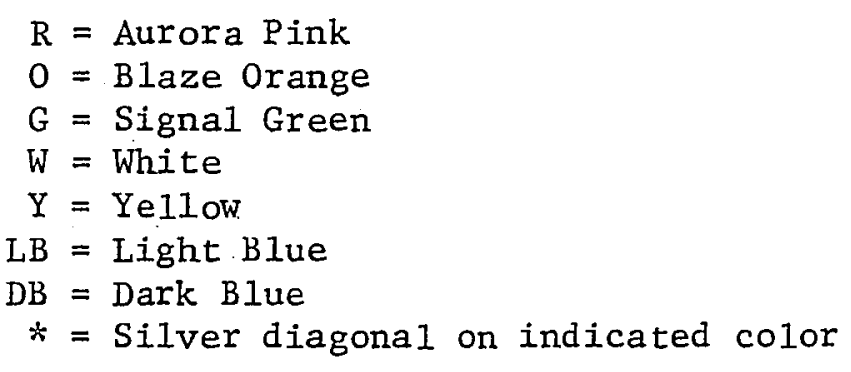




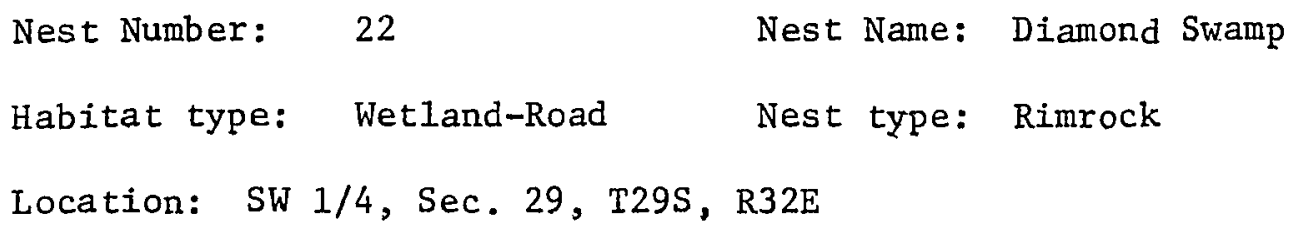

$\begin{array}{lllll}\text { Eggs } & 3-10-77 & 7 & L B * / 0 & 1017-80346 \\ \text { Hatch } & 3-31-77 & 6 & L B * / 0 & 1017-80349 \\ \text { Fledge } & 5-10-77 & 5 & L B * / 0 & 1017-80350 \\ & & & L B * / 0 & 1017-80351\end{array}$

Patagial Colors (left wing/right wing)

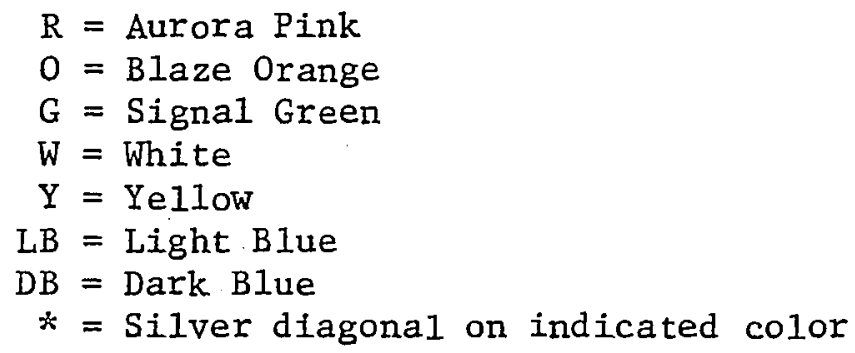


Nest Number: 23a Nest Name: Diamond Cut

Habitat type: Wetland-Road Nest type: Rimrock

Location: SW $1 / 4, \mathrm{Sec}, 21, \mathrm{~T} 29 \mathrm{~S}, \mathrm{R} 32 \mathrm{E}$

1976

Date Number Nest destroyed prior to 5-04-76

Eggs $\quad 3-23-76 \quad 7$

Hatch 4-13-76 5

Fledge 0

1977

Date Banded: $5-17-77$

Date Number Patagial Colors Federal Band No.

$\begin{array}{lllll}\text { Eggs } & 3-21-77 & 5 & \mathrm{DB} * / \mathrm{G} & 1017-80363\end{array}$

$\begin{array}{lllll}\text { Hatch } & 4-11-77 & 2 & \mathrm{DB} * / \mathrm{G} & 1017-80364\end{array}$

Fledge $\quad 5-17-77 \quad 2$

Patagial Colors (left wing/right wing)

$$
\begin{aligned}
\mathrm{R} & =\text { Aurora Pink } \\
O & =\text { Blaze Orange } \\
\mathrm{G} & =\text { Signal Green } \\
\mathrm{W} & =\text { White } \\
\mathrm{Y} & =\text { Yellow } \\
\mathrm{LB} & =\text { Light Blue } \\
\mathrm{DB} & =\text { Dark Blue } \\
* & =\text { Silver diagonal on indicated color }
\end{aligned}
$$


Nest Number: $23 b$

Habitat type: Wetland-Road
Nest Name: Diamond Cut

(Diamond Cut Renesting)

Nest type: Rimrock

Location: SW 1/4, Sec. 21, T29S, R32E

1976

Date Banded: 6-22-76

Date Number Patagial Colors Federal Band No.

$\begin{array}{lllll}\text { Eggs } & 5-02-76 & 5 & \mathrm{G} * / \mathrm{LB} * & 1017-80223 \\ \text { Hatch } & 5-23-76 & 4 & \mathrm{LB} * / \mathrm{G} * & 1017-80224 \\ \text { Fledge } & 6-28-76 & 3 & \mathrm{LB} * / \mathrm{LB} * & 1017-80225\end{array}$

1977

See Nest 23a

Patagial Colors (left wing/right wing)

$$
\begin{aligned}
\mathrm{R} & =\text { Aurora Pink } \\
\mathrm{O} & =\text { Blaze Orange } \\
\mathrm{G} & =\text { Signal Green } \\
\mathrm{W} & =\text { White } \\
\mathrm{Y} & =\text { Yellow } \\
\mathrm{LB} & =\text { Light Blue } \\
\mathrm{DB} & =\text { Dark Blue } \\
* & =\text { Silver diagonal on indicated color }
\end{aligned}
$$




\author{
Nest Number: 24 \\ Nest Name: Hog Wallow Seeding 非 \\ Habitat type: Sagebrush \\ Nest type: Rimrock \\ Location: SW 1/4, Sec. 2, T30S, R32E
}

1976

Date Banded: 5-25-76

Date Number Patagial Colors Federal Band No.

$\begin{array}{lllll}\text { Eggs } & 3-29-76 & 6 & \text { O/LB } & 776-57172 \\ \text { Hatch } & 4-19-76 & 5 & \text { O/DB } & 776-57173 \\ \text { Fledge } & 5-31-76 & 4 & \text { O/W } & 776-57174 \\ & & & \text { G/O } & 776-57175\end{array}$

1977

Date Banded: 6-02-77

Date Number Patagial Colors Federa1 Band No.

$\begin{array}{lllll}\text { Eggs } & 4-02-77 & 7 & \mathrm{G} / \mathrm{W}^{*} & 1017-80404 \\ \text { Hatch } & 4-24-77 & 6 & \mathrm{G} / \mathrm{W}^{*} & 1017-80405 \\ \text { Fledge } & 6-02-77 & 4 & \mathrm{G} / \mathrm{W}^{*} & 1017-80406 \\ & & & \mathrm{G} / \mathrm{W}^{*} & 1017-80407\end{array}$

Patagial Colors (left wing/right wing)

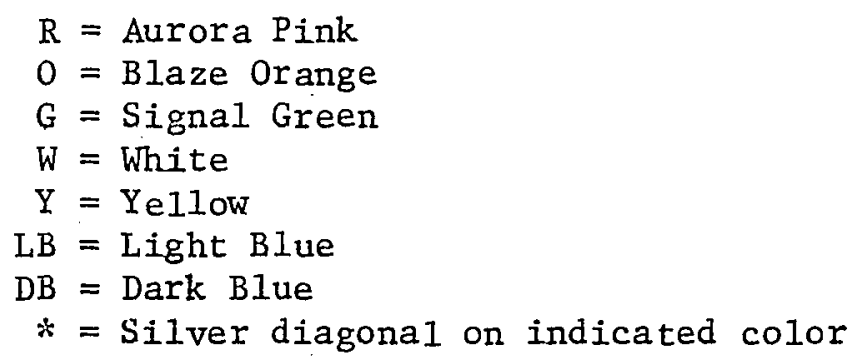


Nest Number: 25 Nest Name: Rock Crusher Point

Habitat type: Wetland-Road Nest type: Rimrock

Location: SW 1/4, Sec. 3, T30S, R3IE

1976

$\begin{array}{lcccc} & & & \text { Date Banded: } & 6-28-76 \\ & \text { Date } & \text { Number } & \text { Patagial Colors Federal Band No. } \\ \text { Eggs } & 5-01-76 & \mathrm{X} & \mathrm{DB} / \mathrm{Y} & 1017-80233 \\ \text { Hatch } & 5-21-76 & 4 & \mathrm{Y} / \mathrm{O} & 1017-80234 \\ \text { Fledge } & 6-30-76 & 4 & \mathrm{O} / \mathrm{Y} & 1017-80235 \\ & & & \mathrm{Y} / \mathrm{R} & 1017-80236\end{array}$

1977

Date Banded: 5-11-77

Date Number Patagial Colors Federal Band No.

$\begin{array}{lllll}\text { Eggs } & 3-10-77 & 6 & \mathrm{DB} * / \mathrm{W} & 1017-80357\end{array}$

$\begin{array}{lllll}\text { Hatch } & 3-28-77 & 4 & \mathrm{DB} * / \mathrm{W} & 1017-80358\end{array}$

Fledge $\quad 5-11-77 \quad 2$

Patagial Colors (left wing/right wing)

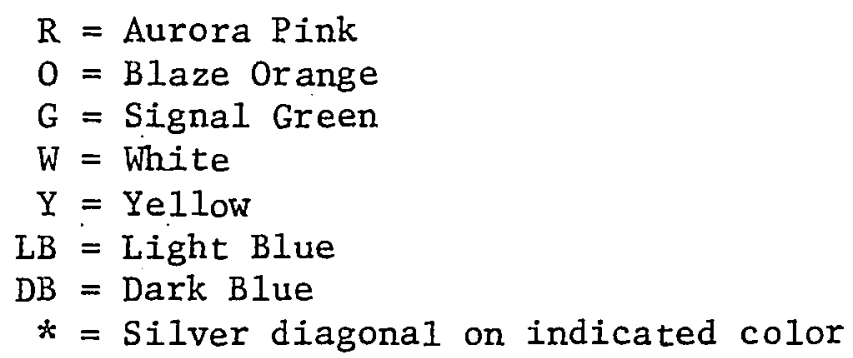




\begin{tabular}{|c|c|c|c|}
\hline Nest Number: & 26 & Nest Name: & Krumbo Swamp \\
\hline Habitat type: & Wetland & Nest iype: & ninrock \\
\hline
\end{tabular}

1976

Date Banded: 6-11-76

Date Number Patagial Colors Federal Band No.

$\begin{array}{lcccc}\text { Eggs } & 4-14-76 & 7 & -/ G * & 1017-80211 \\ \text { Hatch } & 5-05-76 & 5 & G * / G * & 1017-80212 \\ \text { Fledge } & 6-13-76 & 4 & L B * /- & 1017-80213 \\ & & & -/ L B * & 1017-80214\end{array}$

1977

Date Banded: 5-11-77

Date Number Patagial Colors Federal Band No.

$\begin{array}{lllll}\text { Eggs } & 3-09-77 & 5 & \text { LB*/LB } & 1017-80360 \\ \text { Hatch } & 3-30-77 & 5 & \text { LB*/LB } & 1017-80361 \\ \text { Fledge } & 5-11-77 & 5 & \text { LB*/LB } & 1017-80362\end{array}$

Patagial Colors (left wing/right wing)

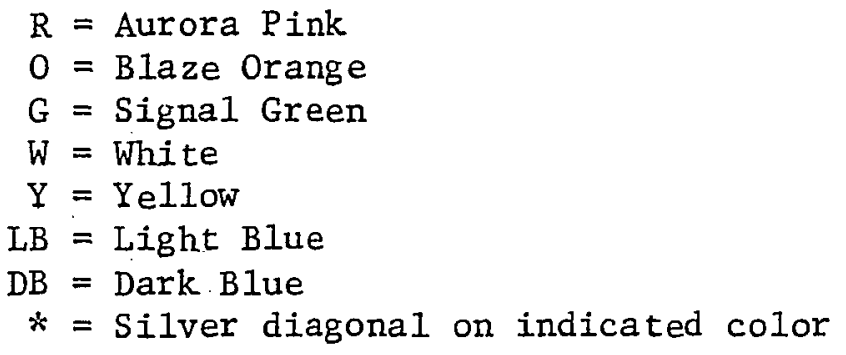




$\begin{array}{lll}\text { Nest Number: } & 27 & \text { Nest Name: Krumbo Valley } \\ \text { Habitat type: } \quad \text { Wetland } & \text { Nest type: Rimrock } \\ \text { Location: NE 1/4, Sec. 23, T30S, R31E }\end{array}$

1976

Date Banded: 5-20-76

Date Number Patagial Colors Federal Band No.

$\begin{array}{lllll}\text { Eggs } & 4-01-76 & 5 & \text { DB/DB } & 817-71698 \\ \text { Hatch } & 4-21-76 & 4 & \text { W/- } & 817-71699 \\ \text { Fledge } & 5-30-76 & 4 & -/ W & 817-71700 \\ & & & \text { G/W } & 776-57161\end{array}$

1977

Date Number Fledges not banded

$\begin{array}{lll}\text { Eggs } & 3-26-77 & 6 \\ \text { Hatch } & 4-16-77 & \mathrm{X} \\ \text { Fledge } & 5-26-77 & 4\end{array}$

Patagial Colors (left wing/right wing)

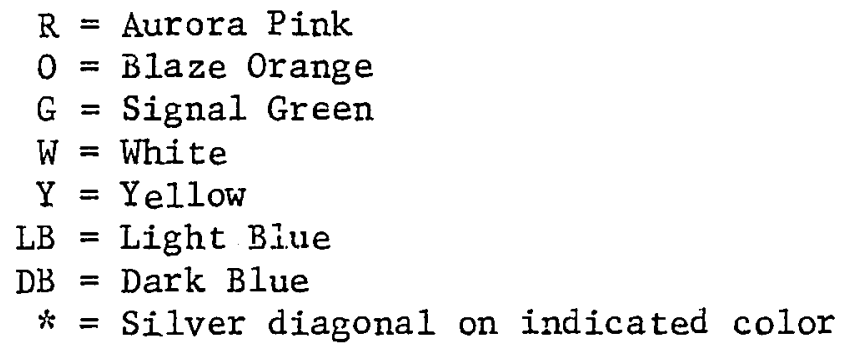




\author{
Nest Number: 28 Nest Name: Krumbo Dam \\ Habitat type: Wetland Nest type: Rimrock \\ Location: SW $1 / 4$, Sec: $19, \mathrm{~T} 30 \mathrm{~S}, \mathrm{R} 32 \mathrm{E}$
}

1976

\begin{tabular}{lcccc} 
& & \multicolumn{3}{c}{ Date Banded: } \\
& Date & Number & Patagial Colors & Federal Band No. \\
Eggs & $4-01-76$ & $\mathrm{X}$ & W/G & $776-57162$ \\
Hatch & $4-21-76$ & $\mathrm{X}$ & LB/W & $776-57163$ \\
Fledge & $5-30-76$ & 5 & W/LB & $776-57164$ \\
& & & DB/W & $776-57165$
\end{tabular}

1977

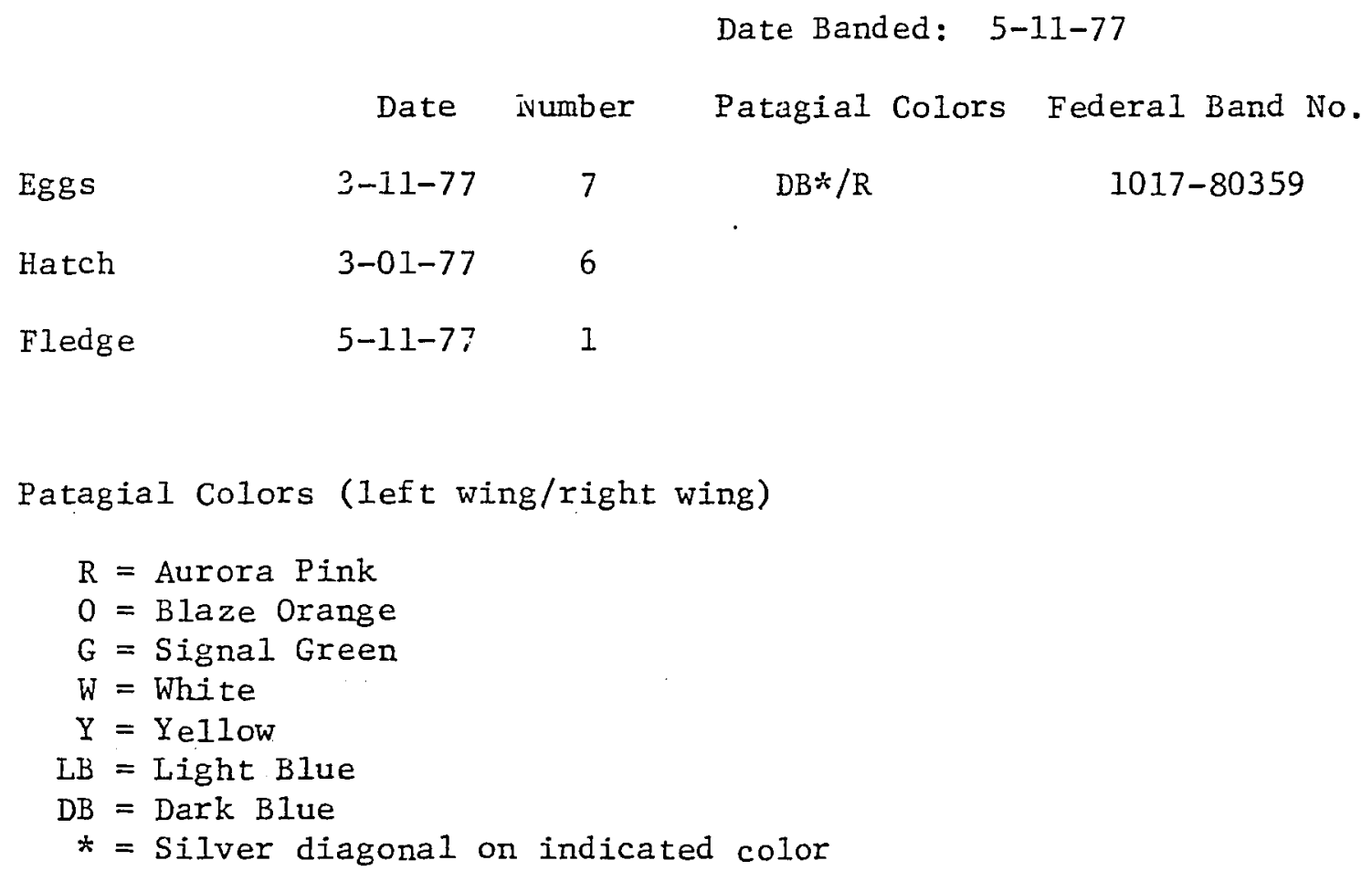




$\begin{array}{lrl}\text { Nest Number: } & 29 & \text { Nest Name: Boca Lake } \\ \text { Habitat type: Wetland } & \text { Nest type: Rimrock } \\ \text { Location: SW 1/4, Sec. 4, T3IS, R32 1/2E }\end{array}$

1976

$\begin{array}{lccc} & \text { Date } & \text { Number } & \\ \text { Eggs } & 4-20-76 & 3 & \text { Nest destroyed prior to } 5-20-76 \\ \text { Hatch } & 5-10-76 & 3 & \\ \text { Fledge } & - & 0 & \end{array}$

1977

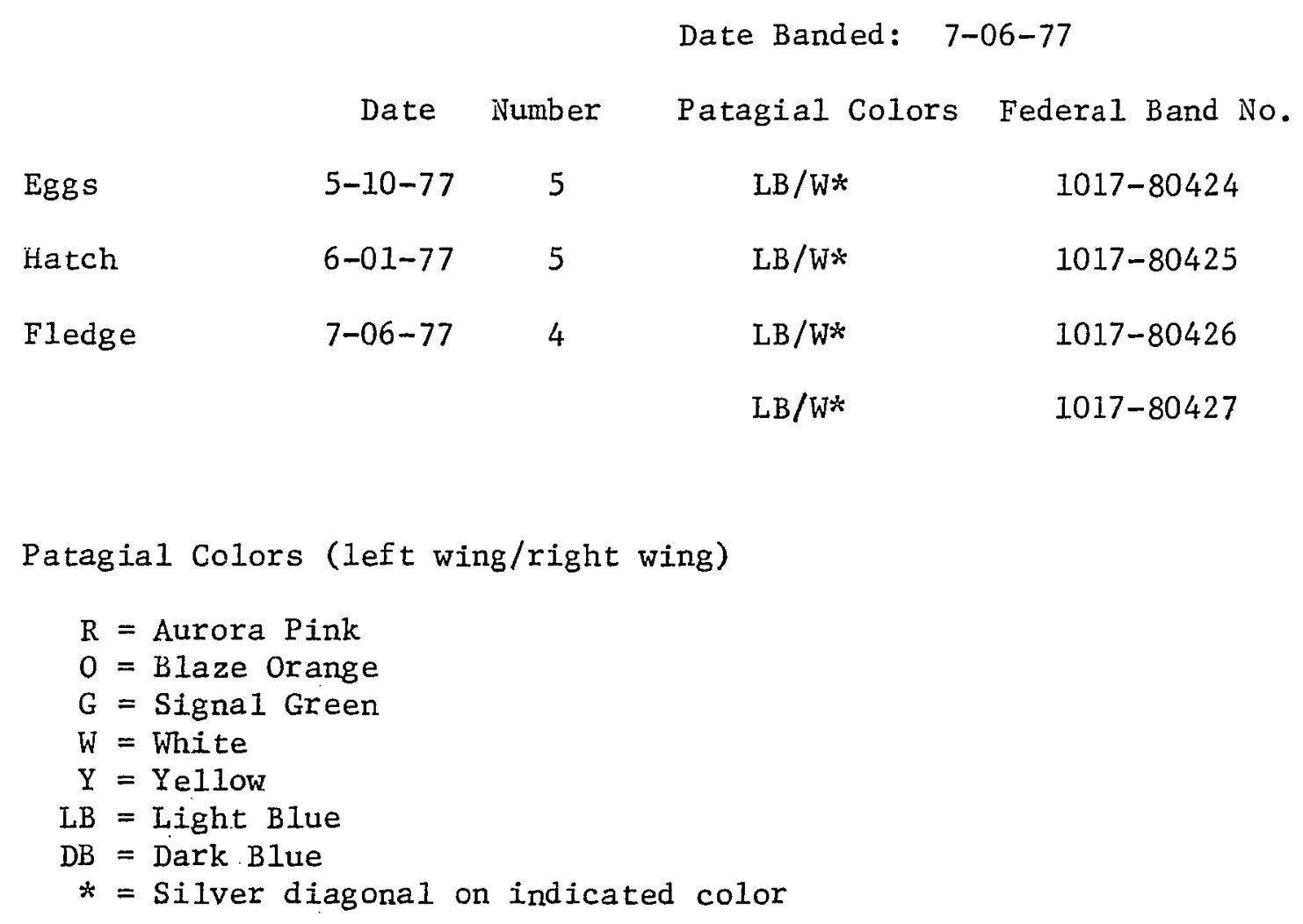


Nest Number: $\quad 30$

Nest Name: Boca East

Habitat type: Sagebrush Nest type: Rimrock

Location: $\mathrm{SW} 1 / 4, \mathrm{Sec}, 3, \mathrm{~T} 31 \mathrm{~S}, \mathrm{R} 32$ 1/2E

1976

Fledges not banded

Date Number

Eggs $\quad 3-16-76 \quad X$

Hatch 4-06-76 X

Fledge $\quad 5-16-76 \quad 1$

1977

Unused 
Nest Number:

Nest Name: Bridge Creek Field

Habitat type: Wetland

Nest type: Rimrock

Location: SE 1/4, Sec. 29, T31S, R32 1/2 E

1976

Nest occupied but inaccessable

1977

Unused 


\begin{tabular}{|c|c|c|c|c|}
\hline Nest Number: & \multicolumn{2}{|l|}{32} & \multirow{2}{*}{\multicolumn{2}{|c|}{$\begin{array}{l}\text { Nest Name: } \\
\text { Nest type: }\end{array}$}} \\
\hline Habitat type: & Wetland & & & \\
\hline Location: NE & 1/4, Sec. & $29, \mathrm{~T} 25 \mathrm{~S}$ & R33E & \\
\hline \multicolumn{5}{|l|}{1976} \\
\hline & & & Fledglings & not banded - nest \\
\hline & Date & Number & inaccess & able \\
\hline Eggs & -- & $\mathrm{X}$ & & \\
\hline Hatch & -- & $\mathrm{X}$ & & \\
\hline Fledge & -- & 1 & & \\
\hline
\end{tabular}

1977

Date Banded: 5-09-77

Date Number Patagial Colors Federal Band No.

$\begin{array}{lllll}\text { Eggs } & 3-10-77 & \mathrm{X} & \mathrm{LB} * / \mathrm{W} & 1017-80347 \\ \text { Hatch } & 4-01-77 & 5 & \mathrm{~L} B * / \mathrm{W} & 1017-80348 \\ \text { Fledge } & 5-09-77 & 2 & & \end{array}$

Patagial Colors (left wing/right wing)

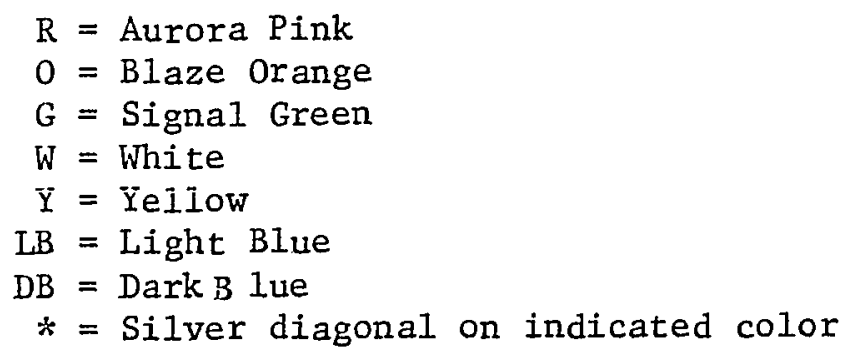


Nest Number: 33

Habitat type: Sagebrush-Road

Location: T25S, R31E

1976

\begin{tabular}{lcccc} 
& & \multicolumn{3}{c}{ Date Banded: } \\
& Date & Number & Patagial Colors & Federa1 Band No. \\
Eggs & $4-19-76$ & $\mathrm{X}$ & $\mathrm{Y} / \mathrm{-}$ & $1017-80215$ \\
Hatch & $5-10-76$ & 5 & $-/ \mathrm{Y}$ & $1017-80216$ \\
Fledge & $6-19-76$ & 5 & $\mathrm{Y} / \mathrm{Y}$ & $1017-80217$ \\
& & & $\mathrm{Y} / \mathrm{G}$ & $1017-80218$
\end{tabular}

1977

Unused

Patagial Colors (left wing/right wing)

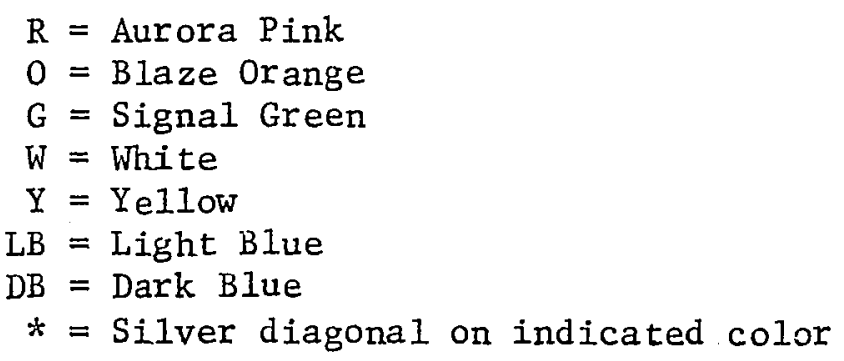




\begin{tabular}{|c|c|c|c|}
\hline Nest Number: & 34 & Nest Name: & Stone $C$ \\
\hline Habitat type: & Sagebrush & Nest type: & Rimrock \\
\hline
\end{tabular}

1976

\begin{tabular}{lcccc} 
& & \multicolumn{3}{c}{ Date Banded: 6-03-76 } \\
& Date & Number & Patagial Colors & Federa1 Band No. \\
Eggs & $4-03-76$ & $\mathrm{X}$ & $\mathrm{R} / \mathrm{LB}$ & $1017-80201$ \\
Hatch & $4-24-76$ & $\mathrm{X}$ & $\mathrm{R} / \mathrm{DB}$ & $1017-80202$ \\
Fledge & $6-03-76$ & 4 & $\mathrm{R} / \mathrm{W}$ & $1017-80203$
\end{tabular}

1977

Unused

Patagial Colors (left wing/right wing)

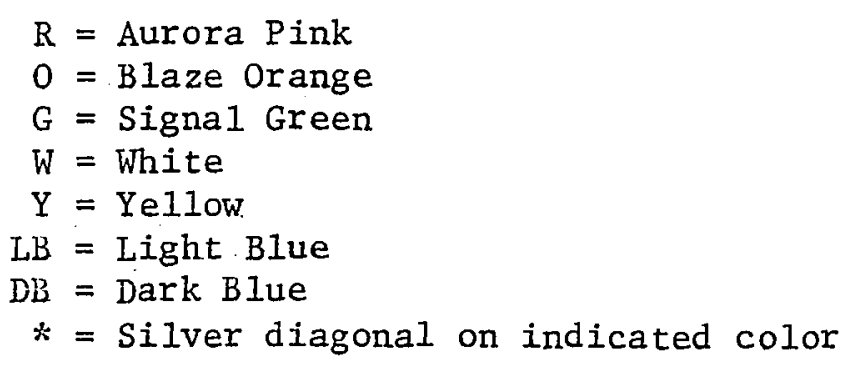


Nest Number: 35

Habitat type: Sagebrush

Location: T25S, R31E

1976

\begin{tabular}{lcccc} 
& & \multicolumn{3}{c}{ Date Banded: } \\
& Date & Number & Patagial Colors & Federal Band No. \\
Eggs & $4-08-76$ & $\mathrm{X}$ & $\mathrm{R} / 0$ & $1017-80204$ \\
Hatch & $4-29-76$ & $\mathrm{X}$ & $\mathrm{G} / \mathrm{R}$ & $1017-80205$ \\
Fledge & $6-08-76$ & 3 & LB/R & $1017-80206$
\end{tabular}

1977

Fledges not banded

Date Number

$\begin{array}{lll}\text { Eggs } & 4-02-77 & \mathrm{X} \\ \text { Hatch } & 4-23-77 & \mathrm{X} \\ \text { Fledge } & 6-02-77 & 6\end{array}$

Patagial Colors (left wing/right wing)

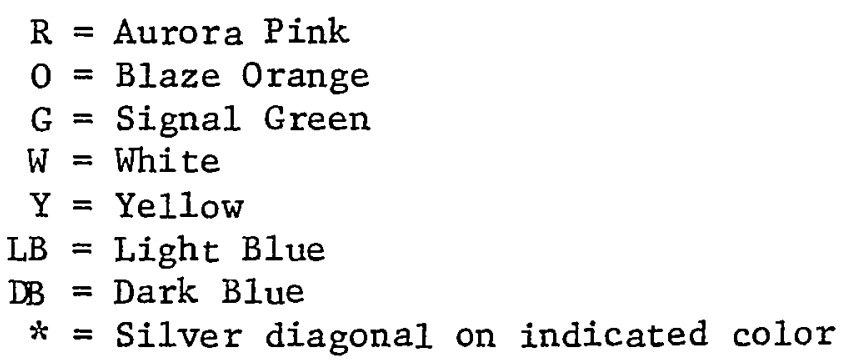




\begin{tabular}{|c|c|c|c|}
\hline Nest Number: & 36 & Nest Name: & House Field \\
\hline Habitat type: & Wetland & Nest type: & Rimrock \\
\hline
\end{tabular}

1976

Nest destroyed prior to $6-28-76$

$\begin{array}{cc}\text { Date } & \text { Number } \\ 5-12-76 & X \\ 6-02-76 & 4 \\ -- & 0\end{array}$

1977

Unused 


Nest Number: 41
Habitat type: Sagebrush
Location: Foot of Jack Creek

1977

\begin{tabular}{lcccc} 
& & \multicolumn{3}{c}{ Date Banded: 6-18-77 } \\
& Date & Number & Patagial Colors Federa1 Band No. \\
Eggs & $4-18-77$ & $\mathrm{X}$ & $\mathrm{G} / \mathrm{R}^{*}$ & $1017-80413$ \\
Hatch & $5-09-77$ & $\mathrm{X}$ & $\mathrm{G} / \mathrm{R}^{*}$ & $1017-80414$ \\
Fledge & $6-18-77$ & 3 & $G / R^{*}$ & $1017-80415$
\end{tabular}

Patagial Colors (left wing/right wing)

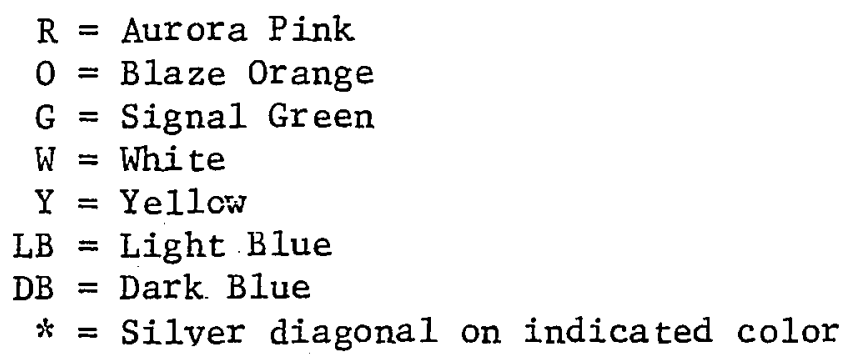


Nest Number: $\quad 42$

Habitat type: Wetland-Road

Location: SE 1/4, Sec. 32, T28S, R31E
Nest Name: Rimrock Field

Nest type: Rimrock

1976

Unused

1977

Nest destroyed prior to 5-19-77

Date Number

$\begin{array}{lcc}\text { Eggs } & 4-21-77 & 6 \\ \text { Hatch } & - & x \\ \text { Fledge } & - & 0\end{array}$


Nest Number: $\quad 43$

Nest Name: East Grain Camp

Habitat type: Wetland-Road Nest type: Rimrock

Location: SW 1/4, Sec. 13, T29S, R31E

1976

\begin{tabular}{lcccc} 
& & \multicolumn{3}{c}{ Date Banded: 6-11-76 } \\
& Date & Number & Patagial Colors & Federal Band No. \\
Eggs & $4-15-76$ & $\mathrm{X}$ & $\mathrm{DB} / \mathrm{R}$ & $1017-80207$ \\
Hatch & $5-06-76$ & 4 & $\mathrm{~W} / \mathrm{R}$ & $1017-80208$ \\
Fledge & $6-15-76$ & 3 & $0 / \mathrm{R}$ & $1017-80209$
\end{tabular}

1977

Unused

Patagial Colors (left wing/right wing)

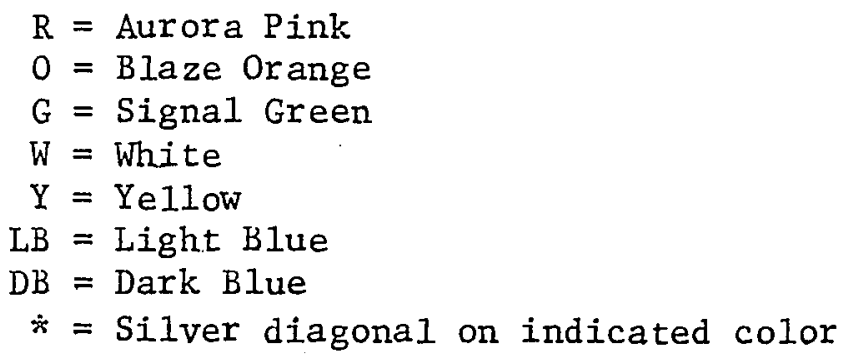




$\begin{array}{ll}\text { Nest Number: } 44 a & \text { Nest Name: Larson Field } \\ \text { Habitat type: } \quad \text { Wetland } & \text { Nest type: Rimrock } \\ \text { Location: SW 1/4, Sec. 14, T29S, R31E }\end{array}$

1976

Date Banded: 7-02-76

Date Number Patagial Colors Federal Band No.

$\begin{array}{lllll}\text { Eggs } & 5-07-76 & \mathrm{X} & \mathrm{R} / \mathrm{Y} & 1017-80237 \\ \text { Hatch } & 5-28-76 & 3 & \mathrm{Y} / \mathrm{W} & 1017-80238 \\ \text { Fledge } & 7-07-76 & 3 & \mathrm{~W} / \mathrm{Y} & 1017-80239\end{array}$

1977

$\begin{array}{llc} & & \text { Nest destroyed prior to } 4-21-77 \\ & \text { Date } & \text { Number } \\ \text { Eggs } & 3-16-77 & 6 \\ \text { Hatch } & 4-07-77 & 4 \\ \text { Fledge } & -- & 0\end{array}$

Patagial Colors (left wing/right wing)

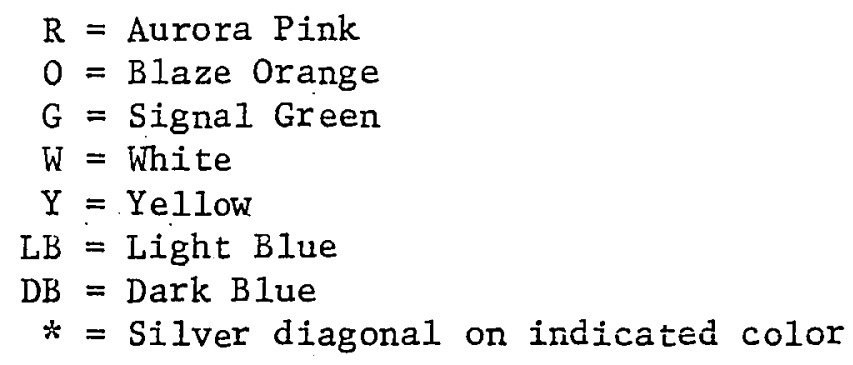




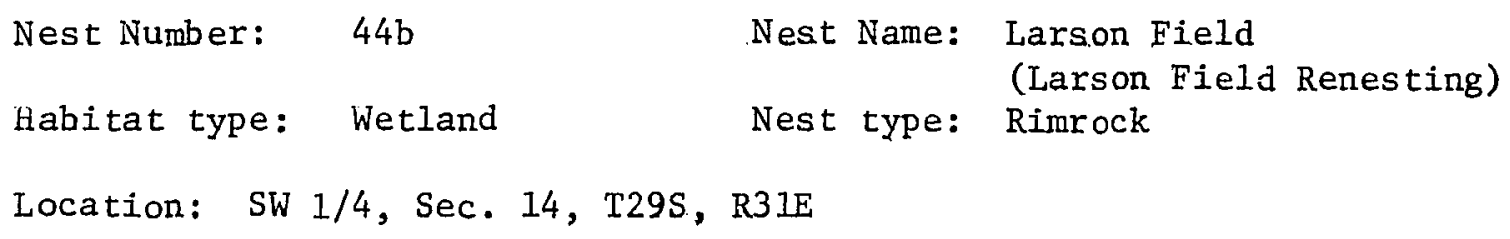

Nest Number: $\quad 44 b$

Nest Name: Larson Field

Habitat type: Wetland

(Larson Field Renesting)

Nest type: Rimrock

Location: SW 1/4, Sec. 14, T29S, R31E

1976

See Nest $44 a$

1977

Nest destroyed prior to 5-19-77

$\begin{array}{lcc} & \text { Date } & \text { Number } \\ \text { Eggs } & 4-19-77 & 5 \\ \text { Hatch } & 5-09-77 & 4 \\ \text { Fledge } & -- & 0\end{array}$




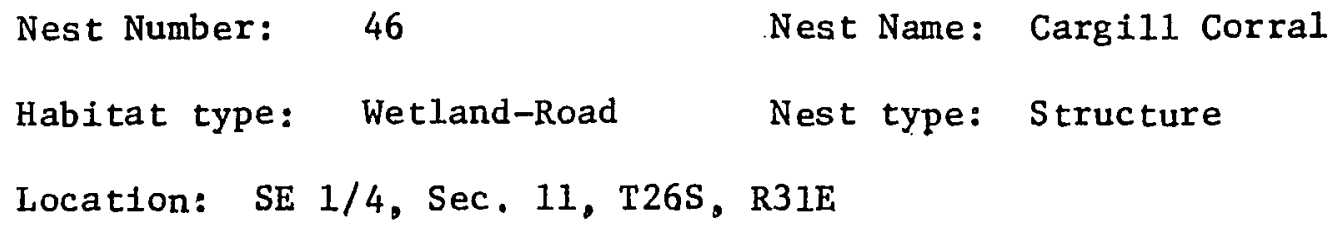

1976

Nest destroyed prior to 6-25-76

$\begin{array}{lcc} & \text { Date } & \text { Number } \\ \text { Eggs } & 4-25-76 & \mathrm{X} \\ \text { Hatch } & 5-16-76 & 2 \\ \text { Fledge } & -- & 0\end{array}$

1977

Nest destroyed prior to 6-01-77

Date Number

$\begin{array}{lcc}\text { Eggs } & 5-05-77 & 5 \\ \text { Hatch } & -- & X \\ \text { Fledge } & -- & 0\end{array}$


Nest Number: $48 \quad$ Nest Name: Big Red S

Habitat type: Sagebrush-Road Nest type: Structure

Location: $\mathrm{SE} 1 / 4$, Sec. 20, T25S, R32E

1976

Nest occupied but inaccessable. All young destroyed prior to fledge.

1977

Nest occupied but inaccessable. All young destroyed prior to fledge. 
Nest Number: 51

Nest Name: Hog Wallow Seeding 非

Habitat type: Sagebrush

Nest type: Rimrock

Location: NW 1/4, Sec. 2, T30S, R32E

1976

Da te Number

Eggs $\quad 4-15-76 \quad X$

Hatch 5-06-76 X

Fledge $\quad 6-15-76 \quad 4^{2}$

1977

Nest location moved

$\begin{array}{lcc} & \text { Date } & \text { Number } \\ \text { Eggs } & -- & \mathrm{X} \\ \text { Hatch } & - & \mathrm{X} \\ \text { Fledge } & -- & 5^{\mathrm{a}}\end{array}$

a Nest not located prior to fledge 
Nest Number: 52

Nest Name: West Grain Camp

Habitat type: Sagebrush-Road Nest type: Rimrock

Location: SW 1/4, Sec. 23, T29S, R31E

1976

U nused

1977

Nest occupied but inaccessable. A11 eggs destroyed prior to 4-12-77 
Nest Number: 53 Nest Name: Unit 8 Pond

Habitat type: Wetland-Road Nest type: Rimrock

Location: SE 1/4, Sec. 29, T29S, R31E

1976

Unused

1977

Date Banded: 5-31-77

Date Number Patagial Colors Federal Band No.

$\begin{array}{lllll}\text { Eggs } & 4-06-77 & 6 & \text { G/DB* } & 1017-80390\end{array}$

$\begin{array}{lllll}\text { Hatch } & 4-27-77 & 6 & \mathrm{G} / \mathrm{DB} * & 1017-80391\end{array}$

$\begin{array}{lllll}\text { Fledge } & 6-06-77 & 6 & \mathrm{G} / \mathrm{DB} * & 1017-80392\end{array}$

G/DB* $\quad 1017-80393$

$\mathrm{G} / \mathrm{DB} * \quad 1017-80394$

$\mathrm{G} / \mathrm{DB} * \quad 1017-80395$

Patagial Colors (left wing/right wing)

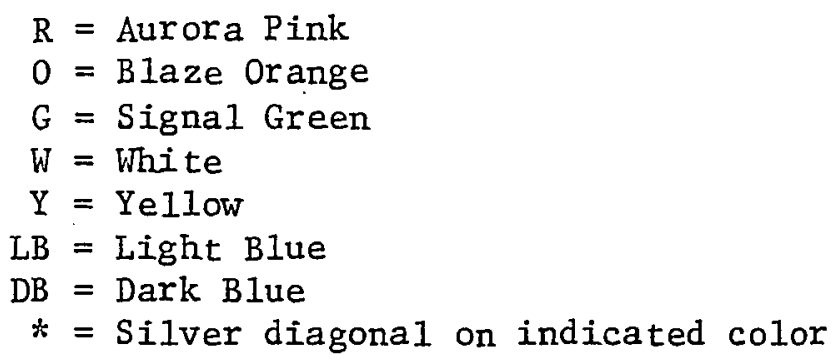




$\begin{array}{lrl}\text { Nest Number: } & 55 & \text { Nest Name: } \\ \text { Habitat Type: } & \text { Sagebrush } & \text { Nest type: Rimrock } \\ \text { Location: SW 1/4, Sec. 12, T25S, R32 } 1 / 2 \mathrm{E}\end{array}$

1976

Unused

1977

Occupied but inaccessable 


\author{
Nest Number: $56 \quad$ Nest Name: Kirk House \\ Habitat type: Wetland Nest type: Building \\ Location: NW 1/4, Sec. 28, T26S, R31E
}

1976

Date Number

$\begin{array}{lll}\text { Eggs } & - & \mathrm{X} \\ \text { Hatch } & - & \mathrm{X} \\ \text { Fledge } & - & 4^{7}\end{array}$

1977

Date Banded: 5-27-77

Date Number Patagial Colors Federal Band No.

$\begin{array}{lllll}\text { Eggs } & 4-01-77 & X & G / L B^{*} & 1017-80381 \\ \text { Hatch } & 4-21-77 & X & G / L B^{*} & 1017-80382 \\ \text { Fledge } & 5-31-77 & 4 & G / L B^{*} & 1017-80383 \\ & & & G / L B^{*} & 1017-80384\end{array}$

$a=$ Nest not located prior to fledge

Patagial Colors (left wing/right wing)

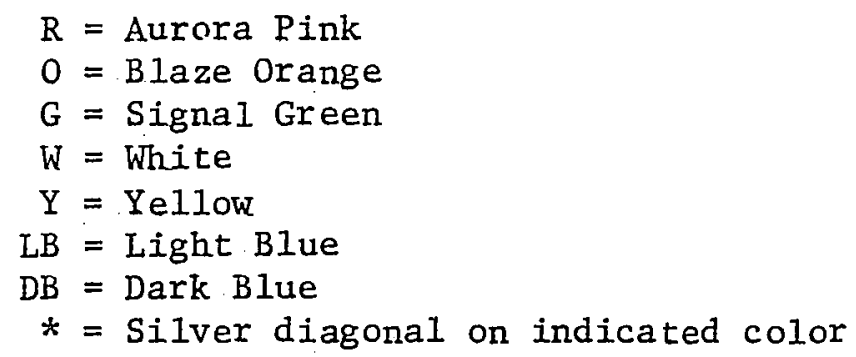




\author{
Nest Number: $\quad 58$ \\ Nest Name: South Harney Lake \\ Habitat type: Sagebrush-Road Nest type: Rimrock \\ Location: $\mathrm{SE} 1 / 4, \mathrm{Sec}, 25 \mathrm{~T} 27 \mathrm{~S}, \mathrm{R} 29 \mathrm{E}$
}

1976

Unused

1977

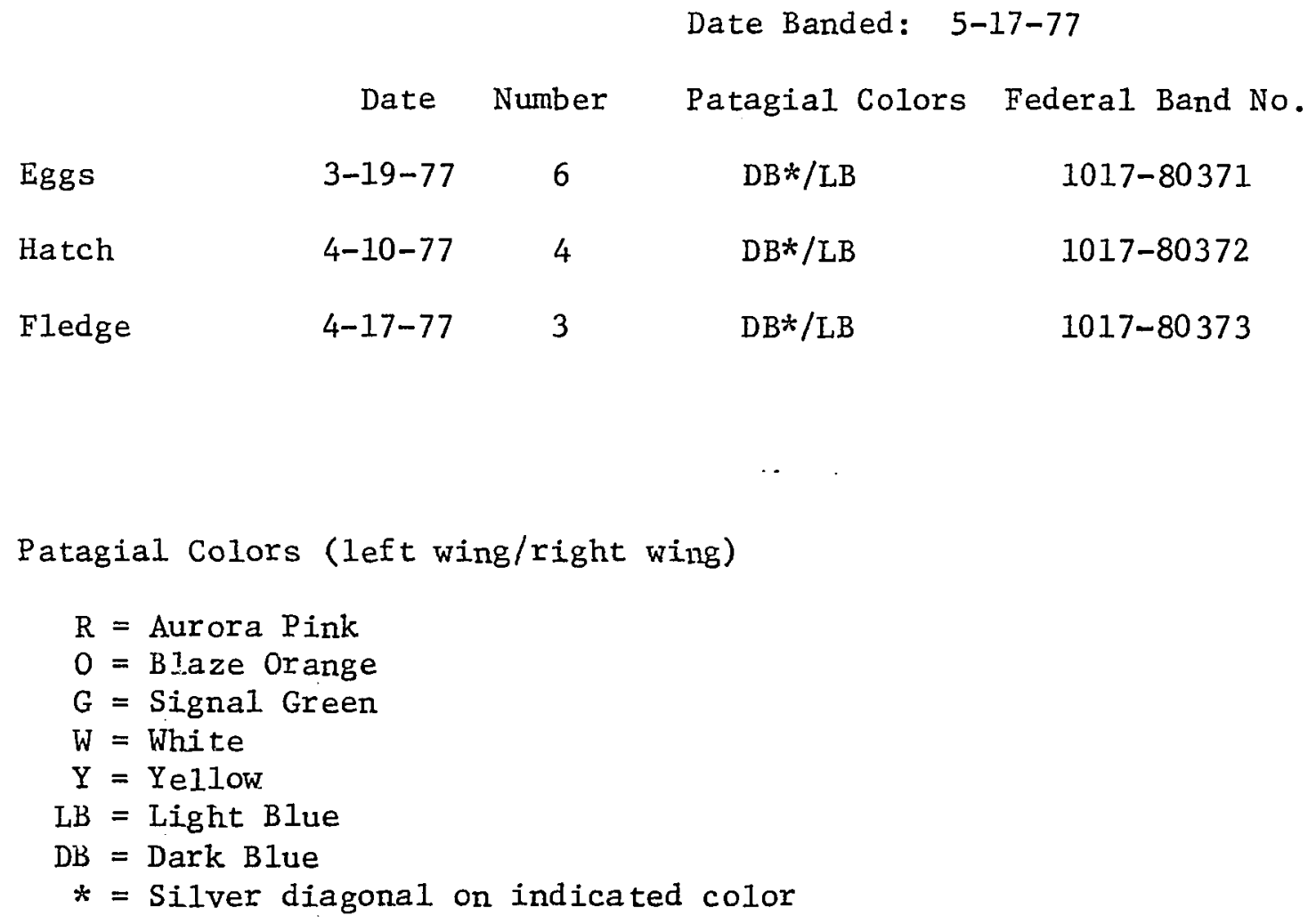




\author{
Nest Number: 59 Nest Name: Eagle's.Nest \\ Habitat type: Sagebrush Nest type: Rimrock \\ Location: NW 1/4, Sec. 10, T27S, R30E
}

1976

Unused

1977

Date Banded: 5-26-77

Date Number Patagial Colors Federal Band No.

$\begin{array}{lllll}\text { Eggs } & 3-27-77 & 6 & \mathrm{DB} * / \mathrm{DB} & 1017-80374 \\ \text { Hatch } & 4-16-77 & 4 & \mathrm{DB} * / \mathrm{DB} & 1017-80375 \\ \text { Fledge } & 5-26-77 & 2 & & \end{array}$

Patagial Colors (left wing/right wing)

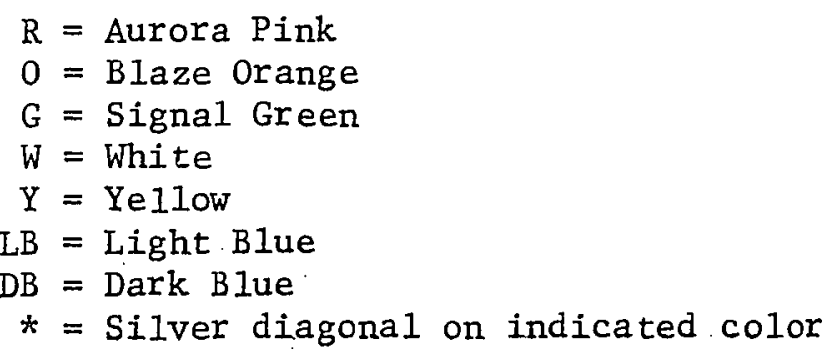




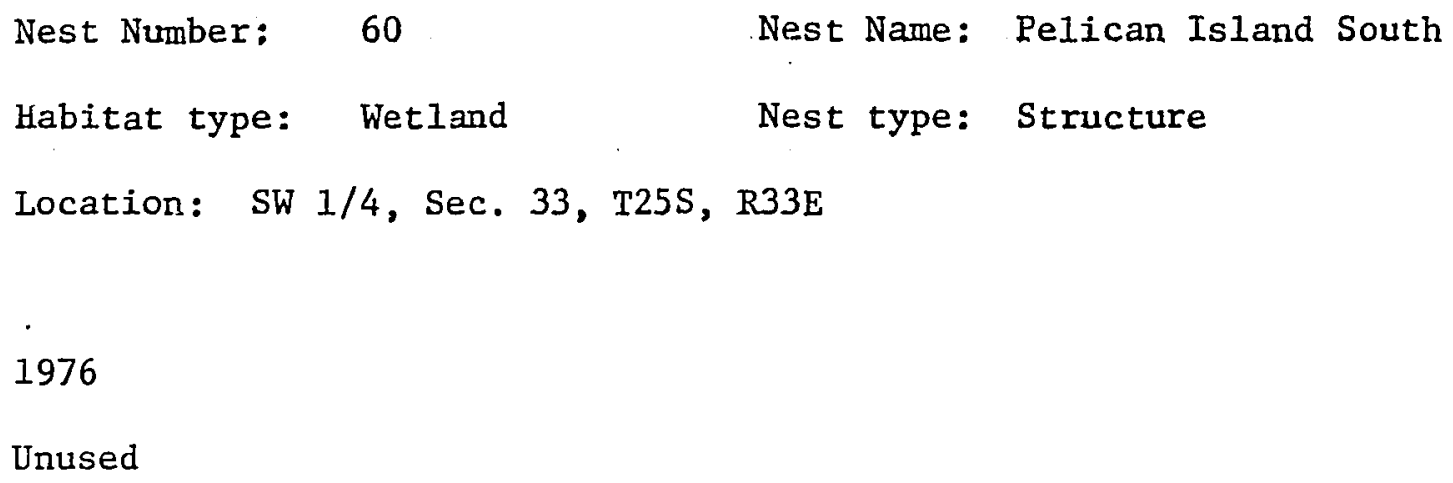

1977

Nest destroyed prior to 5-09-77

$$
\text { Date Number }
$$

$\begin{array}{lcc}\text { Eggs } & 3-25-77 & 6 \\ \text { Hatch } & - & \mathrm{X} \\ \text { Fledge } & -- & 0\end{array}$


APPENDIX B

FOOD ANALYSIS OF NESTING RAVEN PAIRS 
Nest iNumber:

Habitat type: Wetland

Total number of records:

Total number of food items:

Total number of collections:
1 Nest Name: Rock Island Field

Nest type: Rimrock

57

6

$\%$

Rank \% Water-

\begin{tabular}{|c|c|c|c|c|c|c|c|c|c|c|}
\hline Items & 1 & 2 & 3 & 4 & 5 & $T^{a}$ & Total & Occur ${ }^{\mathrm{b}}$ & fow $1^{c}$ & Food Score $\mathrm{d}^{\mathrm{d}}$ \\
\hline Egg & 2 & 3 & & 1 & & 1 & 7 & 12.3 & 14.2 & 6.3 \\
\hline Avian Pts & 15 & 6 & & & & & 21 & 36.8 & 0 & 43.2 \\
\hline Mamnal & 18 & 3 & 3 & 1 & & & 25 & 43.8 & & 47.0 \\
\hline Reptile & & 1 & 2 & & & & 3 & 5.3 & & 1.9 \\
\hline Fish & & & & & & & 0 & 0 & & 0 \\
\hline Insect & & & & & & & 0 & 0 & & 0 \\
\hline Vegetation & 1 & & & & & & 1 & 1.8 & & 1.7 \\
\hline Total & 36 & 13 & 5 & 2 & 0 & 1 & 57 & & & \\
\hline
\end{tabular}




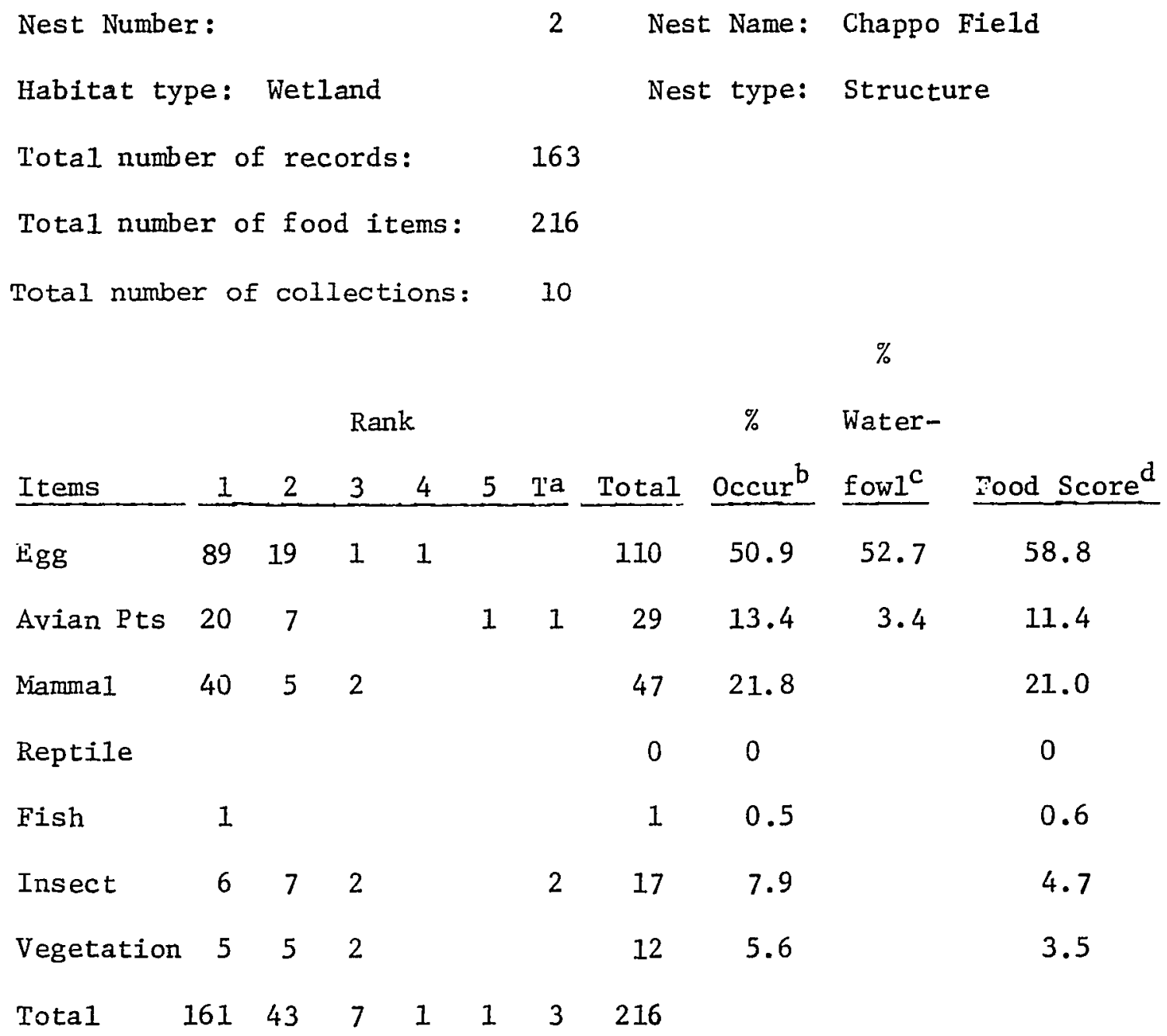

\footnotetext{
a Trace item (less than 1\%)

b (Specific item total/Total food items) $x 100$

c Minimum percent of item derived from waterfowl species

d Weighted value of item (see text)
} 


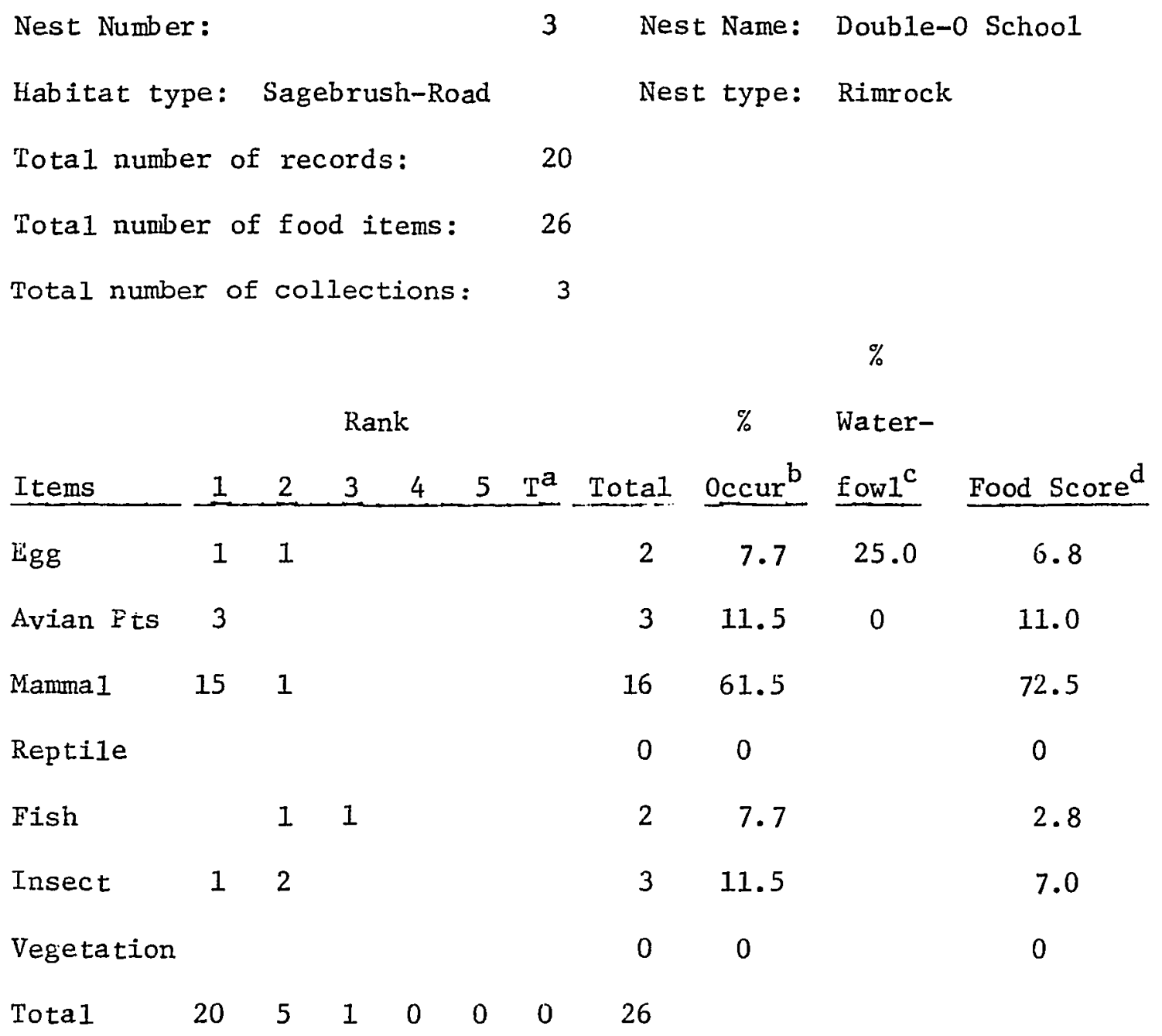

\footnotetext{
a Trace item (less than 1\%)

b (Specific item total/Total food items) $\times 100$

c Minimum percent of item derived from waterfow1 species

d Weighted value of item (see text)
} 


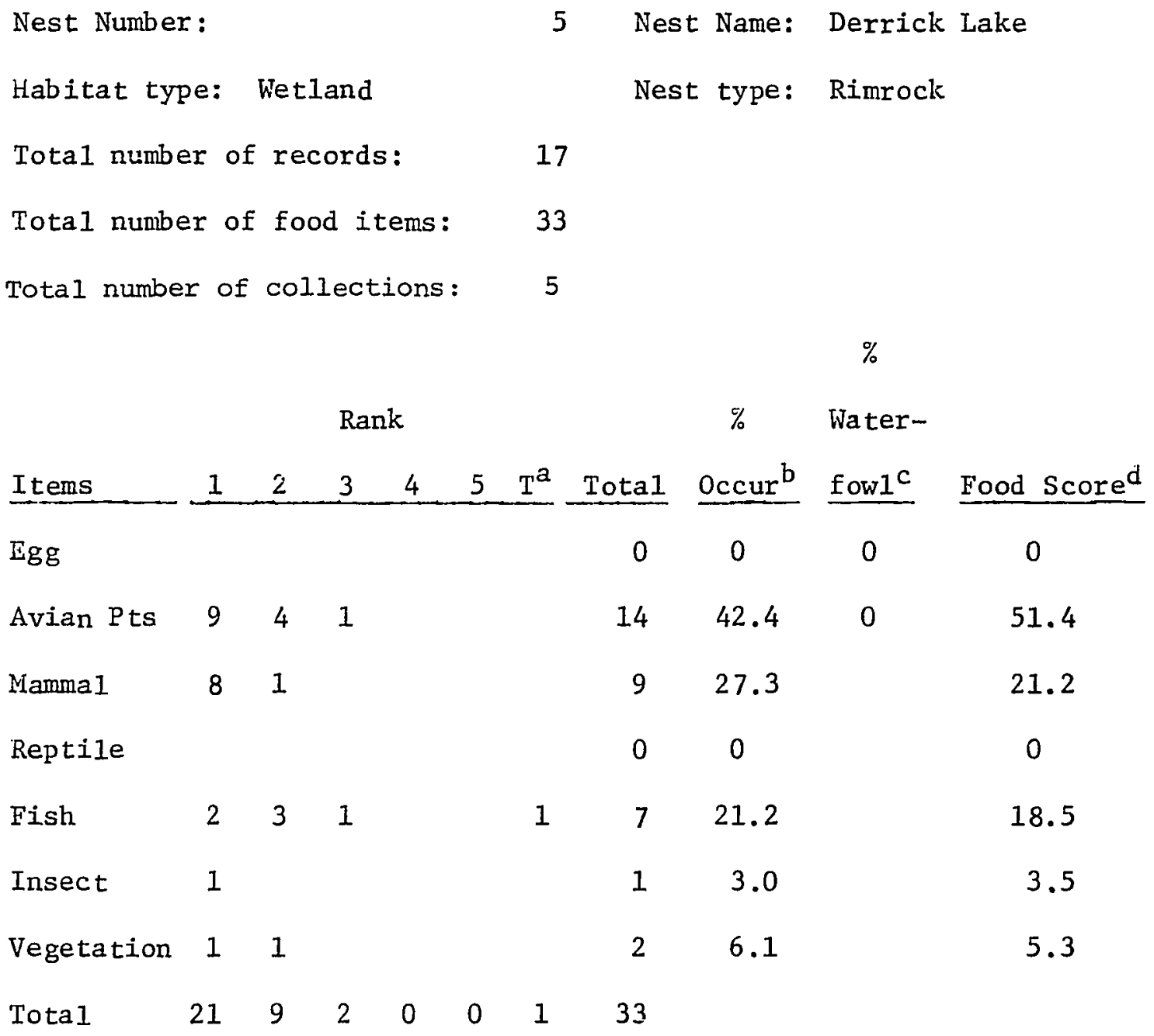

\footnotetext{
a Trace item (less than 1\%)

b (Specific item total/Iotal food items) $\times 100$

c Minimum percent of item derived from wateriow 1 species

d Weighted value of item (see text)
} 


\begin{tabular}{|c|c|c|c|c|c|c|c|c|c|c|c|}
\hline Nest Numbe & & & & & & 6 & Nes & t Name: & Mar tha & Lake & \\
\hline Habitat ty & pe: & Wet & and & & & & Nes & t type: & Rimrock & & \\
\hline Total numb & er o & E $r e$ & ord & & & 18 & & & & & \\
\hline Total numb & er o & E fo & $d i$ & ems & & 27 & & & & & \\
\hline Total numbe & & $c 0$ & lec & Lons & & 3 & & & & & \\
\hline & & & & & & & & & $\%$ & & \\
\hline & & & hia & & & & & $\%$ & Water- & & \\
\hline Items & 1 & 2 & 3 & 4 & 5 & $\mathrm{~T}^{\mathrm{a}}$ & Tota 1 & Occur $^{b}$ & fow $1^{c}$ & Food & Score \\
\hline Egg & & 4 & 1 & & & & 5 & 18.5 & 80.0 & & 9.7 \\
\hline Avian Pts & 13 & 2 & & & & & 15 & 55.6 & 6.7 & & 55.3 \\
\hline Mamma1 & 5 & & & & & & 5 & 18.5 & & & 17.2 \\
\hline Reptile & & & & & & & 0 & 0 & & & 0 \\
\hline Fish & 1 & & & & & & 1 & 3.7 & & & 5.6 \\
\hline Insect & & & & 1 & & & 1 & 3.7 & & & 2.2 \\
\hline Vegetation & & & & & & & 0 & 0 & & & 0 \\
\hline Tota1 & 19 & $\ddot{6}$ & 1 & 1 & 0 & 0 & 27 & & & & \\
\hline
\end{tabular}

\footnotetext{
a Trace item (1ess than 1\%)

b (Specific item total/Total food items) $\times 100$

c Minimum percent of item derived from waterfowl species

d Weighted value of item (see text)
} 


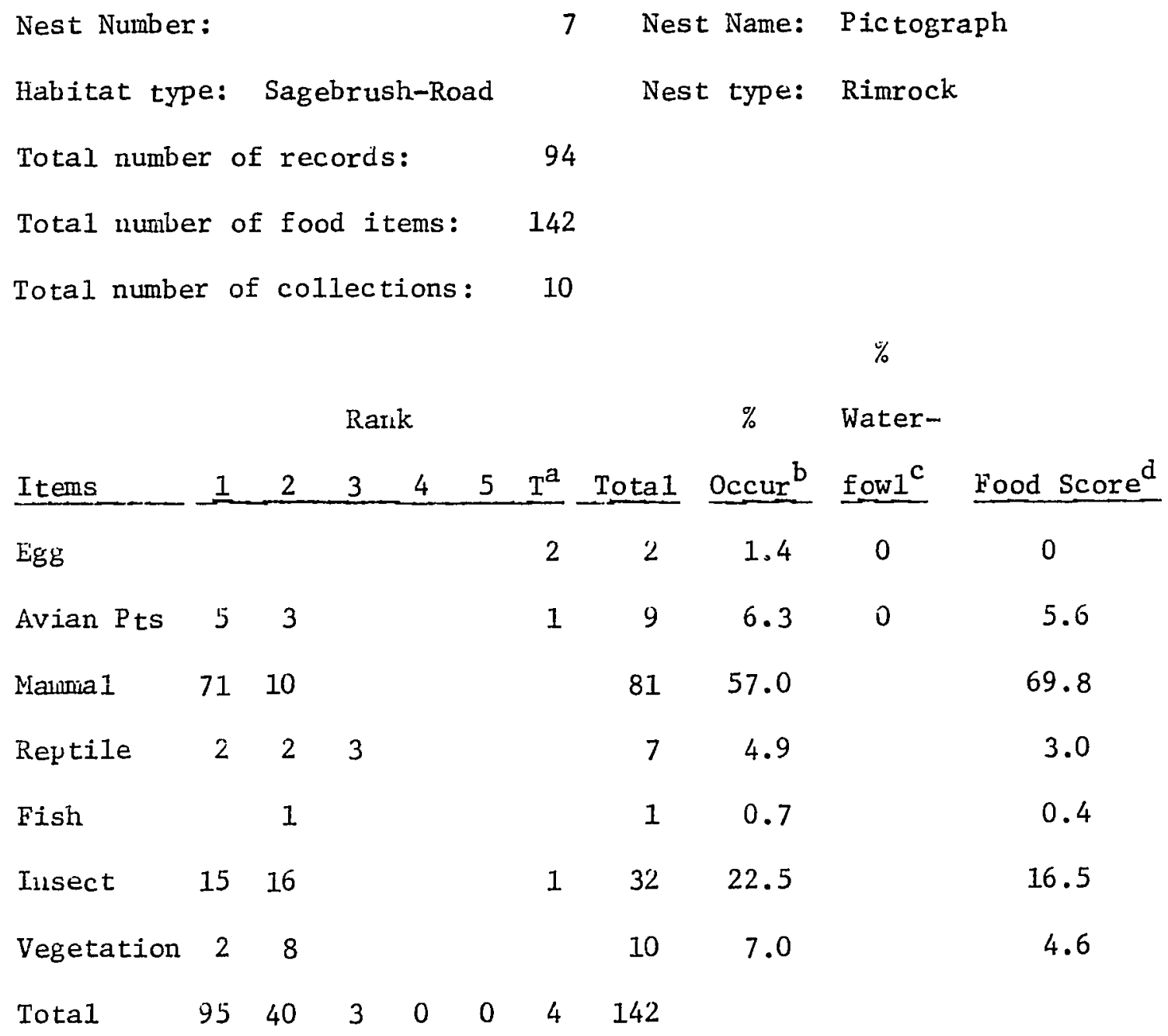

\footnotetext{
a Trace item (less than 1\%)

b (Specific item total/Total food items) $\times 100$

c Minimum percent of item derived from wateríowl species

d Weighted value of item (see text)
} 
$\begin{array}{lr}\text { Nest Number: } & 9 \\ \text { Habitat type: Wetland } & \\ \text { Total number of records: } & 123 \\ \text { Total number of food items: } & 246 \\ \text { Total number of collections: } & 8\end{array}$

9 Nest Name: Gibson House

Nest type: Building

Total numer of collections: 8

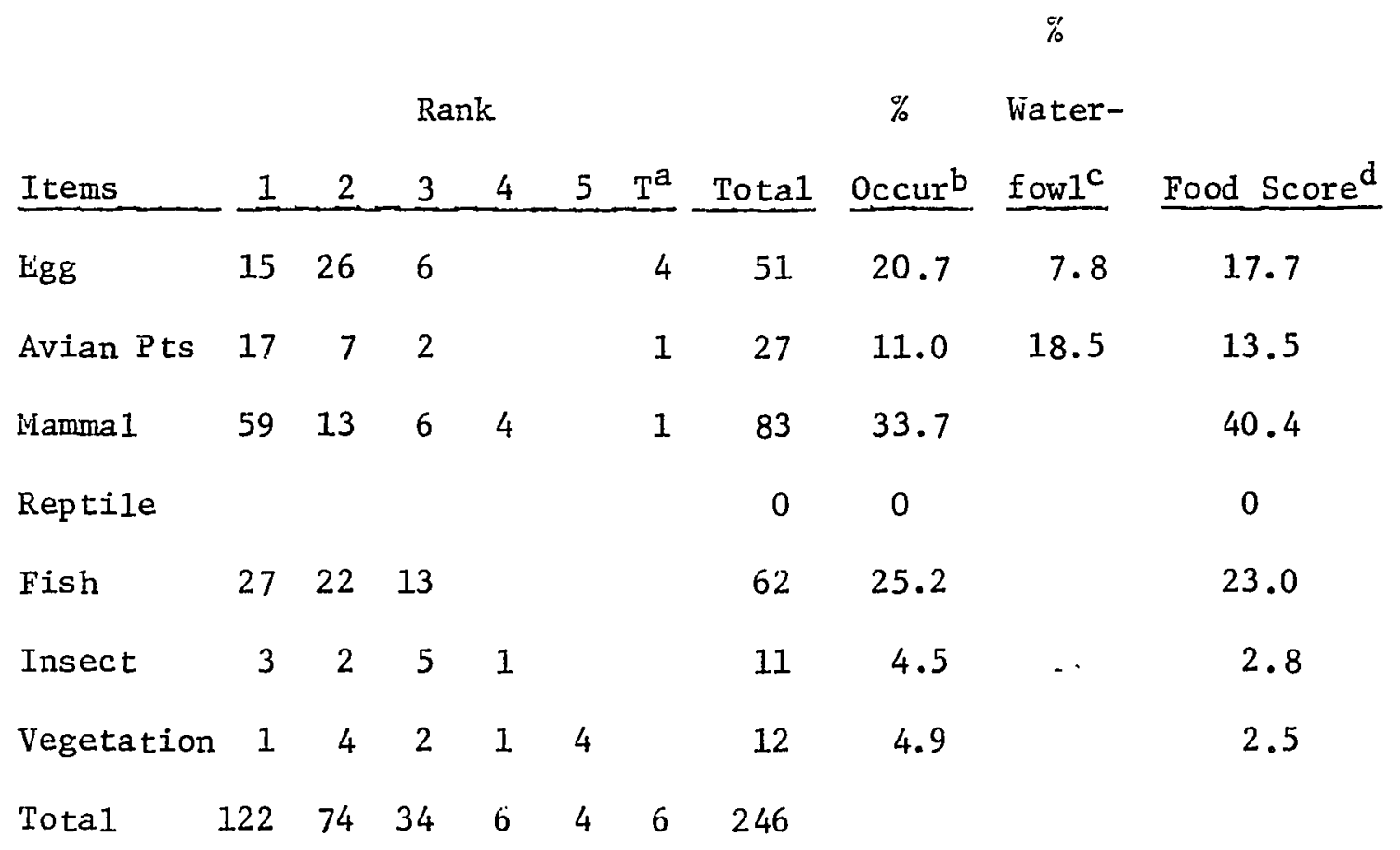

\footnotetext{
a Trace item (less than 1\%)

b (Specific item tota1/Total food items) $\times 100$

c Minimum percent of item derived from waterfowl species

d Weighted value of item (see text)
} 
Nest Number:

Habitat type: Wetland

Total number of records:

Tota1 number of food items: 103

Total number of collections:
55

4
10

Nest Name: Baccus Lake

Nest type: Building

\begin{tabular}{|c|c|c|c|c|c|c|c|c|c|c|}
\hline \multirow[b]{2}{*}{ Items } & \multirow[b]{2}{*}{1} & \multirow[b]{2}{*}{2} & \multicolumn{2}{|c|}{ Rank } & \multirow[b]{2}{*}{5} & \multirow[b]{2}{*}{$\mathrm{T}^{\mathrm{a}}$} & \multirow[b]{2}{*}{ Total } & \multirow{2}{*}{$\begin{array}{c}\% \\
\text { Occurb } \\
\end{array}$} & \multirow{2}{*}{$\begin{array}{l}\text { Water- } \\
\text { fowlc } \\
\end{array}$} & \multirow[b]{2}{*}{ Food Score } \\
\hline & & & 3 & 4 & & & & & & \\
\hline E'gg & 6 & 2 & 4 & & & 1 & 13 & 12.6 & 0 & 10.3 \\
\hline Avian Pts & 6 & 2 & 2 & & & & 10 & 9.7 & 10.0 & 9.5 \\
\hline Mamma I & 34 & 7 & 3 & 1 & & & 45 & 43.7 & & 54.3 \\
\hline Reptile & & & & & & & 0 & 0 & & 0 \\
\hline Fisin & 7 & 16 & 3 & 2 & & & 28 & 27.2 & & 20.9 \\
\hline Insect & 2 & 1 & 1 & 1 & & & 5 & 4.9 & & 4.0 \\
\hline Vegetation & & 1 & 1 & & & & 2 & 1.9 & & 1.0 \\
\hline Tota1 & 55 & 29 & 14 & 4 & 0 & 1 & 103 & & & \\
\hline
\end{tabular}

\footnotetext{
a Trace item (less than $1 \%$ )

b (Specific item total/Total food items) $\times 100$

c Minimum percent of item derived from waterfowl species

d Weighted value of item (see text)
} 


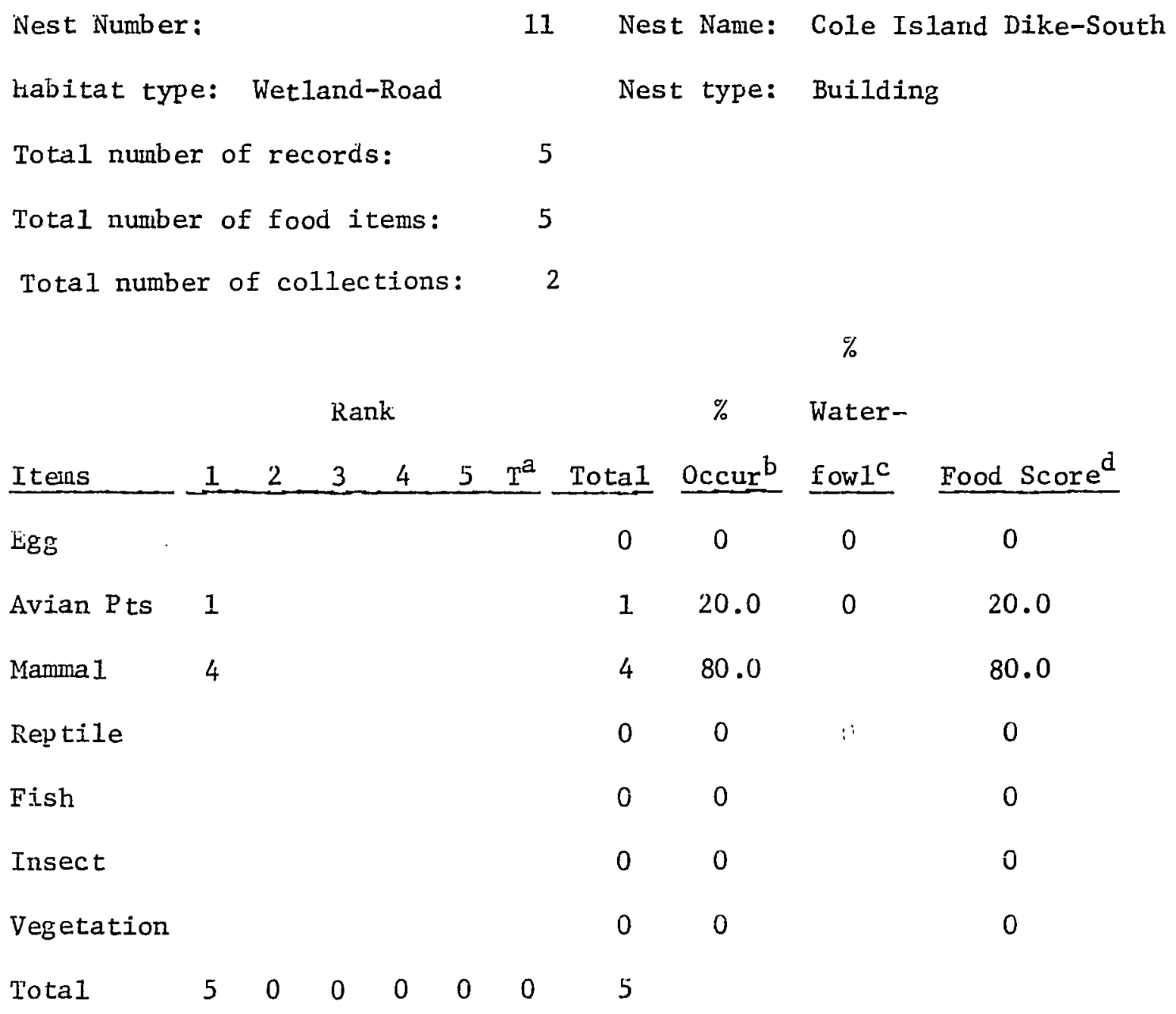

\footnotetext{
a Trace item (less than $1 \%$ )

b (Specific item total/Total food items) $\times 100$

c Minimum percent of item derived from waterfowl species

d Weighted value of item (see text)
} 


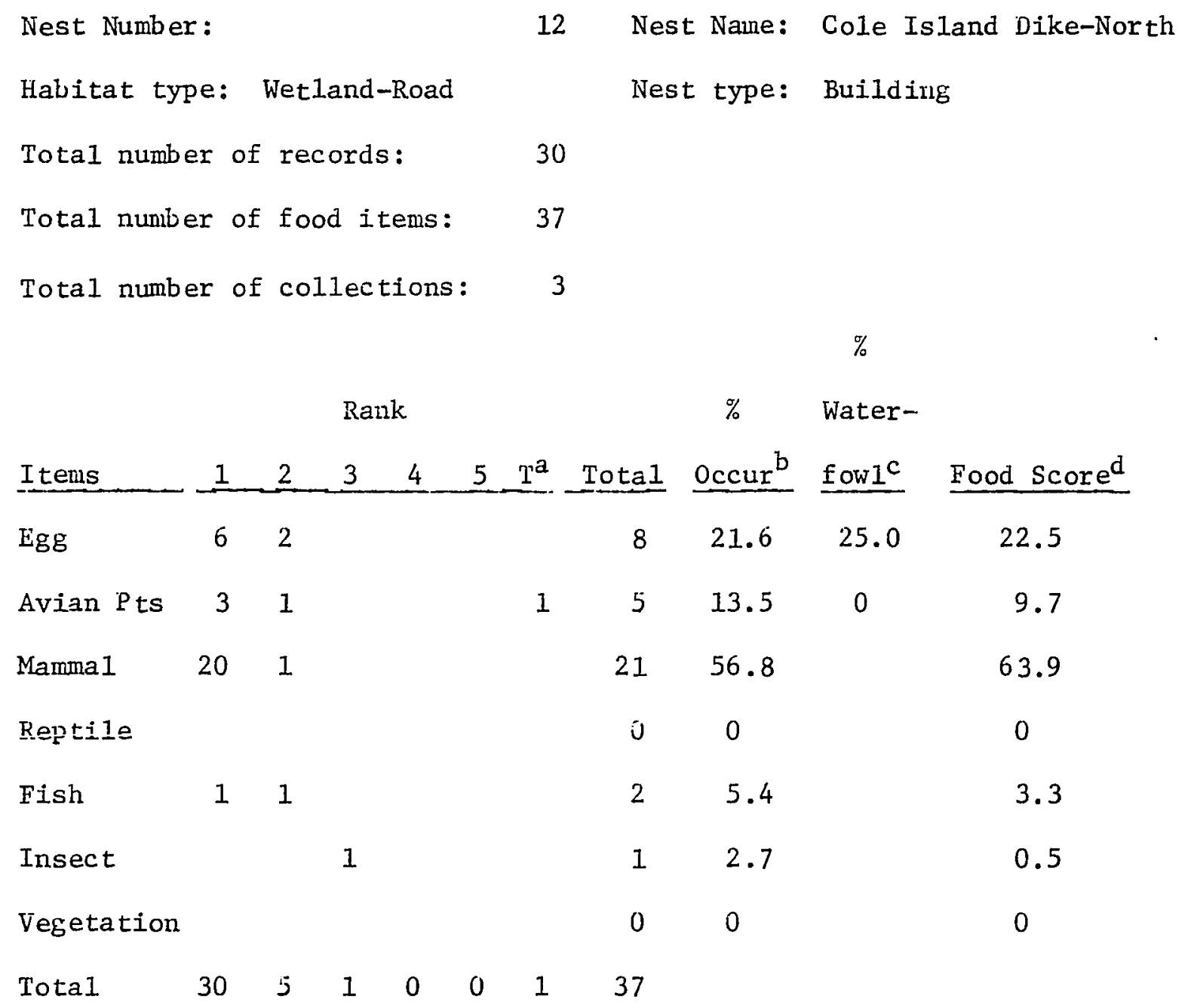

\footnotetext{
a Trace item (less than 1\%)

b (Specific item total/Total food items) $x 100$

c Minimum percent of item derived from waterfowl species

d Weighted value of item (see text)
} 
Nest Number:

Habitat type: Sagebrush-Road

Total number of records:

Total number of food items: 145

Total number of collections: 10
13 Nest Name: Blacky Corner

Nest type: Rimrock
86

$$
0
$$

\begin{tabular}{|c|c|c|c|c|c|c|c|c|c|c|}
\hline \multirow[b]{2}{*}{ Items } & \multicolumn{6}{|c|}{ Rank } & & $\%$ & $\begin{array}{c}\% \\
\text { Water- }\end{array}$ & \\
\hline & 1 & 2 & 3 & 4 & 5 & $\mathrm{~T}^{\mathrm{a}}$ & Total & Occurb & fow $1^{c}$ & Food Score \\
\hline Egg & 1 & 2 & 3 & & & & 6 & 4.1 & 0 & 2.8 \\
\hline Avian Pts & 14 & 9 & 2 & 1 & & & 26 & 17.9 & 7.7 & 16.6 \\
\hline Mamma I & 61 & 16 & 5 & 1 & & 1 & 84 & 57.9 & & 66.4 \\
\hline Reptile & 2 & & & & & & 2 & 1.4 & & 1.9 \\
\hline Fish & 2 & 1 & 1 & & & & 4 & 2.8 & & 1.8 \\
\hline Insect & 8 & 6 & 5 & & & 2 & 21 & 14.5 & & 10.0 \\
\hline Vegetation & & 1 & 1 & & & & 2 & 1.4 & & 0.6 \\
\hline Tota1 & 88 & 35 & 17 & 2 & 0 & 3 & 145 & & & \\
\hline
\end{tabular}

\footnotetext{
a Trace item (less than $1 \%$ )

b (Specific item total/Total food items) $x 100$

c Minimum percent of item derived from waterfowl species

d Weighted value of item (see text)
} 


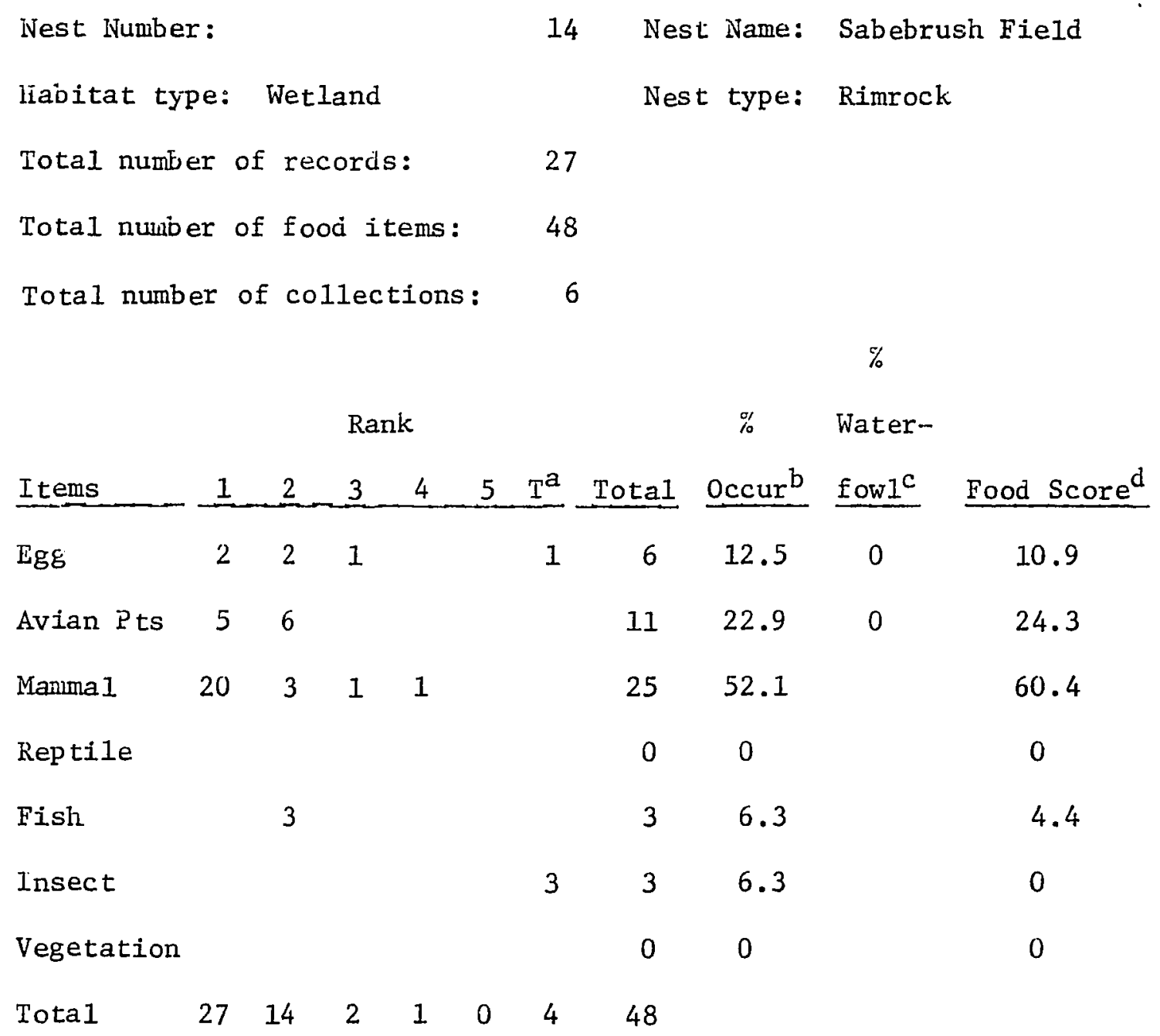

\footnotetext{
a Trace item (less than 1\%)

b (Specific item total/Total food items) $\times 100$

c Minimum percent of item derived from waterfowl species

d Weighted value of item (see text)
} 
Nest Number:

Hiabitat type: Sagebrush-Road

Total number of records:

Total number of food items: 66

Total number of collections: 7
59
15 Nest Name: Davies Ranch .

Nest type: Rimrock

\begin{tabular}{|c|c|c|c|c|c|c|c|c|c|c|}
\hline \multirow[b]{2}{*}{ Items } & \multicolumn{6}{|c|}{ Rank } & \multirow[b]{2}{*}{ Total } & \multirow{2}{*}{$\begin{array}{c}\% \\
\text { Occur } b \\
\end{array}$} & \multirow{2}{*}{$\begin{array}{l}\text { Water- } \\
\text { fow }{ }^{c}\end{array}$} & \multirow[b]{2}{*}{ Food Scored } \\
\hline & 1 & 2 & 3 & 4 & 5 & $T^{a}$ & & & & \\
\hline Egg & & & & & & & 0 & 0 & 0 & 0 \\
\hline Avian Pts & 1 & & & & & & 1 & 1.5 & 0 & 1.7 \\
\hline Mamma 1 & 57 & 3 & & & & & 60 & 90.9 & & 94.5 \\
\hline Reptile & 1 & 1 & & & & 1 & 3 & 4.5 & & 2.4 \\
\hline Fish & & & & & & & 0 & 0 & & 0 \\
\hline Insect & & 2 & & & & & 2 & 3.0 & & 1.4 \\
\hline Vegetation & & & & & & & 0 & 0 & & 0 \\
\hline Tota1 & 59 & 6 & 0 & 0 & 0 & 1 & 66 & & & \\
\hline
\end{tabular}

a Trace item (less than 1\%)

b (Specific item total/Total food itens) $\times 100$

c Minimum percent of item derived from waterfowl species

d Weighted value of item (see text) 


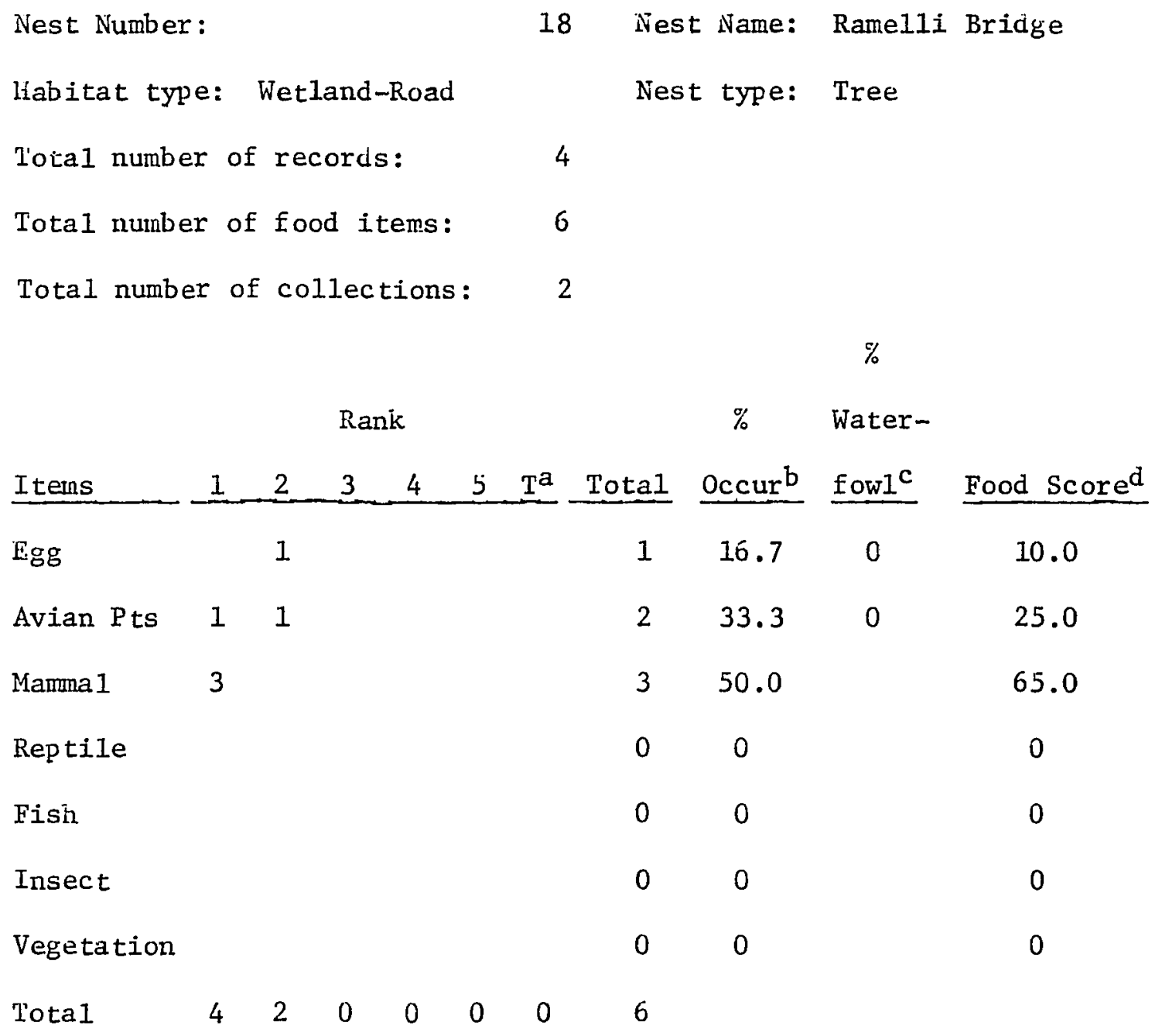

\footnotetext{
a Trace item (less than $1 \%$ )

b (Specific item total/Total food items) $\times 100$

c Minimum percent of item derived from waterfowl species

d Weighted value of item (see text)
} 


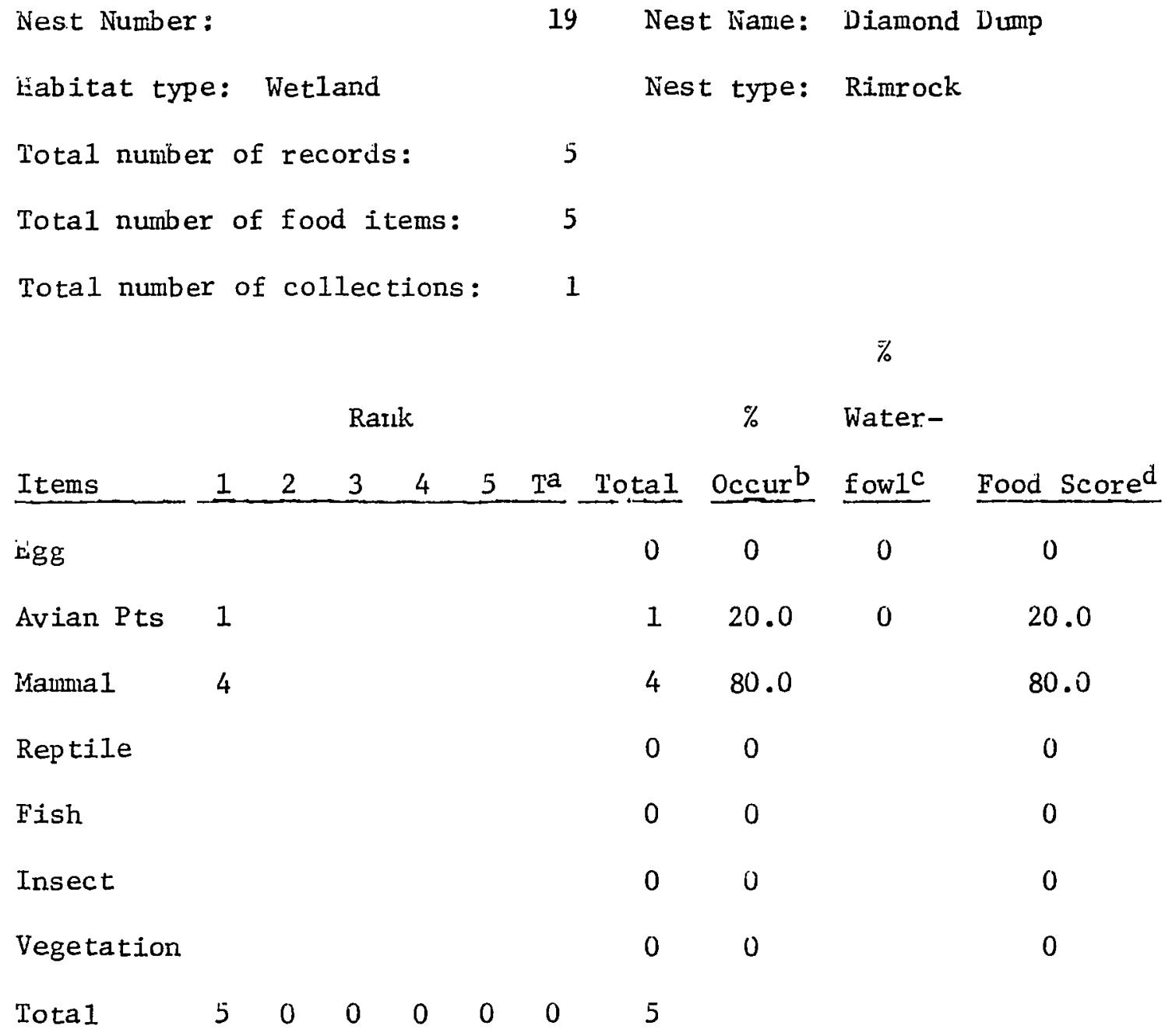

\footnotetext{
a Trace item (less than $1 \%$ )

b (Specific item total/Total food items) $\times 100$

c Minimum percent of item derived from waterfow1 species

d Weighted value of item (see text)
} 


\begin{tabular}{|c|c|c|c|c|c|c|c|c|c|c|}
\hline Nest Numbe & & & & & & 20 & Nes & t Name: & Diamond & Point-Ditch \\
\hline Habitat ty & pe: & Wet & and & & & & Nes & t type: & Rimrock & \\
\hline Total numb & er o & & ord & & & 22 & & & & \\
\hline Tota1 numb & er o & & $d i$ & ems & & 23 & & & & \\
\hline Total numb & er & & $1 e c$ & ior & & & & & & \\
\hline & & & & & & & & & $\%$ & \\
\hline & & & $\mathrm{Ra}$ & & & & & $\%$ & Water- & \\
\hline Items & 1 & 2 & 3 & 4 & 5 & $\mathrm{~T}^{\mathrm{a}}$ & Tota1 & Occur ${ }^{b}$ & fow $1^{c}$ & Food Score ${ }^{d}$ \\
\hline Egg & 18 & & & & & & 18 & 78.3 & 94.4 & 81.8 \\
\hline Avian Pts & & 1 & & & & & 1 & 4.3 & 0 & 1.8 \\
\hline Niamma1 & 4 & & & & & & 4 & 17.4 & & 16.3 \\
\hline Reptile & & & & & & & 0 & 0 & & 0 \\
\hline Fish & & & & & & & 0 & 0 & & 0 \\
\hline Insect & & & & & & & 0 & 0 & & 0 \\
\hline Vegetation & & & & & & & 0 & 0 & & 0 \\
\hline tal & 22 & 1 & 0 & 0 & 0 & 0 & 23 & & & \\
\hline
\end{tabular}

\footnotetext{
a 'i'race item (less than $1 \%$ )

b (Specific item total/Total food itens) $\times 100$

c linimum percent of item derived from waterfowl species

d Weighted value of item (see text)
} 


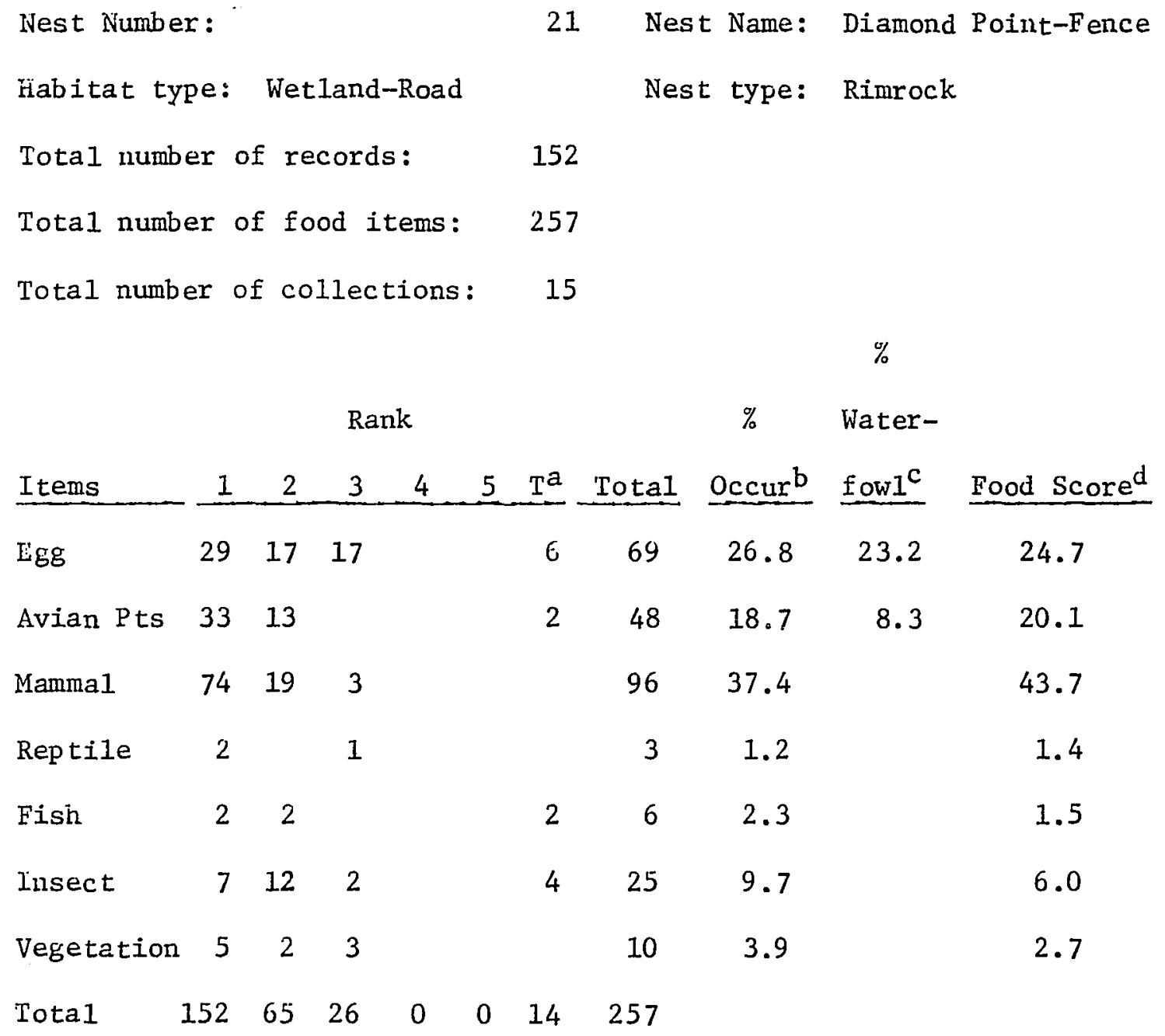

\footnotetext{
a Trace item (less than $1 \%$ )

b (Specific item total/Total food items) $\times 100$

c Minimum percent of item derived from waterfow1 species

d Weighted value of item (see text)
} 
$\begin{array}{lr}\text { Nest Number: } & 23 \\ \text { Kabitat type: Wetland-Road } & \\ \text { Total number of records: } & 75 \\ \text { Total nunber of food items: } & 105 \\ \text { Total number of collections: } & 6\end{array}$

$\%$

\begin{tabular}{|c|c|c|c|c|c|c|c|c|c|c|}
\hline \multirow[b]{2}{*}{ Items } & \multicolumn{6}{|c|}{ Rank } & \multirow{2}{*}{\multicolumn{2}{|c|}{$\begin{array}{c}\% \\
\text { Tota1 0ccur b } \\
\end{array}$}} & \multirow{2}{*}{$\begin{array}{l}\text { Water- } \\
\text { fow }{ }^{\mathrm{c}}\end{array}$} & \multirow[b]{2}{*}{ Food Scored } \\
\hline & 1 & 2 & 3 & 4 & 5 & $\mathrm{~T}^{\mathrm{a}}$ & & & & \\
\hline ¿gg & 30 & 4 & 3 & & & 1 & 38 & 36.2 & 13.2 & 42.2 \\
\hline Avian Pts & 11 & 2 & 1 & & & & 14 & 13.3 & 14.3 & 12.7 \\
\hline Mamma1 & 30 & 4 & & & & & 34 & 32.4 & & 35.2 \\
\hline Reptile & & & & & & & 0 & 0 & & 0 \\
\hline Fisin & 1 & 3 & & & & 3 & 7 & 6.7 & & 2.9 \\
\hline Insect & 1 & 5 & & & & & 6 & 5.7 & & 3.1 \\
\hline Vegetation & 2 & 3 & 1 & & & & 6 & 5.7 & & 3.9 \\
\hline Total & 75 & 21 & 5 & 0 & 0 & 4 & 105 & & & \\
\hline
\end{tabular}

\footnotetext{
a Trace item (less than 1\%)

b (Specific item total/Total food items) $\times 100$

c Minimum percent of item derived from waterfowl species

d Weighted value of item (see text)
} 


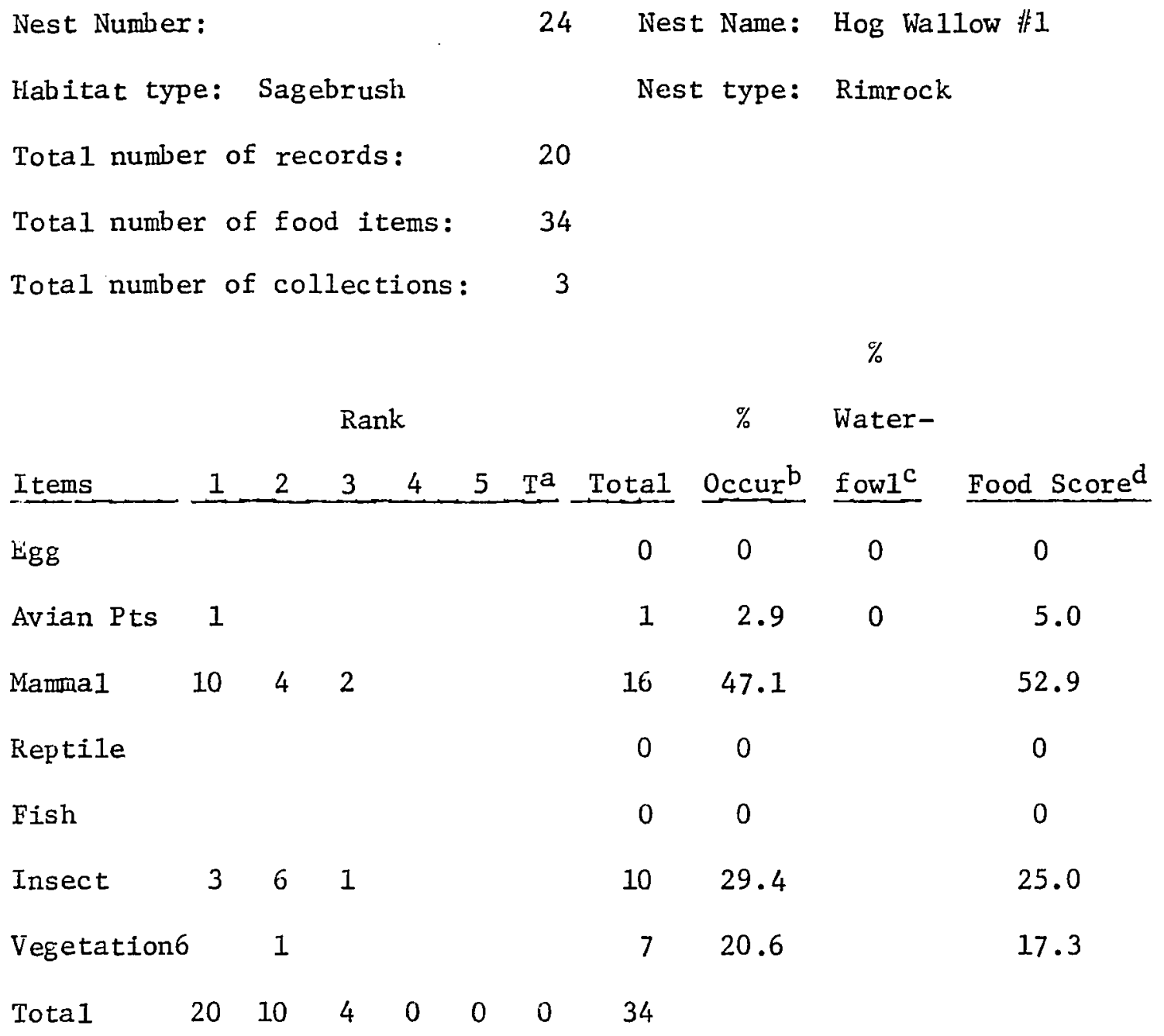

\footnotetext{
a Trace item (less than $1 \%$ )

b (Specific item total/Total food items) $\times 100$

c Minimum percent of item derived from waterfowl species

d Weighted value of item (see text)
} 
iNest Number:

Habitat type: Wetland-Road
25 Nest Name: Rock Crusher Point Nest type: Rimrock

'Total number of recoras:

Total number of food items:

31

Total number of collections:

\begin{tabular}{|c|c|c|c|c|c|c|c|c|c|c|}
\hline \multirow[b]{2}{*}{ Items } & \multirow[b]{2}{*}{1} & \multirow[b]{2}{*}{2} & \multicolumn{4}{|c|}{ Rank } & \multirow[b]{2}{*}{ Total } & \multirow{2}{*}{$\begin{array}{c}\% \\
\text { Occurb } \\
\end{array}$} & \multirow{2}{*}{$\begin{array}{l}\text { Water- } \\
\text { fow }{ }^{\mathrm{c}}\end{array}$} & \multirow[b]{2}{*}{ Food Scored } \\
\hline & & & 3 & 4 & 5 & $\mathrm{~T}^{\mathrm{a}}$ & & & & \\
\hline Egg & 1 & 1 & & & & & 2 & 6.5 & 0 & 3.8 \\
\hline Avian $P$ ts & 4 & 2 & & & & & 6 & 19.4 & 16.7 & 16.9 \\
\hline Mamuna 1 & 20 & & & & & & 20 & 64.5 & & 72.0 \\
\hline Reptile & & 1 & & & & & 1 & 3.2 & & 1.5 \\
\hline Fish & 1 & 1 & & & & & 2 & 6.5 & & 5.4 \\
\hline Insect & & & & & & & 0 & 0 & & 0 \\
\hline Vegetation & & & & & & & 0 & 0 & & 0 \\
\hline Totaly & 26 & 5 & 0 & 0 & 0 & 0 & 31 & & & \\
\hline
\end{tabular}

\footnotetext{
a Trace iteni (less tiran 1\%)

b (Specific item tota1/Total food items) $\times 100$

c Mirimum percent of item derived from waterfowl species

d Weighted value of item (see text)
} 


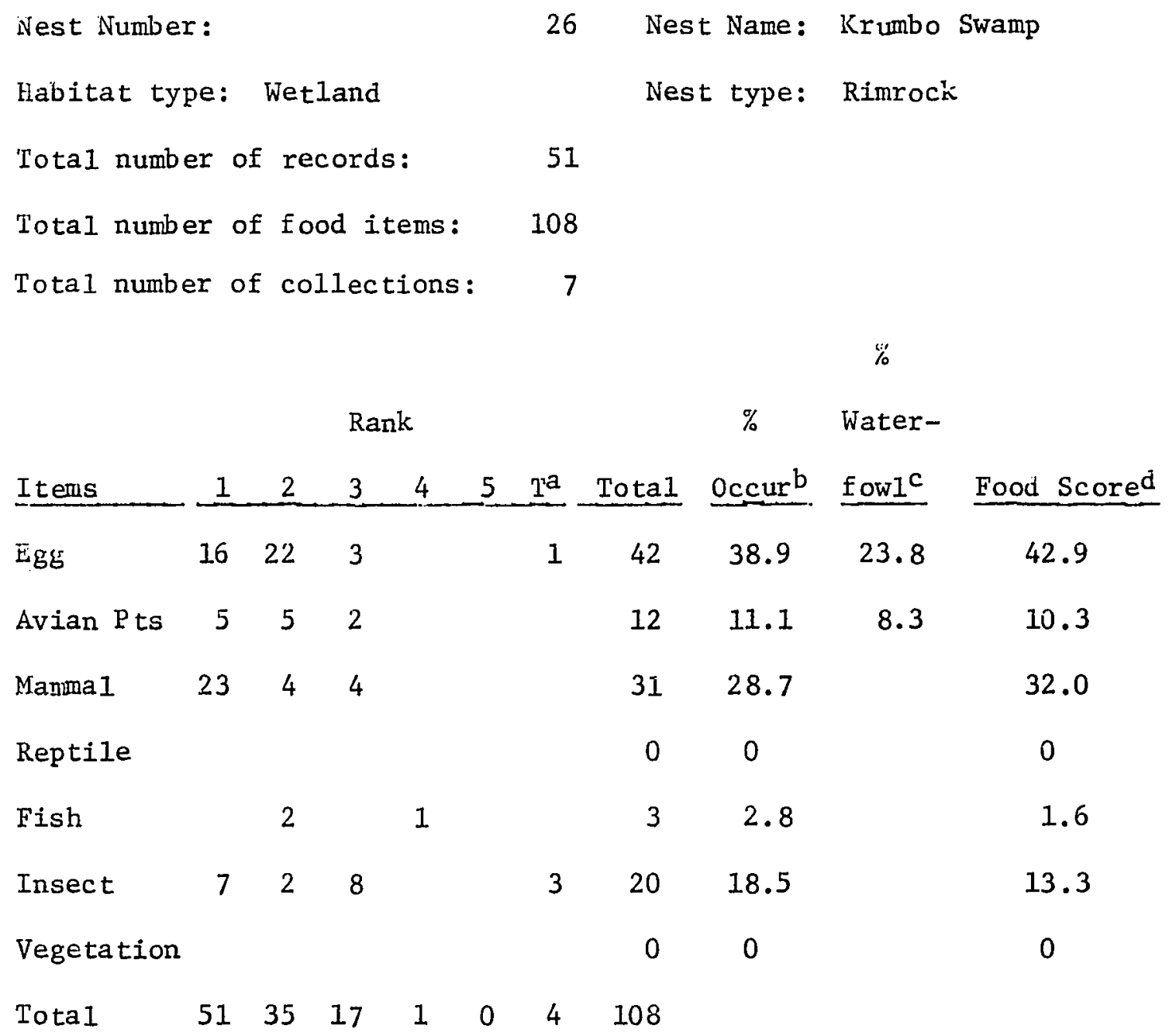

\footnotetext{
a Trace item (Iess than 1\%)

b (Specific item total/Total food items) $\times 100$

c ilinimum percent of item derived from waterfowl species

d Weighted value of item (see text)
} 
Nest liumber:

Habitat type: Wetland

Total number of records:

Total number of food items:

Total number of collections:
27 Nest Name: Krumbo Valley

Nest type: Rimrock
25

41

2

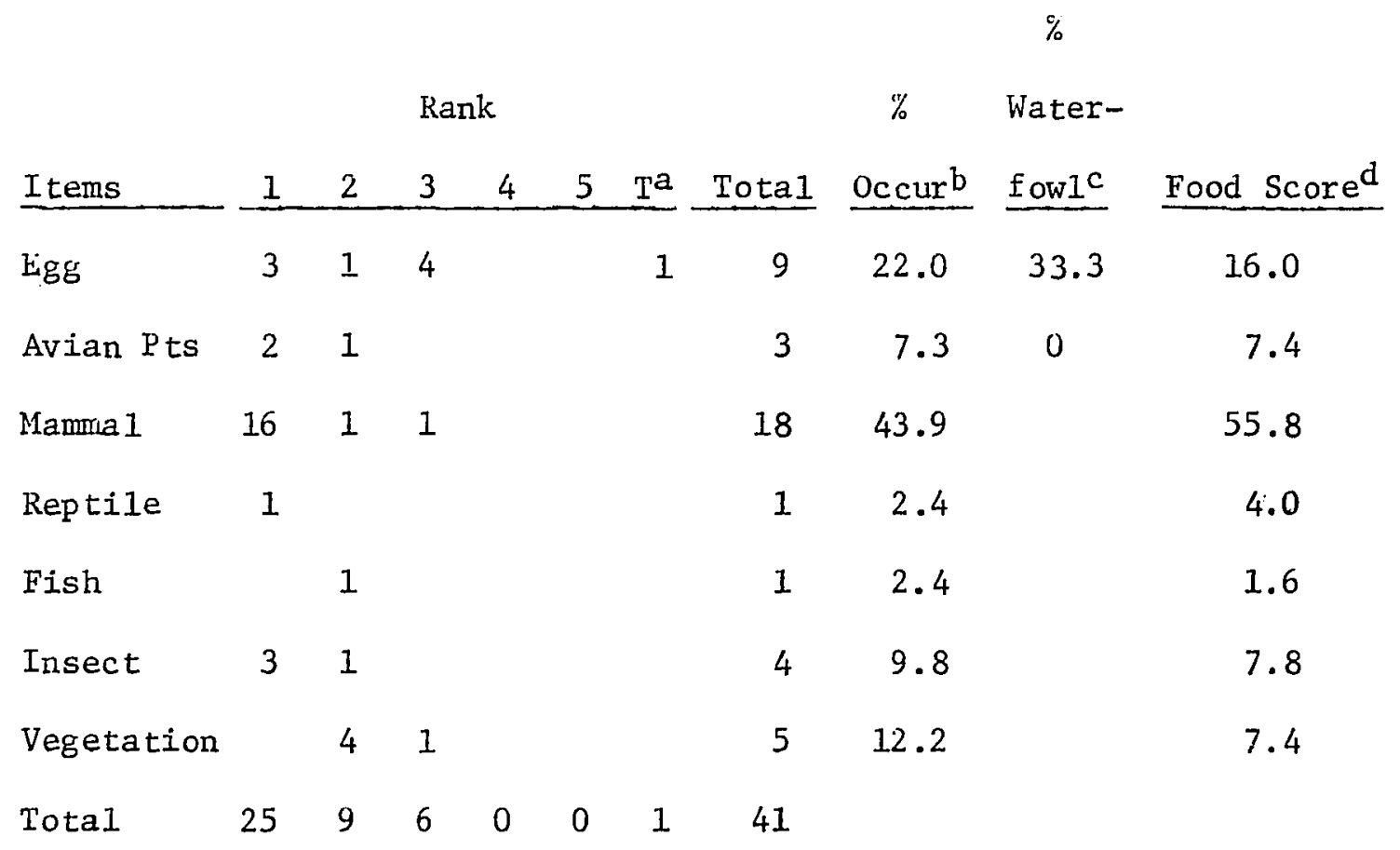

\footnotetext{
a Trace item (less than 1\%)

b (Specific item total/Total food items) $\times 100$

c Minimum percent of item derived from waterfowl species

d Weighted value of item (see text)
} 
Nest Number:

Habitat type: Wetland

Total number of records:

Total number of food items:

Total number of collections:

\section{Nest Nane: Krumbo Dam \\ Nest type: Rimrock}

51

87

5

\begin{tabular}{|c|c|c|c|c|c|c|c|c|c|c|}
\hline \multirow[b]{3}{*}{ Items } & \multirow{2}{*}{\multicolumn{6}{|c|}{ Rank }} & \multicolumn{4}{|c|}{$\%$} \\
\hline & & & & & & & & $\%$ & Water- & \\
\hline & 1 & 2 & 3 & 4 & 5 & $\mathrm{~T}^{\mathrm{a}}$ & Total & $\underline{O c c u r}{ }^{b}$ & fow $1^{c}$ & Food Score $\mathrm{d}^{\mathrm{d}}$ \\
\hline $\mathrm{Egg}$ & 5 & 5 & 5 & & & 3 & 18 & 20.7 & 22.2 & 14.2 \\
\hline Avian Pts & 3 & 1 & 1 & & & & 5 & 5.7 & 0 & 6.1 \\
\hline Mamma 1 & 35 & 1 & 2 & & & & 38 & 43.7 & & 54.0 \\
\hline Reptile & & & & & & & 0 & 0 & & 0 \\
\hline Fish & 3 & 13 & 2 & & & 1 & 19 & 21.8 & & 15.2 \\
\hline Insect & 4 & 2 & & & & & 6 & 6.9 & & 9.3 \\
\hline Vegetation & 1 & & & & & & 1 & 1.1 & & 1.2 \\
\hline Total & 51 & 22 & 10 & 0 & 0 & 4 & 87 & & & \\
\hline
\end{tabular}

\footnotetext{
a Trace item (less than 1\%)

b (Specific item total/Total food items) $\times 100$

c Minimum percent of item derived from waterfowl species

d Weighted value of item (see text)
} 


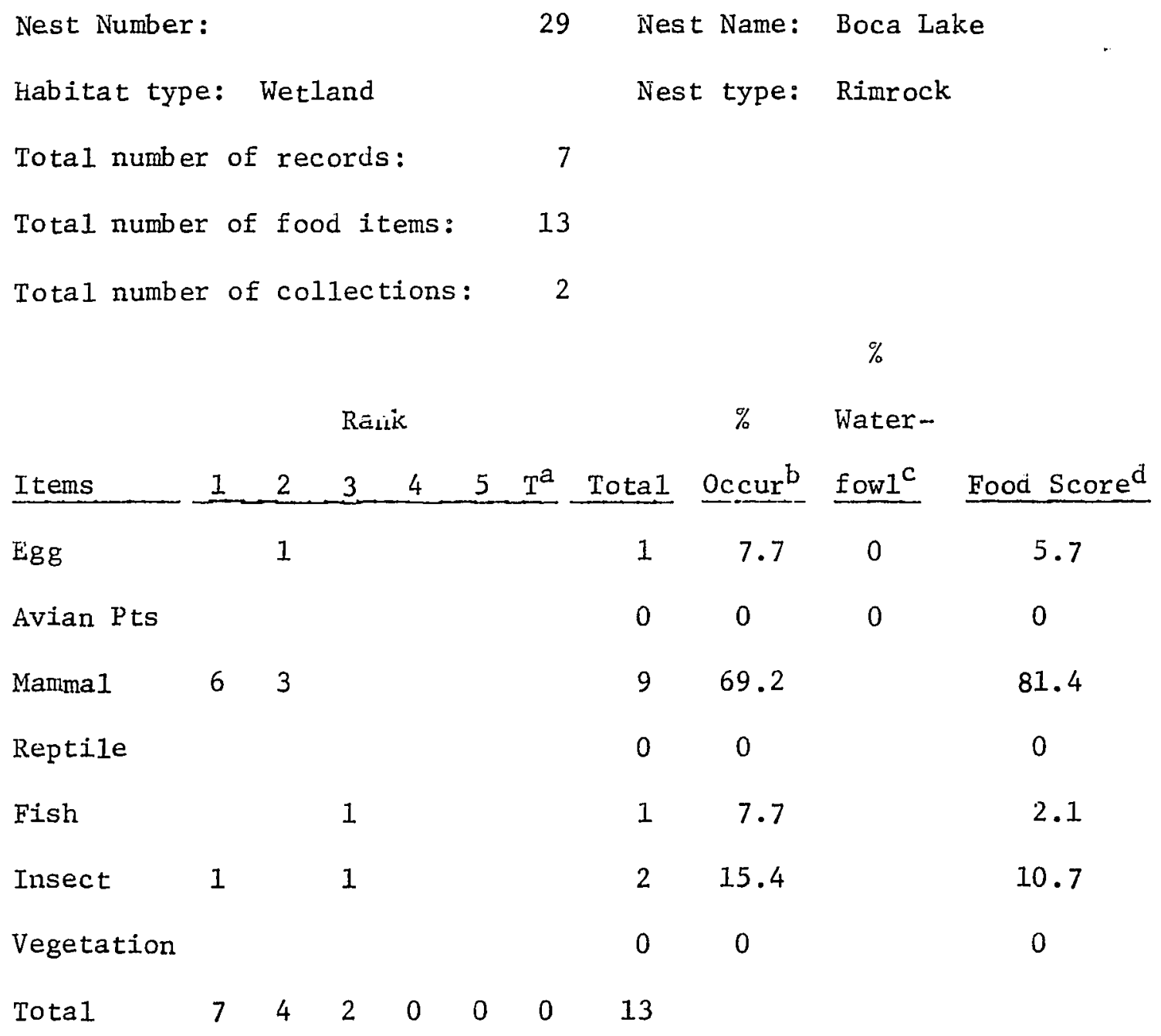

\footnotetext{
a Trace item (less than $1 \%$ )

b (Specific item total/Total food items) $\times 100$

c Ninimum percent of item derived from waterfow 1 species

d Weighted value of item (see text)
} 


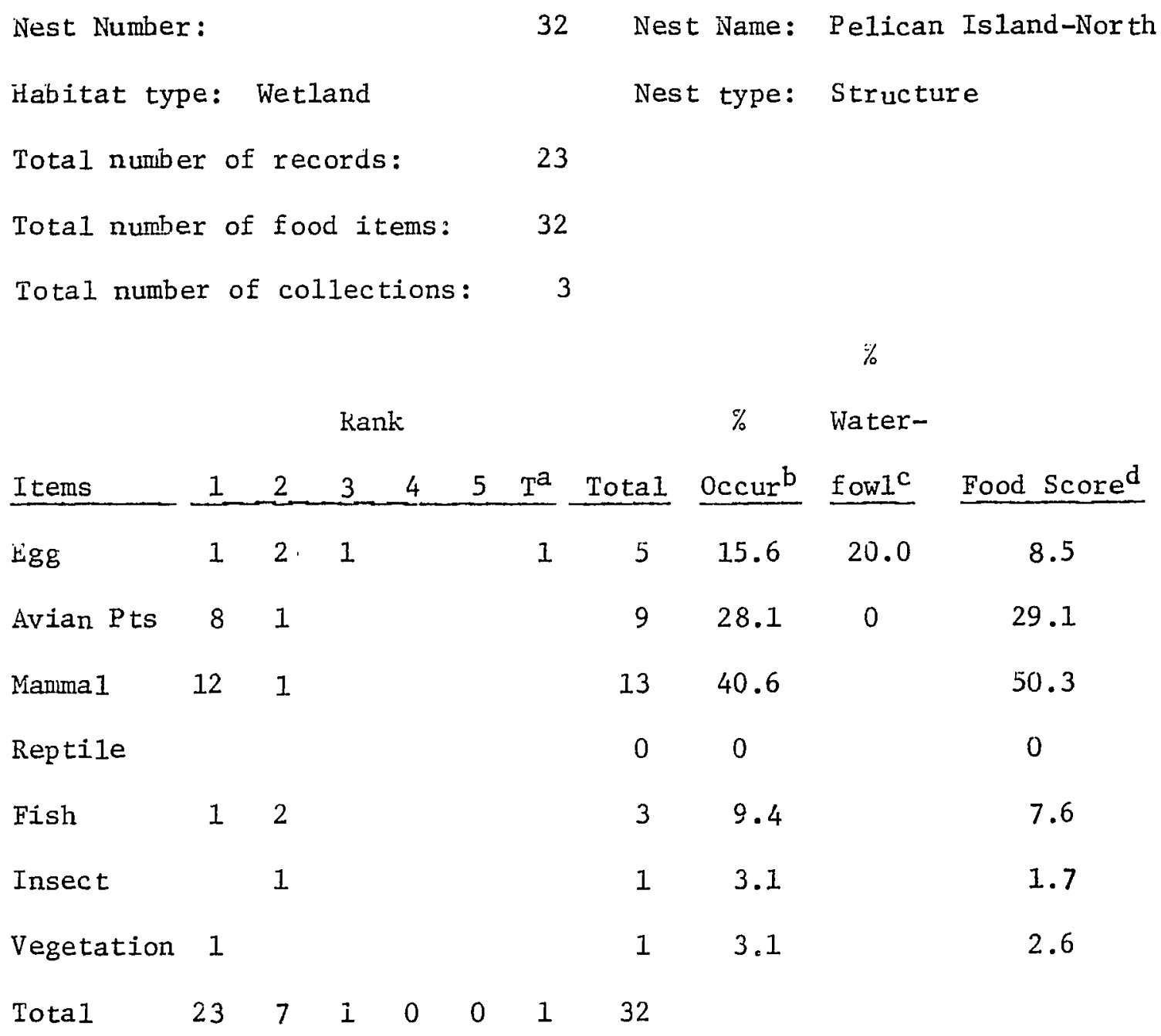

\footnotetext{
a Trace item (less than $1 \%$ )

b (Specific item total/Total food items) $\times 100$

c Minimum percent of item derived from waterfowl species

d Weighted value of item (see text)
} 


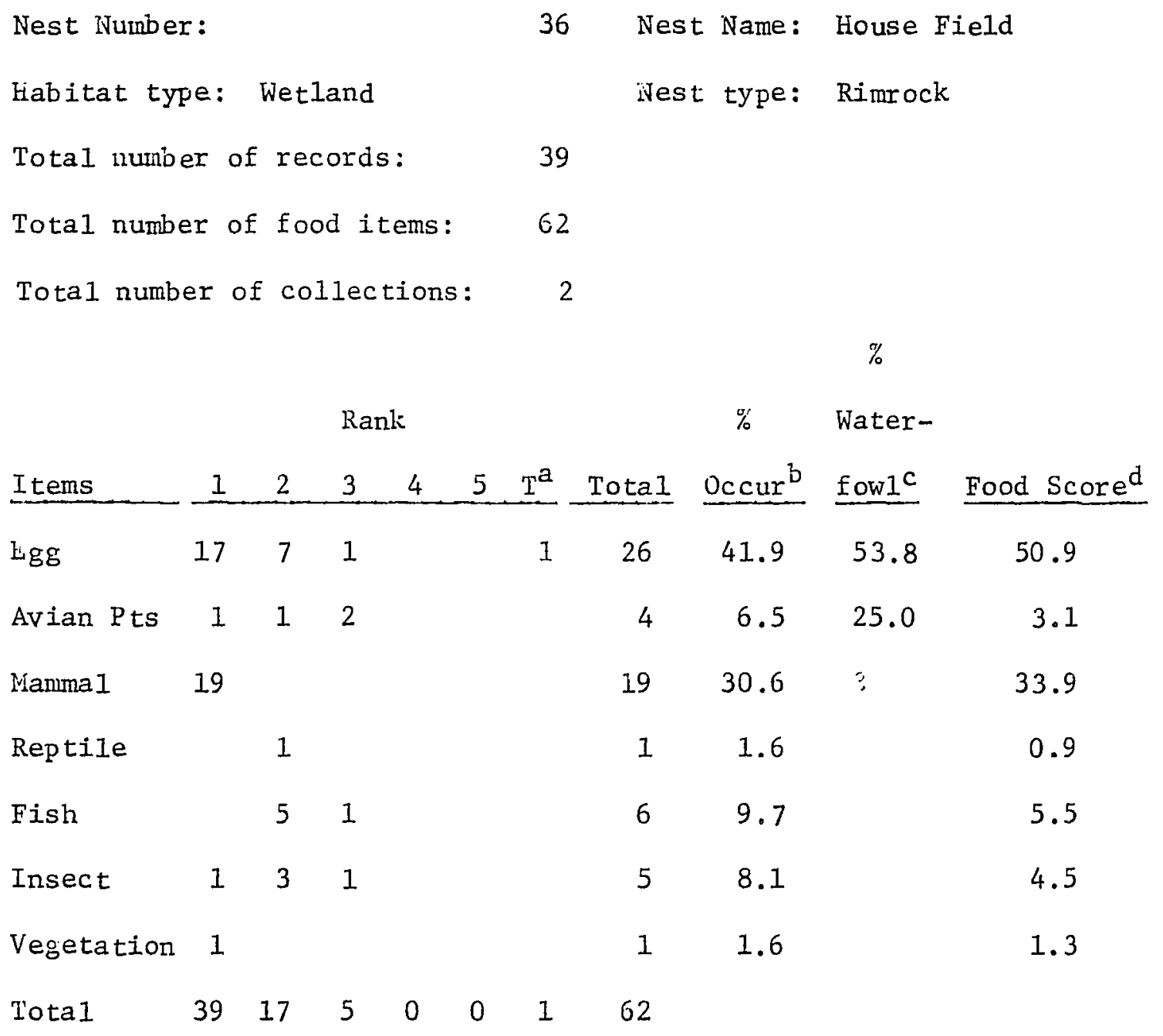

\footnotetext{
a Trace item (1ess than 1\%)

b (Specific item total/Total food items) $\times 100$

c Ninimum percent of item derived from waterfowl species

d Weighted value of item (see text)
} 


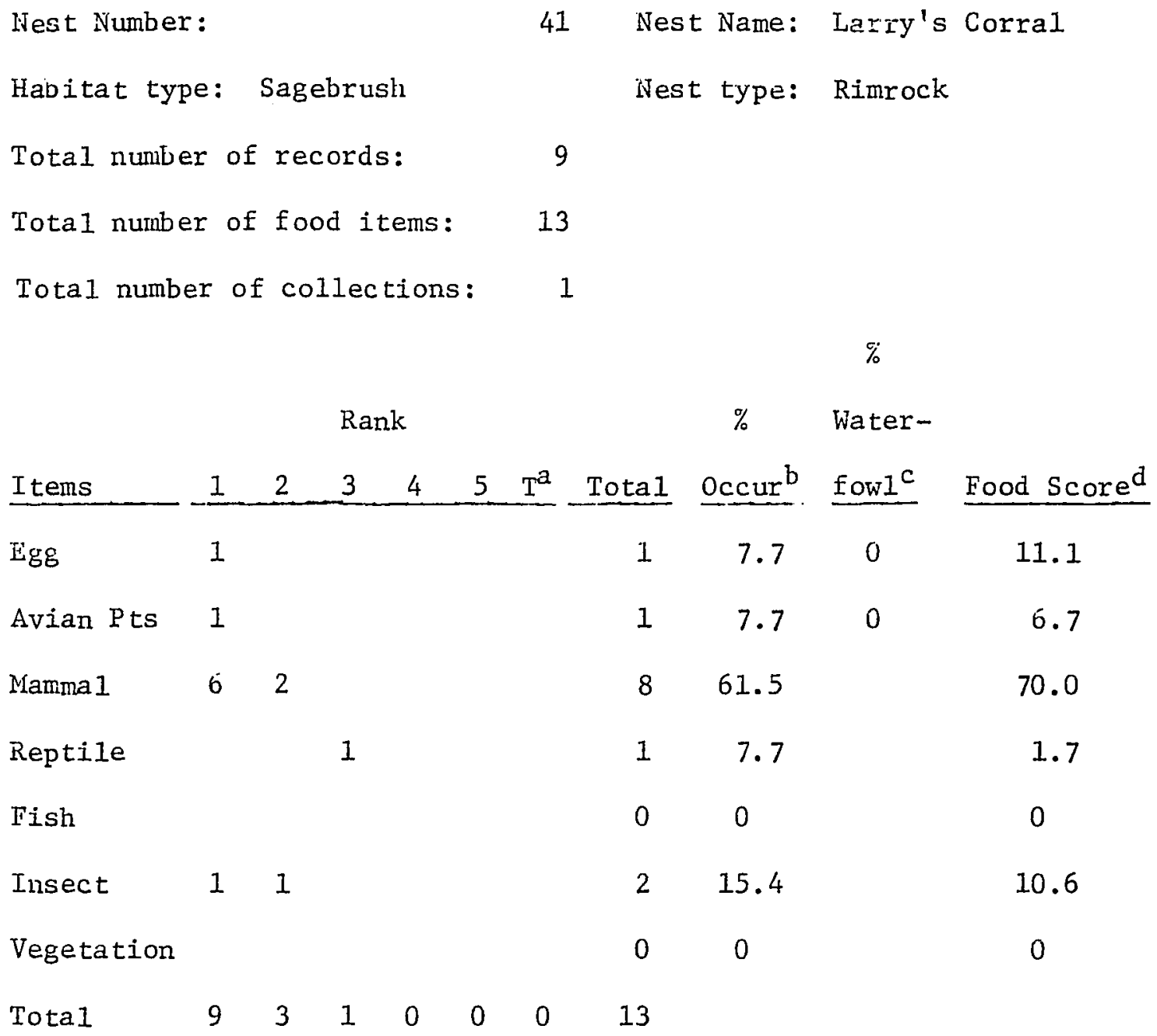

a Trace item (less than $1 \%$ )

b (Specific item total/Total food itens) $\times 100$

c Minimum percent of item derived from waterfowl species

$d$ Weighted value of item (see text) 


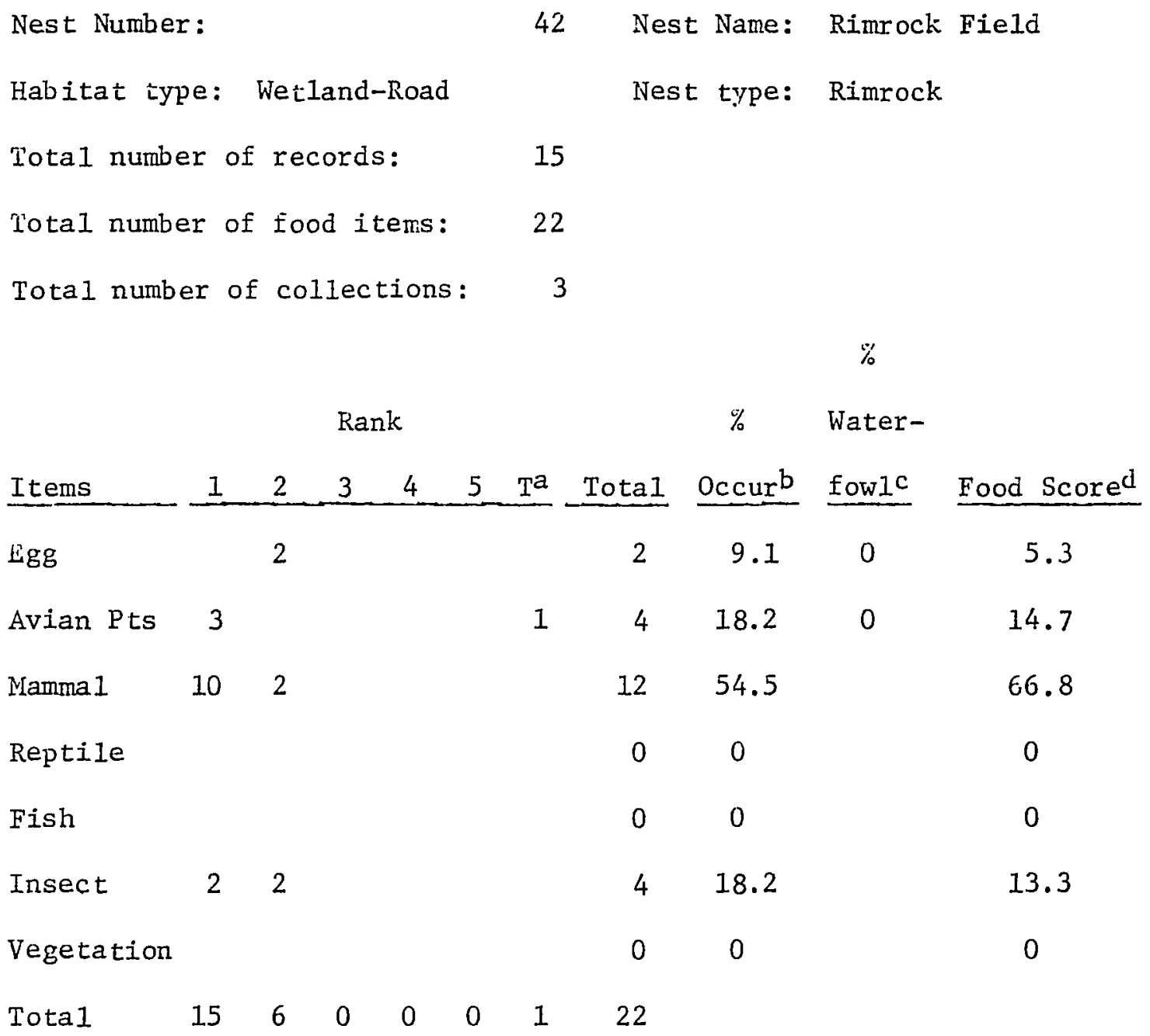

\footnotetext{
a Trace item (less than $1 \%$ )

b (Specific item total/Total food items) x 100

c Minimum percent of item derived from waterfowl species

d Weighted value of item (see text)
} 
Nest Number:

liabitat type: Wetland-Road

Total number of records:

Total number of food items:

Total number of collections:
43

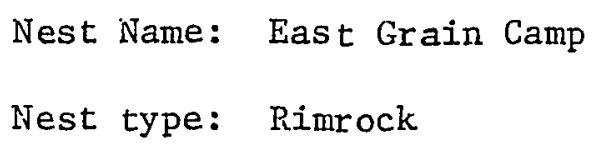

84

98

4

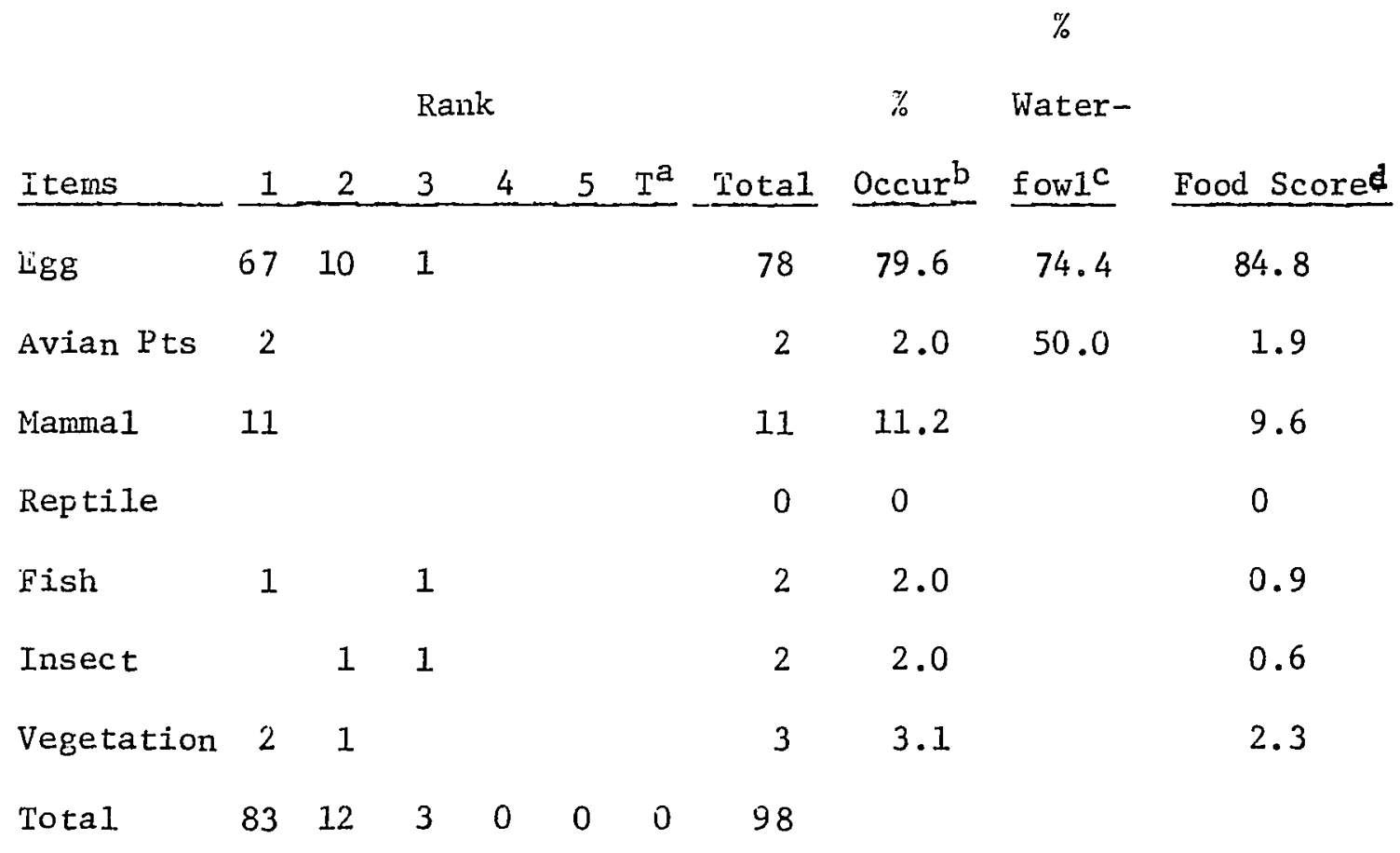

\footnotetext{
a Trace item (less than $1 \%$ )

b (Specific item total/Total food items) $\times 100$

c Minimum percent of item derived from waterfowl species

d Weighted value of item (see text)
} 


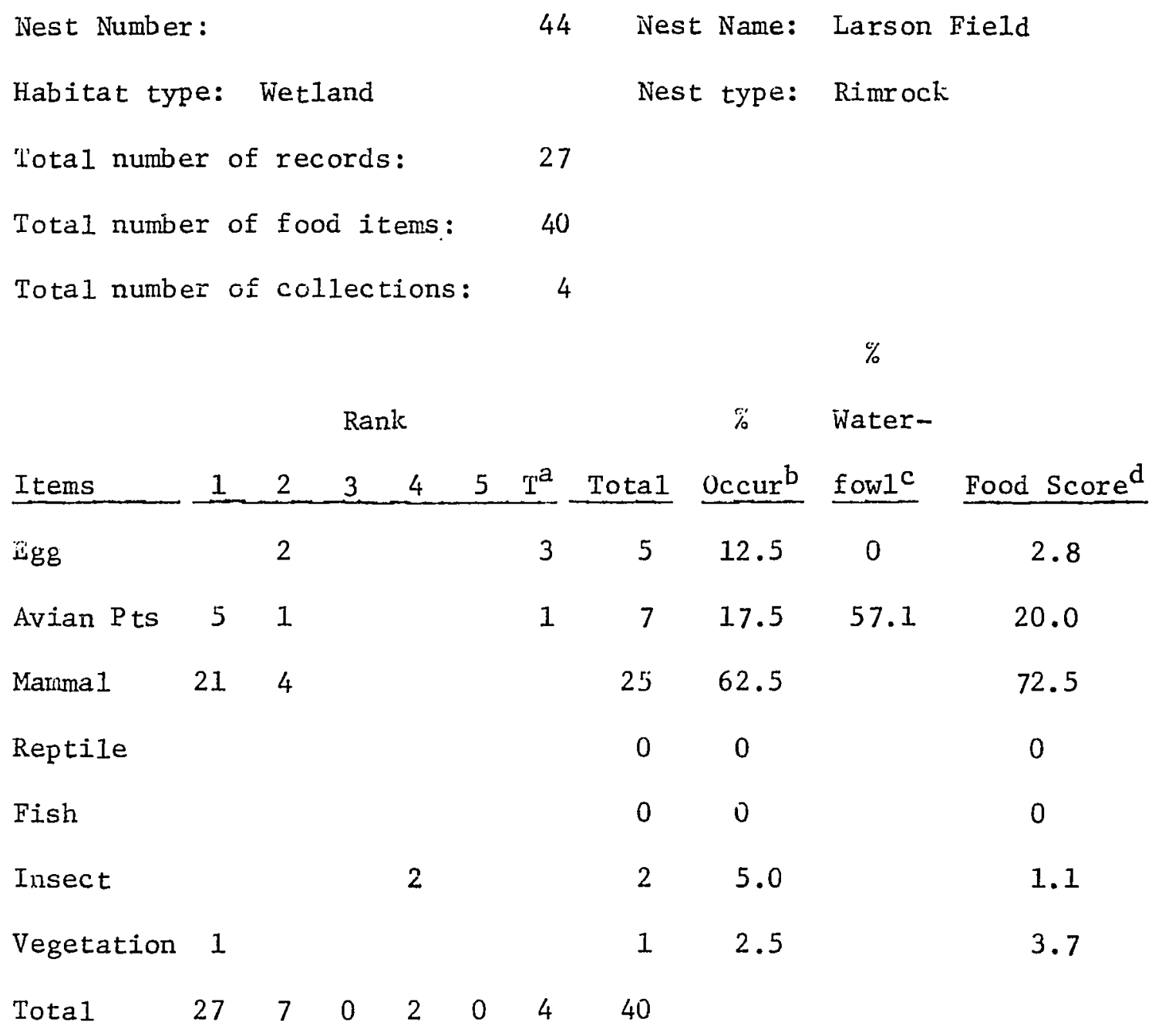

\footnotetext{
a irace item (less than 1\%)

b (Specific item total/Total food items) $\times 100$

c Minimum percent of item derived from waterfowl species

d Weighted value of item (see text)
} 
Nest Number:

Habitat type: Wetland-Road

Total number of records:

Total number of food items:

Total number of collections:
46

Nest Name: Cargill Corral

Nest type: Structure

17

25

3

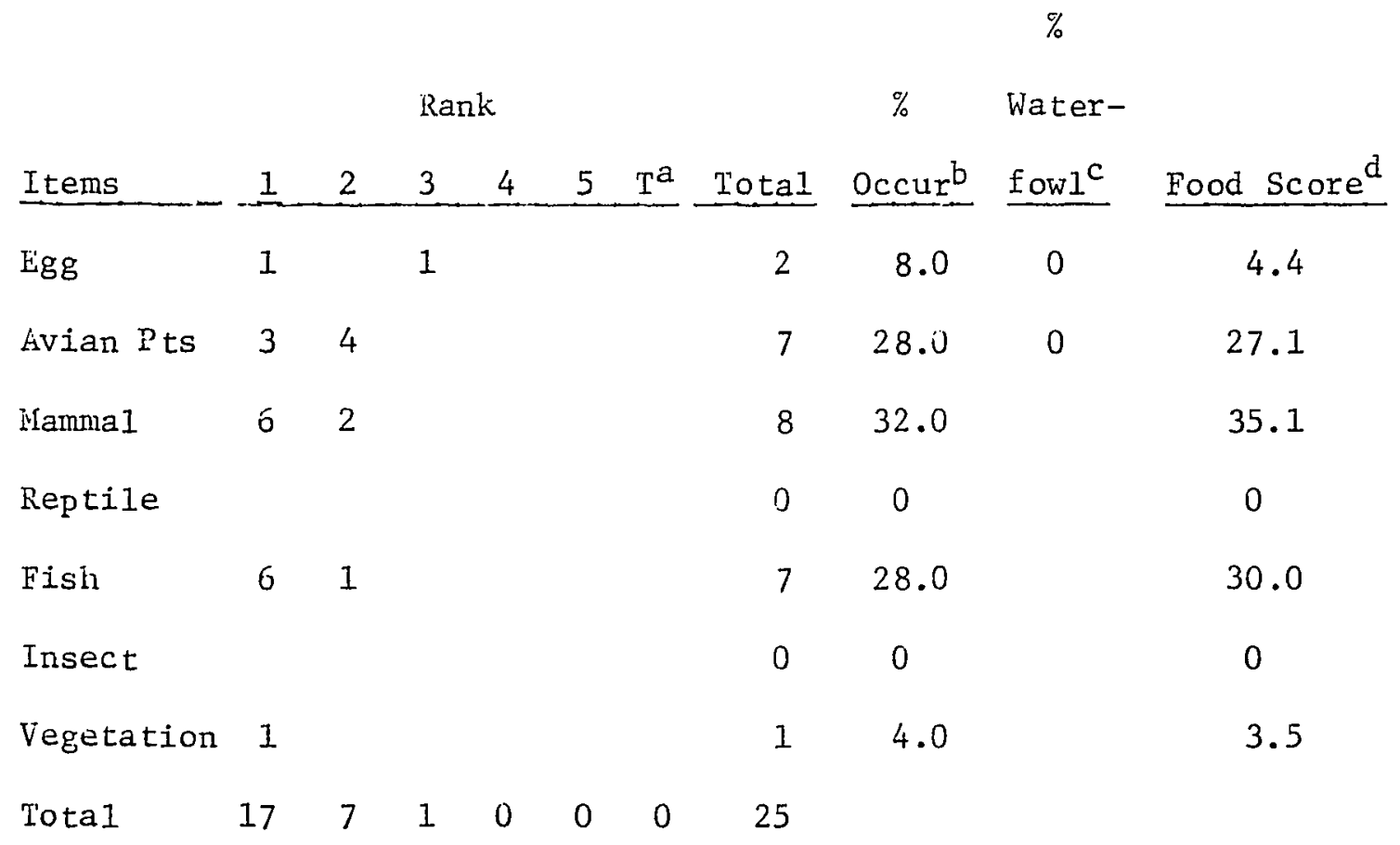

\footnotetext{
a Trace item (less than $1 \%$ )

b (Specific item total/Total food items) $\times 100$

c Minimum percent of item derived from waterfowl species

d Weighted value of item (see text)
} 


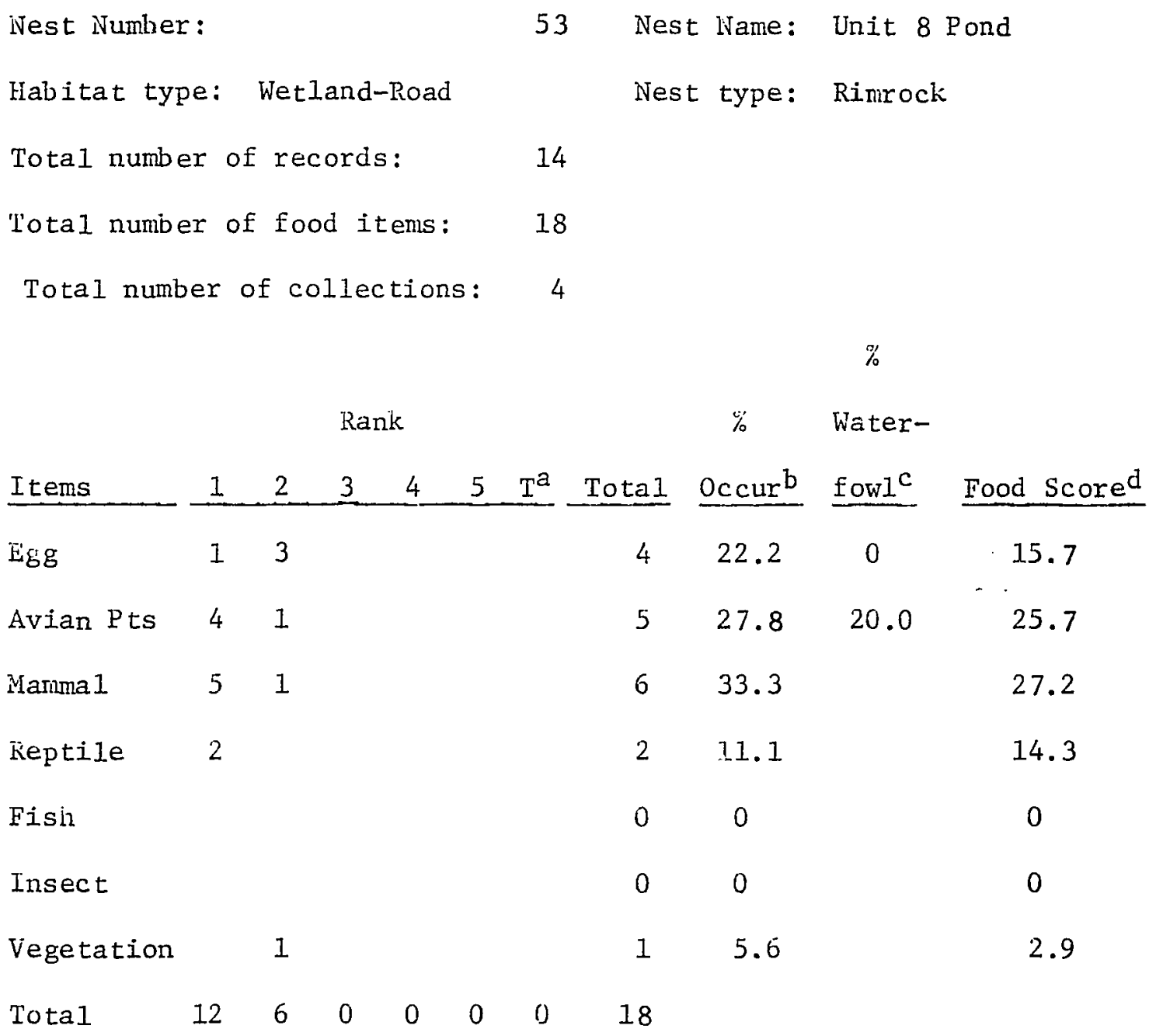

a Trace item (less than $1 \%$ )

b (Specific item total/Total food items) $\times 100$

c Minimum percent of item derived from waterfowl species

d Waighted value of item (see text) 


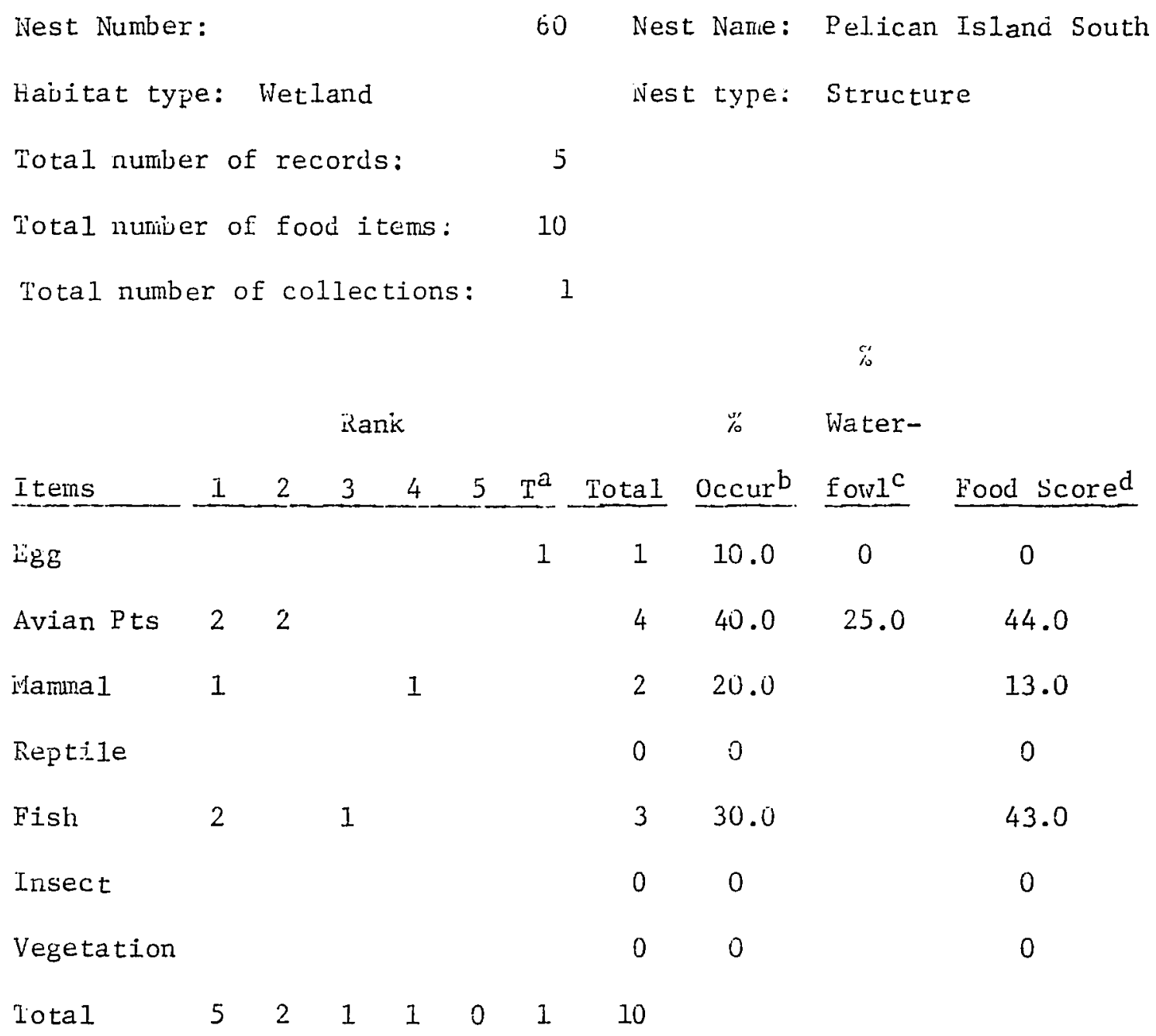

\footnotetext{
a Trace item (less than $1 \%$ )

b (Specific iter. total/lotal food items) $\times 100$

c Mininum percent of item derived from waterfowl species

d Weighted value of item (see text)
} 